\title{
Health problems after spinal cord injury rehabilitation: who cares?
}


Graphity: Ramon Bax and Frank van Ansem

Cover design: Debby Thebrath

Lay-out: Maurice Bloemen

Printing: Datawyse, Universitaire Pers Maastricht

Health problems after spinal cord injury rehabilitation: who cares? /

Jos Bloemen-Vrencken - Maastricht University - With references - With summary -

With summary in Dutch

ISBN-10: 90-5278-566-X

ISBN-13: 978-90-5278-566-0

Copyright (C) 2006 Jos Bloemen-Vrencken, Beek

The studies presented in this thesis were financial supported by:

- ZonMw, the Netherlands Organisation for Health Research and Development, Rehabilitation programme, grant no. 01432030

- Health care insurance companies Agis and CZ

- Institute for Rehabilitation Research, iRv

- Rehabilitation Foundation Limburg, SRL 


\section{Health problems after spinal cord injury rehabilitation: who cares?}

\section{Proefschrift}

ter verkrijging van de graad van doctor aan de Universiteit Maastricht, op gezag van de Rector Magnificus, Prof. mr. G.P.M.F. Mols, volgens het besluit van het College van Decanen, in het openbaar te verdedigen

op vrijdag 13 oktober 2006 om 12.00 uur

door

Josephine Huguette Anna Bloemen-Vrencken

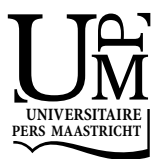




\section{Promotor}

Prof. dr. W.J.A. van den Heuvel

\section{Co-promotores}

Dr. L.P. de Witte

Dr. M.W.M. Post

\section{Beoordelingscommissie}

Prof. dr. C. Spreeuwenberg, voorzitter Dr. C. Kiekens

Prof. dr. E. Lindeman

Prof. dr. H. Philipsen

Prof. dr. R. de Wit 


\section{Contents}

$\begin{array}{lll}1 & \text { General introduction } & 7\end{array}$

2 Post-discharge nursing problems of spinal cord injured patients: on which fields can nurses contribute to rehabilitation?

3 Health problems of persons with spinal cord injury living in the Netherlands

4 Health behaviour of persons with spinal cord injury

5 Follow-up care for persons with spinal cord injury living in the community: a systematic review of interventions and their evaluation

6 Transmural care in the rehabilitation sector: implementation experiences with a transmural care model for people with spinal cord injury

7 Effects of a Dutch follow-up care model for spinal cord injured patients on health problems, re-admissions, and quality of care

8 General discussion

Summary

Samenvatting

Dankwoord

About the author 

1

General introduction 


\section{Introduction}

Spinal cord injury (SCI) has a profound impact on the lives of those with SCI as well as their families. SCI can lead to many medical problems that alter body functions, hamper socialisation, produce permanent impairments and affect an individual's ability to engage in daily activities. Until a few decades ago, the care for persons with SCI focused on survival. Since the life expectancy of persons with SCI has greatly increased since 1950 [1-4], issues regarding long-term management have become increasingly important [2-6].

This thesis describes the results of a research project about persons with SCI, who were treated at a rehabilitation centre. It reports on the health problems these people with chronic disabilities encounter in their daily lives once they have been discharged from rehabilitation. Furthermore, this thesis reports on an attempt to improve the follow-up care offered to persons with SCI after discharge from clinical rehabilitation. We used the nursing perspective as a starting point for improvements to follow-up care.

This chapter briefly describes SCI and its prevalence, as well as the care routing of persons with SCI. It then presents the research questions and an outline of the thesis.

\section{Spinal cord injury}

The spinal cord is a major bundle of nerves that is responsible for the communication systems of the body, including sensory, motor and autonomic functions. The spinal cord transmits messages between the brain and the rest of the body. Because the spinal cord is such an important part of the nervous system, it is surrounded by protective bone segments, called vertebrae.

The term SCI refers to any injury to the neural elements within the spinal canal. Damage to the spinal cord most frequently occurs due to a trauma to the vertebral column, which may result from incidents like traffic accidents, falls and sports accidents [7, 8]. Besides traumas, several non-traumatic causes can lead to SCI, including spina bifida, infections, thrombosis, embolisms and tumours [7, 8].

Damage to the spinal cord leads to a disruption of ascending and/or descending nerve impulses and may lead to loss of voluntary control of movement, loss of sensation, and to severe impairment of bladder, bowel and sexual functions as well as visceral and autonomic functions. The consequences of an SCI are determined by the level and completeness of the lesion. The higher the level of the lesion, the greater the loss of function. When the lesion is located between the first cervical vertebra and the first thoracic vertebra, the injury will result in tetraplegia. The body's motor and/or sensory functions affected by tetraplegia include all four extremities and the trunk. 
Lesions below the second thoracic vertebra result in paraplegia, which means that the lower part of the body and the legs are affected. A complete injury means that there is no function below the level of the injury, no sensation and no voluntary movement. Both sides of the body are equally affected. An incomplete injury means that there is some function below the primary level of the injury. Persons with an incomplete injury may be able to move one limb more than another, may be able to feel parts of the body that they cannot move, or may have better function on one side of the body than the other.

The incidence of SCI has been examined in various studies. In the international literature, the incidence data vary from 9 to 53 new injuries per million persons per year $[9,10]$. Schönherr et al. [11] studied the incidence of SCI in the Netherlands (both traumatic and non-traumatic), and estimated it to be 16 per million persons per year. Van Asbeck et al. [12] estimated the incidence of traumatic SCI to be 10 per million persons per year. Reliable figures on the prevalence of SCI in the Netherlands are not available [13].

\section{Care routing of persons with spinal cord injury}

In the care routing of persons with SCI, several phases can be distinguished: the acute phase, the rehabilitation phase and the chronic phase [14].

\section{Acute phase}

The acute phase starts at the moment the SCI occurs and continues until the person with the SCI is physically stable and the priority survival needs have been addressed. In this phase, surgical or non-surgical measures or both are taken to stabilise the spine to preserve neurological functioning and to prevent medical complications like pressure sores and contractures. The management of autonomous functions and the prevention of complications regarding ventilation, bladder and bowel function are also of great importance. As soon as the patient is physically stable, the rehabilitation process starts. In hospital, most attention is given to the patient's physical condition. The length of hospital stay depends on the patient's physical state and the opportunities for admission to a rehabilitation centre. A recent study showed that the length of hospital stay in the Netherlands varies considerably and is on average almost 50 days [15].

\section{Rehabilitation phase}

As mentioned above, rehabilitation starts as soon as the patient is physically stable, which may already be the case during admission in hospital. Most rehabilitation gains are achieved during the active rehabilitation period in a rehabilitation centre, but the rehabilitation process continues for years after discharge $[14,16,17]$. The general aim 
of rehabilitation is to enhance 'activity' and 'participation', more specifically by: (1) minimising medical complications, (2) optimising physical function, (3) facilitating social independence, (4) enhancing emotional adaptation and (5) promoting reintegration into the community [16]. The following care disciplines are involved: rehabilitation physicians, occupational therapists, physiotherapists, nurses, social workers, psychologists and sports teachers. To increase the chances of successful rehabilitation, persons with SCI are involved in establishing their own goals as much as possible.

In the Netherlands, the length of stay in clinical rehabilitation varies considerably, with an average of about nine months [15]. The rehabilitation process at a rehabilitation centre mostly consists of a period of inpatient rehabilitation and a period of day treatment. The inpatient rehabilitation mostly consists of four subphases:

- The introduction phase takes place in the first week after admission. It consists of acquaintance, assessment, development and the start of the treatment plan. This period ends with the first team meeting.

- Regularly there is an immobilisation phase, for instance when patients have pressure sores or fractures that are not yet stable. Maintenance and improvements of strength, mobility, bladder and bowel function is very important in this phase, as is the attention for the consequences of the SCI on psychosocial functioning.

- In the training phase, the patients are trained to achieve their maximum level of performance in different areas of daily functioning. The physical training starts in therapy sessions and is later on transferred to the SCI unit and the future home situation. The patients also receive psychosocial support to help them to deal and cope with the psychosocial problems they encounter after having sustained an SCI. Besides having to adapt to the sudden loss of control of movement and loss of sensation, persons with SCI are also confronted with an imminent loss of independence, participation in the community, work and income, as well as alterations in their relationships with their partners, children and friends. In the training phase, family members are very much involved in the rehabilitation process, patients go home for weekends to practice their skills in their home situation, and information meetings are organised for patients and their partners and/or other family members to inform them about SCI and its various consequences. Every six to eight weeks, there are team meetings where the rehabilitation team, the patient and his/her partner and/or other family members evaluate the rehabilitation process and set the rehabilitation goals for the next period.

- In the discharge phase, the future home situation is simulated as much as possible at the SCI unit, for instance regarding the amount of care the patient will receive at home. If necessary, arrangements are made for personal care and 
therapy in the home situation. Preparations are made for social reintegration and adaptations to the home environment.

When patients need help from two or more care disciplines to achieve their rehabilitation goals, they receive a period of day-care treatment in addition to their inpatient rehabilitation. The duration and intensity of this day-care treatment is variable. This transitional stage provides an opportunity to try out the new living situation and to evaluate the amount of care, equipment and adaptations. In this phase, issues such as return to work and leisure activities become important [18].

\section{Chronic phase}

The chronic phase starts when the impairments and the limitations to activities and participation have become evident. This often takes at least six months after the SCI occurred [14]. Following discharge from initial rehabilitation, persons with SCI face the difficult challenge of adapting to life with a disability [19, 20]. Instead of returning home, persons with SCI may also be discharged to a supported living facility or a nursing home. Daily medical and nursing care for persons with SCI is usually transferred from the rehabilitation centre to primary health care. Until several years ago, the follow-up care provided by Dutch rehabilitation teams to persons with SCI living in the community consisted of regular outpatient visits to a rehabilitation physician. During these visits, a comprehensive assessment of functioning is performed and, if necessary, interventions are applied or other forms of support are given.

Previous research has revealed several shortcomings in the care routing of persons with SCI [14, 21]. De Witte [21] studied the functioning of persons with SCI during clinical rehabilitation and after discharge. One of his major conclusions was that follow-up care is not adequate. The coordination and tailoring of care after discharge from clinical rehabilitation is far from perfect. This applies to the coordination between the rehabilitation centre and primary health care as well as to the coordination within primary care. Furthermore, there is very little agreement between professionals about who is primarily responsible for different aspects of care. These findings were supported by those of another study [22]. Post et al. showed that persons with SCI are not satisfied about the SCI knowledge among general practitioners and district nurses. Persons with SCI would like to receive extra support after discharge in the form of telephonic consulting hours, peer meetings and/or home visits. Professionals at the rehabilitation centre were preferred to primary care professionals to deliver this follow-up care.

Several studies have also illustrated that persons with SCI experience many problems in daily life, including secondary conditions such as urinary tract infections $[4,13,23,24]$ and pressure sores $[4,13,23,24]$; problems of psychosocial adjustment such as dependence on personal help [1,25] and sexual problems [25]; and problems 
of daily living such as difficulties with personal care $[1,25]$ and problems of functioning in unadapted environments and arranging home modifications [20, 26].

Assuming that at least some secondary conditions can be prevented or delayed by means of a healthy lifestyle, much attention is given during rehabilitation to education and training about health maintenance and prevention of health problems. However, most of the educational programmes designed to teach persons with SCI about health behaviours to prevent or delay secondary conditions have not been evaluated for their effectiveness in reducing the occurrence of secondary conditions once the persons return to the community [27].

\section{Aims of the study and outline of the thesis}

The problems of care routing after clinical rehabilitation and the occurrence of health problems after discharge were the starting points of the research reported on in this thesis. Health problems negatively affect the functioning of persons with SCI, in that they tend to increase the level of disability and decrease the level of community integration $[28,29]$. Therefore, it is very important to develop efficient methods for the prevention and early treatment of health problems. The assumption was made that many of the health problems persons with SCI experience lie within the professional scope of rehabilitation nurses, and thus might be mitigated by nursing interventions.

The primary aims of the present study were to describe the nursing problems and health problems persons with SCI experience after discharge, and to evaluate the effectiveness and feasibility of a transmural nursing care model aimed at the prevention and early treatment of health problems after discharge from clinical rehabilitation.

The main research questions were:

- What nursing problems and health problems do persons with SCI experience after discharge from clinical rehabilitation and what health behaviours do persons with SCI engage in to prevent or delay these problems?

- What are relevant barriers and enabling factors for successful implementation of a transmural care model in rehabilitation practice?

- What are the effects of a transmural nursing care model (and other follow-up care programmes) on the prevalence of health problems, re-admissions and the quality of follow-up care perceived by persons with SCI?

It was hypothesised that the transmural nursing care model would lead to a decrease in health problems and re-admissions after discharge from rehabilitation. In addition, we expected the perceived quality of follow-up care to increase. 
Chapter 2 presents the results of a study that explored which of all the problems that persons with SCI experience after discharge from rehabilitation are within the scope of the nursing discipline (i.e. are nursing problems). The study aimed to find a basis for improving nursing care during and after rehabilitation, and preventing nursing problems after discharge. Chapter 3 reports on the prevalence of health problems among persons with SCI living in the Netherlands, identifying the health problems that are perceived as most important and the perceived impact of these most important problems on daily activities and social life. Chapter 4 describes the results of a study into the health behaviour of persons with SCI who are living in the community and the relationships between health behaviour, respondent/injury characteristics and health-related variables. Chapter 5 discusses the results of a systematic review of follow-up care programmes implemented by rehabilitation centres, and their effects on the occurrence of secondary impairments, well-being and the quality and costs of care. Chapter 6 presents the development and content of the transmural care model and the feasibility and implementation experiences in two rehabilitation centres. The study examined the extent to which the care model was implemented, enabling factors and barriers for implementation and the strengths and weaknesses of the care model. Chapter 7 reports on the effects of the transmural care model on the prevalence of health problems and re-admissions to hospitals and rehabilitation centres, and the perceived quality of follow-up care. Chapter 8 completes this thesis by discussing the main findings and providing methodological reflections, recommendations for future research and practice implications. 


\section{References}

[1] Charlifue SW, Weitzenkamp DA, Whiteneck GG. Longitudinal outcomes in spinal cord injury: aging, secondary conditions, and well-being. Archives of Physical Medicine and Rehabilitation 1999; 80(11): 1429-34.

[2] Dunn M, Love L, Ravesloot C. Subjective health in spinal cord injury after outpatient healthcare follow-up. Spinal Cord 2000; 38(2): 84-91.

[3] Levi R, Hultling C, Seiger A. The Stockholm Spinal Cord Injury Study. 3. Health-related issues of the Swedish annual level-of-living survey in SCI subjects and controls. Paraplegia 1995; 33(12): 726-30.

[4] Noreau L, Proulx P, Gagnon L, Drolet M, Laramee MT. Secondary impairments after spinal cord injury: a population-based study. American Journal of Physical Medicine and Rehabilitation 2000; 79(6): 526-35.

[5] Anson CA, Shepherd C. Incidence of secondary complications in spinal cord injury. International Journal of Rehabilitation Research 1996; 19(1): 55-66.

[6] McKinley WO, Jackson AB, Cardenas DD, DeVivo MJ. Long-term medical complications after traumatic spinal cord injury: a regional model systems analysis. Archives of Physical Medicine and Rehabilitation 1999; 80(11): 140210.

[7] Beckers DML, Buck MJI, Pons C. De revalidatie van dwarslaesiepatiënten: een multidisciplinaire benadering. Lochem: De Tijdstroom; 1992.

[8] van Asbeck FWA. Handboek dwarslaesie revalidatie. Houten/Diegem: Bohn Stafleu Van Loghum; 1998.

[9] Shingu H, Ikata T, Katoh S, Akatsu T. Spinal cord injuries in Japan: a nationwide epidemiological survey in 1990. Paraplegia. 1994; 32(1): 3-8.

[10] Shingu H, Ohama M, Ikata T, Katoh S, Akatsu T. A nationwide epidemiological survey of spinal cord injuries in Japan from January 1990 to December 1992. Paraplegia. 1995; 33(4): 183-8.

[11] Schönherr MC, Groothoff JW, Mulder GA, Eisma WH. Rehabilitation of patients with spinal cord lesions in The Netherlands: an epidemiological study. Spinal Cord 1996; 34(11): 679-83. 
[12] van Asbeck FW, Post MW, Pangalila RF. An epidemiological description of spinal cord injuries in The Netherlands in 1994. Spinal Cord 2000; 38(7): 4204.

[13] Post MW. Living with spinal cord injury: A study of health status and life satisfaction of independently living people with a spinal cord injury (thesis). Utrecht (Elinkwijk bv); 1997.

[14] Benjaminsen SACH. Kwaliteit en doelmatigheid van zorg voor slachtoffers van verkeersongevallen. Trajectbeschrijving van slachtoffers van een verkeersongeval, die een dwarslaesie hebben opgelopen. Hoensbroek: iRv, Kenniscentrum voor Revalidatie en Handicap; 2004.

[15] Post MW, Dallmeijer AJ, Angenot EL, van Asbeck FW, van der Woude LH. Duration and functional outcome of spinal cord injury rehabilitation in the Netherlands. Journal of Rehabilitation Research and Development 2005; 42(3 Suppl 1): 75-85.

[16] Janssen-Potten YJM. Effects of chair configuration on sitting balance in spinal cord injured persons (thesis). Maastricht: University Maastricht; 2001.

[17] Whiteneck GG, Charlifue SW, Gerhart KA, Lammertse DP, Manley S, Menter RR, et al. Aging with spinal cord injury. New York: Demos Publications; 1993.

[18] Schönherr MC. Functional outcome after spinal cord injury: Activities and participation (thesis). Groningen: Rijksuniversiteit Groningen; 2003.

[19] Boschen KA, Tonack M, Gargaro J. Long-term adjustment and community reintegration following spinal cord injury. International Journal of Rehabilitation Research. 2003; 26(3): 157-64.

[20] Harrison C, Kuric J. Community reintegration of SCI persons: problems and perceptions. SCI Nursing 1989; 6(3): 44-7.

[21] de Witte LP. After the rehabilitation centre: A study into the course of functioning after discharge from rehabilitation (thesis). Maastricht: University Maastricht; 1991.

[22] Post MWM, Bloemen-Vrencken JHA, Hendriks J, De Reus EC, de Witte LP. Gezondheid en behoefte aan zorg van mensen met een dwarslaesie na ontslag uit het revalidatiecentrum. Hoensbroek: $i R v$, Kenniscentrum voor Revalidatie en Handicap; 2002. 
[23] Raadsen HP, van Asbeck FWA. Over leven met een dwarslaesie: een retrospectief onderzoek onder 117 personen met een dwarslaesie. Utrecht: De Hoogstraat; 1990.

[24] Richards JS, Waites K, Chen YY, Kogos S, Schmitt MM. The epidemiology of secondary conditions following spinal cord injury. Topics in Spinal Cord Injury Rehabilitation 2004; 10(1): 15-29.

[25] Widerström-Noga EG, Felipe-Cuervo E, Broton JG, Duncan RC, Yezierski RP. Perceived difficulty in dealing with consequences of spinal cord injury. Archives of Physical Medicine and Rehabilitation 1999; 80(5): 580-6.

[26] Johnson RL, Gerhart KA, McCray J, Menconi JC, Whiteneck GG. Secondary conditions following spinal cord injury in a population-based sample. Spinal Cord 1998; 36(1): 45-50.

[27] Garber SL, Rintala DH, Don Rossi C, Hart KA, Fuhrer MJ. Reported pressure ulcer prevention and management techniques by persons with spinal cord injury. Archives of Physical Medicine and Rehabilitation 1996; 77(8): 744-749.

[28] Ravesloot C, Seekins T, Young Q. Health promotion for people with chronic illness and physical disabilities: The connection between health psychology and disability prevention. Clinical Psychology and Psychotherapy 1998; 5: 76-85.

[29] Cardol M, De Jong BA, Van den Bos GAM, Beelen, De Groot IJM, De Haan RJ. Beyond disability: perceived participation in people with a chronic disabling condition. Clinical Rehabilitation 2002; 16: 27-35. 


\section{Post-discharge nursing problems of spinal cord injured patients: on which fields can nurses contribute to rehabilitation?}

Published in:

Clinical Rehabilitation 2003; 17(8): 890-898

Jos Bloemen-Vrencken and Luc de Witte 


\section{Abstract}

Objective: To identify nursing problems of spinal cord injured (SCI) patients after discharge from clinical rehabilitation and to identify gaps in the nursing care regarding the prevention of these problems.

Design: The study had an exploratory character and was divided into three phases. Phase 1 had a qualitative nature. Eight patients were interviewed to obtain insight into experienced problems after discharge. In phase 2, a panel of experts regarding nursing care for SCI patients selected nursing problems out of all problems mentioned. Phase 3 consisted of a mailed questionnaire including the nursing problem areas identified in phase 2, which was sent to all patients that were discharged during the last 18 months before the study.

Setting: Specialist rehabilitation centre, the Netherlands.

Subjects: Eight patients participated in phase 1 (100\% response rate), 35 nurses participated in phase $2(87.5 \%$ response rate) and 35 patients participated in phase 3 (62.5\% response rate).

Results: The most important nursing problems in the response group appeared to be: limitations to activities of daily living, having difficulties to ask for help (assertiveness), pain, coping with the disability, dependency on personal help and problems with changed bladder regulation. The respondents made several suggestions for improving nursing care, involving both clinical care and care after discharge.

Conclusions: SCI patients experience serious problems after discharge from clinical rehabilitation. Nurses can give input on a wide variety of these problems. 


\section{Introduction}

Improvements in post-injury care and rehabilitation have eliminated or minimised many of the early complications that typically accompany those who have a new spinal cord injury (SCI) [1]. Since 1950, early death from medical complications after SCI, such as respiratory insufficiency, renal failure, or septicaemia has decreased greatly [2, 3]. Nevertheless, much has still to be learned about preventing long-term complications and achieving an optimal quality of life [1,3-5]. During rehabilitation patients receive information and training from several care disciplines, which should give sufficient skills and knowledge about the injury to deal with its consequences in daily life. However, following discharge from initial rehabilitation, SCI patients face the difficult challenge of adapting to life with a disability [6, 7]. The literature concerning the psychological adjustment to SCI describes the period following discharge from the hospital as the most critical period in the patient's adjustment process. The problems which must be dealt with become much more apparent after the individual has left the sheltered hospital environment [6].

From previous studies it is known that, once discharged, SCI patients are confronted with problems that negatively affect functioning. Reported problems include physical problems like pain $[1,2,4,8,9]$, spasm [1-4, 9], pressure sores [1-4, 810], bladder [2-4, 8, 9] and bowel problems [2, 4, 8, 9]. The literature also mentions transportation and financial problems $[1,2,4,6,8]$, difficulties in care management $[6$, 8], feelings of sadness $[4,8]$ and lack of adequate housing $[1,6,8]$.

Since there are so many problems, the need for continuing care after discharge from clinical rehabilitation is emphasised in several reports [7, 11-16].

This study looks at the problems that, of all the problems that SCI patients experience after discharge from clinical rehabilitation, are in the scope of the nursing discipline (nursing problems). It may be possible to find a basis for improving the nursing care during and after rehabilitation, aiming at the prevention of nursing problems after discharge. To the best of our knowledge this is one of the first attempts to study health problems of SCI patients after discharge and to relate these problems to the nursing discipline.

In the literature the term 'nursing diagnoses' is often used instead of nursing problems. The term refers to problems belonging to the scope of the nursing responsibilities, for which consensus is reached in the nursing profession concerning nomenclature, definitions and the accompanying aetiology, signs and symptoms [17]. In this study the major aim is to explore which experienced problems are judged to be in the scope of the responsibility of the nursing discipline. Therefore the term 'nursing problems' is used. 


\section{Methods}

The study consisted of three phases.

\section{Phase 1}

The purpose of phase 1 was to obtain detailed insight into the experiences and problems in relation to the SCI that patients are confronted with after discharge. A group of eight patients, discharged during the past year, were interviewed at home, using an unstructured format. The unstructured interview has been referred to as an intensive, in-depth, or qualitative interview. We used it to get information in the respondent's own words, to gain a description of situations, and to elicit detail. In unstructured interviews, an interview guide can be used containing a set of brief, general questions or a topical outline [18]. In our study the patients were invited to talk about the alterations in life compared to the situation before the SCI, problems that were correlated with their SCI, the severity of these problems and the consequences for their social life. The following topics were used: physical, psychological, social and communicative functioning and functioning regarding activities of daily living. To find problems representative for the whole group of SCI patients, a selection of respondents was made such that both sexes as well as paraplegia and tetraplegia were equally represented. The interviews were tape-recorded and the full text was transcribed. Four out of eight anonymised transcriptions were read by a staff member of the nursing discipline and a research assistant without nursing background, to identify the problems mentioned. This means they marked sentences in the interview-texts in which in their opinion problems were mentioned. Two nurses of the spinal cord department did the same for all eight transcriptions. All problems identified and marked by any of the four independent researchers were listed in terms used by the patients themselves.

\section{Phase 2}

In the second phase, the problem areas that were most strongly linked to the nursing responsibility were identified. The problem list resulting from phase 1 was sent to all 40 members of the nursing staff in the spinal cord department of the rehabilitation centre. They independently gave their opinion on whether nursing care was not relevant at all, slightly relevant or very relevant for each problem listed. These judgements were translated into scores of 1,2 and 3 respectively. Each item with an average score above 2 was considered to be a nursing problem. After that, the researcher coded each nursing problem. Statements reflecting more than one problem, got more than one code. Problems with the same codes were combined and given a label. 


\section{Phase 3}

The purpose of phase 3 was to assess the occurrence of nursing problems in a larger sample of SCI patients in order to improve the nursing care in the centre. A questionnaire was developed incorporating all nursing problems identified in phase 2 . It was sent to all SCI patients who had been discharged from the rehabilitation centre during the last 18 months before the study. The participants of phase 1 were not asked to participate in phase 3. For each applicable problem, each patient was asked:

- to judge its severity as minimal, moderate or severe;

- to indicate whether it caused none, some or considerable impediment to social activities;

- to state the moment of first occurrence: in the acute phase, during admission into the rehabilitation centre, after discharge;

- to state the period in which the problem was most apparent (manifest) : in the acute phase, during admission into the rehabilitation centre, after discharge;

- to give suggestions for improvement of nursing care.

In the second part of phase 3 , the most important nursing problems were extracted. To this end the following variables were used:

- A: the number of patients who experienced the problem (prevalence);

- B: the average severity (range 1 - 3);

- C: the average impediment to social activities (range 1 - 3).

For each of these variables the problems were ranked, giving the highest value of each variable a ranking score of 1 . The sum of the rankings $\mathrm{A}, \mathrm{B}$ and $\mathrm{C}$ determined the final ranking.

Chi-square tests were performed to compare the response and non-response group on the following characteristics: gender, level of the injury (tetraplegia, paraplegia), the number of patients who received day treatment in the rehabilitation centre after clinical rehabilitation and the number of patients who had been hospitalised in the rehabilitation centre more than once.

\section{Results}

\section{Description of the respondents}

In phase 1, eight patients were asked to participate and they all did. In phase 2, 35 members $(87.5 \%)$ of the nursing staff of 40 people responded. The nursing staff can be considered experienced since $36(90 \%)$ members had worked between five and 10 years with spinal cord injuries. In phase 3 , the questionnaire was sent to 56 patients of whom $35(62.5 \%)$ responded. Table 1 presents the general characteristics of the response group of phases 1 and 3 and the non-response group of phase 3. 
Table 1: Patients characteristics

\begin{tabular}{|c|c|c|c|}
\hline & Phase $1(\mathrm{~N}=8)$ & $\begin{array}{r}\text { Phase } 3(\mathrm{~N}=35) \\
\text { Responders }\end{array}$ & $\begin{array}{l}\text { Phase } 3(\mathrm{~N}=21) \\
\text { Nonresponders }\end{array}$ \\
\hline Average age (SD) & $45.8(9.2)$ & $46.3(14.4)$ & 46.0 \\
\hline Men & $4(50 \%)$ & $22(63 \%)$ & $13 \quad(62 \%)$ \\
\hline Women & $4(50 \%)$ & $13(37 \%)$ & $8 \quad(38 \%)$ \\
\hline Tetraplegia & $4(50 \%)$ & $13(37 \%)$ & $10 \quad(48 \%)$ \\
\hline Paraplegia & $4(50 \%)$ & $22 \quad(63 \%)$ & $11 \quad(52 \%)$ \\
\hline Day treatment ${ }^{a}$ & $2(25 \%)$ & $13(37 \%)$ & $8 \quad(38 \%)$ \\
\hline Re-admission ${ }^{b}$ & $0 \quad(0 \%)$ & $11(31 \%)$ & $3(14 \%)$ \\
\hline
\end{tabular}

a Received day treatment in the centre following clinical rehabilitation

${ }^{b} \mathrm{Had}$ been hospitalised in the rehabilitation centre twice or more often

No significant differences were found between the response group and the nonresponse group of phase 3 for: gender $(p=0.94)$, level of the injury $(p=0.44)$, the number of patients who received day treatment after clinical rehabilitation $(\mathrm{p}=0.94)$ and the number of patients who had been hospitalised in the rehabilitation centre more than once $(\mathrm{p}=0.15)$. The reasons for declining to participate are not known.

\section{Results phase 1}

The staff member of the nursing discipline and the research assistant identified 60 and 23 problems respectively out of four interviews. The two nurses of the spinal cord department, who read all eight transcriptions, identified 80 and 81 problems respectively. In total a set of 96 problems were listed in terms used by the patients themselves of which 19 were identified by all four researchers, 33 by three, 25 by two and 19 by only one of the four researchers. The problem list included a wide variety of problems including both physical and psychosocial issues.

\section{Results phase 2}

The nursing staff considered 52 of the 96 problems to be slightly or very relevant to the nursing responsibility (average score above 2). Several statements got the same code and these were combined into one nursing problem area. Below, two examples are given.

\section{Bladder regulation}

"The changes in bladder regulation are the worst consequences of the SCI", "Being incontinent of urine and not being able to control the bladder", "Not being able to catheterise", "Dealing with the changes in bladder regulation in unadapted environments is often difficult", "Being afraid to swim because of incontinence".

Having difficulties to ask for help, to stand up for oneself, to be assertive (assertiveness) "It is hard to ask for help and if you ask, you experience yourself as annoying", "Over and over again you have to stand up for yourself, you have to become more 
emancipated and assertive, you have more stress and frustration", "It is difficult to ask for help, but sometimes you just have to do, otherwise you become a prisoner of your own body or home".

Table 2 shows the 20 nursing problem areas found and the mean scores for the degree in which the problem was considered to be relevant for the nursing discipline.

Table 2: Twenty nursing problem areas in rank order

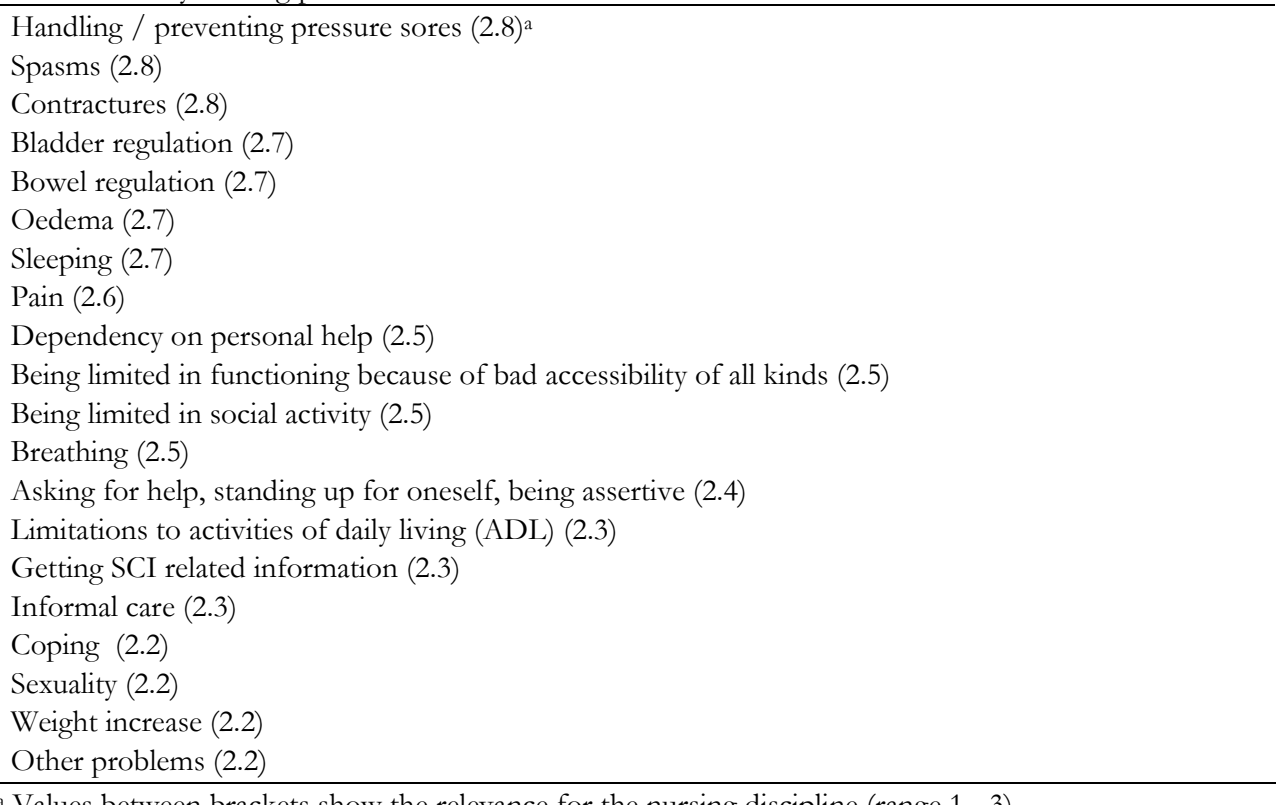

a Values between brackets show the relevance for the nursing discipline (range 1 - 3)

The problem list in table 2 shows that the nurses involved felt responsible for a wide array of problems. However, problems like pressure sores, spasms, contractures, bladder and bowel regulation were considered most relevant for nursing care (highest scores: from 2.7 to 2.8). Problems considered not relevant included arranging good facilities and adaptations at home and in public buildings, additional costs, public transportation and vacations (lowest scores: from 1.4 to 1.5 ).

\section{Results phase 3}

In phase 3 we studied the occurrence of nursing problems in a larger sample of SCI patients. Table 3 shows the ranking of the problems with regard to prevalence, severity and impact on social life. The highest value per variable has been translated into a score of 1 , the lowest into a score of 20 . A few variables have not been investigated. These were given the lowest ranking score and are printed italic. 
Table 3: Patient ranking per nursing problem $(n=35)$ :

\begin{tabular}{lcccc}
\hline & Prevalence $^{\mathbf{b}}$ & Severity $^{\mathbf{b}}$ & Impact on social life $^{\mathbf{b}}$ & Sum score $^{-}$ \\
\hline Limitations to ADL & 3 & 7 & 6 & 16 \\
Assertiveness & 14 & 1 & 2 & 17 \\
Pain & 3 & 11.5 & 5 & 19.5 \\
Coping & 1 & 9.5 & 11.5 & 22 \\
Dependency & 11 & 2 & 11.5 & 24.5 \\
Bladder & 5 & 14 & 8.5 & 27.5 \\
Informal care & 19 & 6 & 3 & 28 \\
Pressure sores & 15 & 5 & 8.5 & 28.5 \\
Other & 20 & 8 & 1 & 29 \\
Social activities & 7 & 3 & $19.5 \mathrm{c}$ & 29.5 \\
Breathing & 16.5 & 9.5 & 4 & 30 \\
Bowel & 8.5 & 15 & 8.5 & 32 \\
Unadapted environment & 11 & 4 & $19.5 \mathrm{c}$ & 34.5 \\
Sexuality & 11 & 13 & 15 & 39 \\
Spasms & 3 & 20 & 16 & 39 \\
Sleeping & 16.5 & 17 & 8.5 & 42 \\
Getting information & 18 & 11.5 & 13 & 42.5 \\
Oedema & 6 & 19 & 17.5 & 42.5 \\
Contractures & 13 & 16 & 14 & 43 \\
Weight increase & 8.5 & 18 & 17.5 & 44 \\
\hline The & 16 & & \\
\hline
\end{tabular}

a The highest value per variable got a score of 1 , the lowest 20

b 0.5 ratings in the first three columns indicate that more than one problem had this ranking

c These variables indicates that no data have been obtrained, so these variables were appointed the lowest ranking score

Combining all rankings showed that from nursing perspective the top six of most important problem areas after discharge were:

\section{Limitations to activities of daily living}

Twenty-four patients (69\%) experienced this problem. The score on severity was 2.45 (range 1-3), the score on impediment to social life was 2.14 (range 1-3). Two thirds of the patients with this problem experienced the highest impact of this problem after discharge $(n=16,66.6 \%)$, although the problem originated together with the SCI.

\section{Assertiveness}

Compared to the other problems this problem did not occur very frequently $(n=13$, $37 \%$ ), but the problem scored high on severity (2.77) and impediment to social activities (2.31).

\section{Pain}

Twenty-four patients (69\%) experienced pain. The score on severity was 2.38 and the score on impediment to social life was 2.17. Half of the patients $(n=12,50 \%)$ with this problem experienced the highest impact of the problem after discharge. 


\section{Coping with the disability}

Of all problems, this one occurred most frequently: 25 patients experienced it $(71 \%)$. The score on severity was 2.40 and the score on impediment to social life was 2.05 . For $60 \%$ of the patients with this problem $(\mathrm{n}=15)$, this problem was also most apparent after discharge.

\section{Dependency on personal help}

17 patients (19\%) experienced this problem. The score on severity was 2.75 and the score on impediment to social life was 2.05 . Almost $60 \%$ of the patients with this problem $(\mathrm{n}=10,58.8 \%)$, experienced the highest impact of the problem after discharge.

\section{Bladder regulation}

This problem was reported by 22 patients (63\%). The score on severity was 2.30 and the score on impediment to social life was 2.10 . Half of the patients $(n=11,50 \%)$ with this problem experienced the highest impact of the problem after discharge.

Table 4 shows the percentages of patients in whom the problems occurred or became more important in the period after discharge. Especially problems with informal care, pressure sores, unadapted environments and weight increase occurred and were most apparent after discharge.

For each problem area the respondents made several suggestions for improving nursing care, involving both clinical care and care after discharge. In general, patients wanted to be better prepared during rehabilitation for the period after discharge. Some suggestions were to organise meetings with SCI patients who are living in the community to discuss the period after discharge from rehabilitation, and to attune the care more closely to their needs and the situation after discharge. During rehabilitation the nursing team should not give help too quickly; more stimulation could be given to patients to solve problems themselves. More attention could also be paid to dealing with the changed bladder and bowel regulation during all kinds of social activities and to getting around in unadapted environments. After discharge, patients would like to receive more aftercare from the rehabilitation centre. They suggested organising consulting hours, meetings with independently living patients and a longer period of day treatment in the rehabilitation centre after clinical rehabilitation. 
Table 4: Percentage of patients in whom the problems occurred or became more important after discharge

\begin{tabular}{|c|c|c|c|}
\hline & Prevalence & Started after discharge $^{a}$ & Most apparent after discharge \\
\hline Limitations to ADL & 24 & $41.6(10)$ & $66.6(16)$ \\
\hline Assertiveness & 13 & $30.8 \quad(4)$ & $\mathrm{b}$ \\
\hline Pain & 24 & $8.3(2)$ & $50.0(12)$ \\
\hline Coping & 25 & $20.0 \quad(5)$ & $60.0(15)$ \\
\hline Dependency & 17 & $11.8 \quad(2)$ & $58.8(10)$ \\
\hline Bladder & 22 & $18.2(4)$ & $50.0(11)$ \\
\hline Informal care & 8 & $62.5 \quad(5)$ & $87.5(7)$ \\
\hline Pressure sores & 11 & $54.5(6)$ & $63.6(7)$ \\
\hline Other & 7 & 57.1 (4) & 71.4 (5) \\
\hline Social activities & 20 & $45.0 \quad(9)$ & $70.0(14)$ \\
\hline Breathing & 10 & 10.0 & $30.0 \quad(3)$ \\
\hline Bowel & 18 & $16.7 \quad(3)$ & $55.5(10)$ \\
\hline Unadapted environment & 17 & $70.5(12)$ & $76.5(13)$ \\
\hline Sexuality & 17 & $17.6 \quad(3)$ & $58.8(10)$ \\
\hline Spasms & 24 & $8.3(2)$ & $37.5(9)$ \\
\hline Sleeping & 10 & $20.0 \quad(2)$ & $60.0 \quad(6)$ \\
\hline Getting information & 9 & $\mathrm{~b}$ & b \\
\hline Oedema & 21 & 33.3 (7) & $47.6(10)$ \\
\hline Contractures & 14 & $35.7 \quad(5)$ & $64.3(9)$ \\
\hline Weight increase & 18 & $72.2(13)$ & $83.3(15)$ \\
\hline
\end{tabular}

\section{Discussion}

Our study supports previous research findings [1-9] that SCI patients, once discharged from clinical rehabilitation, are confronted with many problems. The study also showed that a wide variety of these problems were judged to be within the professional focus of nursing. The most important nursing problem areas were: limitations to activities of daily living, having difficulties to ask for help (assertiveness), pain, coping with the disability, dependency on personal help and problems with changed bladder regulation.

These results were consistent with other research that also was focused on investigating nursing related problems of SCI patients after clinical rehabilitation. De Boer and Plagge [19] investigated nursing diagnoses. In their response group the following nursing diagnoses occurred most frequently: altered urinary and faecal elimination patterns; impaired physical mobility; pain; sexual dysfunction; coping strategies; sleep dysfunction and self care deficit. Although the problem labels are different, all the themes recur in the nursing problem areas as identified in this study. 
Pye [20] also studied nursing diagnoses of long-term SCI patients. Again there was considerable overlap in the most frequently occurring problems and the scope of the nursing responsibility.

Due to the exploratory character of this study, it is not possible to generalise our findings to the entire population. For this reason and because of differences in definition and data collection it was not possible to precisely compare our results regarding the prevalence of problems to the results of other studies. Nevertheless, Widerström et al. [4] and Dunn et al. [12], also found high percentages of patients with pain $(76.7 \%$ and $62 \%$ respectively), bladder dysfunction $(86 \%$ and $72 \%$ respectively), problems with mobility (85.6\% and $75 \%$ respectively).

The presence of a wide variety of nursing problems indicates that nurses can give important input to improve nursing care after clinical rehabilitation. Until now aftercare for SCI patients in Dutch rehabilitation centres is mainly given by rehabilitation doctors. Patients do not receive regular follow-up from other care disciplines. Certainly the high occurrence and impact of the more psychosocial problems, like dependency and assertiveness, subscribe the idea that it is not sufficient to provide only medical follow-up [11]. We think that a number of disciplines are required to support patients with their problems after clinical rehabilitation. After all, health care delivery is the combined objective of several care disciplines. Each profession operates more or less separately, and each offers its own parcel. Differences exist in the way health problems are approached. For example, the main focus of medicine is the diagnosis and treatment of disease (cure) [21]. Nursing concentrates on care [21] and the consequences of impairments for activities of daily living [17]. In the area of pressure sores and bladder and bowel management of SCI patients, in particular, we believe based on our clinical experience that nurses have important input. Because of this, the broad focus of the nursing profession and the fact that nurses also have delegated activities in which they help patients to carry out treatment plans [21], we think nurses could have an important role in aftercare.

We recommend starting an experiment in which a nurse of the rehabilitation centre acts as a liaison person between the patient, home care organisations and the rehabilitation centre after discharge. He or she could give advise to patients, make home visits if necessary and support the home care nursing staff with the specialised care for SCI patients. We think it is important to make it possible for patients to call upon support of the other care disciplines in the rehabilitation centre if necessary.

We also recommend a critical evaluation of the care during clinical rehabilitation in view of the most important problems. We think it is very important to discuss the future home situation in more detail and to attune the care more closely to the patients' needs and their situation after discharge. Although the SCI patients participating in our study already gave useful recommendations to improve nursing care during and after clinical rehabilitation, we find it important that spinal cord patients are involved in elaborating the ideas to improve nursing aftercare. 
Our study had a number of weaknesses. In phase 1 there was a large difference between the number of problems identified by the researchers. Although not calculated, the interrater reliability was not expected to be high. Probably, the relatively low number of problems identified by the research assistant, can be explained by the fact that the research assistant was the only researcher who had no health service or nursing background. There were no reasons to assume that the other three researchers missed the identification of a large number of problem statements.

Another limitation of our study was that only one person coded and combined the 52 problem statements into 20 nursing problem areas. If more people had analysed the statements and if the results had been presented to some of the participants of phase 1 , the validity of the results might have been increased. In the second phase, a large panel of experts were questioned individually to identify the problem areas that were most strongly linked to the nursing responsibility. For 11 problem statements the opinions about the relevance for the nursing responsibility were about equally divided. Half of the respondents judged them to be not relevant at all, and half of them judged them to be relevant. For some topics, we think it would have been useful to investigate why the judgements were so different. For example, how to deal with the consequences of the SCI in raising children and organising daily life.

For future research we recommend researchers to further investigate the focus of nursing in the care for SCI patients. It would be useful to study nursing problems of SCI patients in the long-term. Also, more attention should be paid to investigating the relationship between the nursing care given in the rehabilitation centre and the occurrence of certain nursing problems after discharge.

Although this study did have weaknesses, we think it provided an important contribution clarifying post-discharge nursing needs of SCI patients. It increased the ability to communicate the contribution of nursing to patients and other care disciplines and to co-ordinate post-discharge care activities.

\section{Clinical messages}

- Spinal cord injured patients experience serious nursing problems after discharge from clinical rehabilitation.

- Nurses can give important input to improve nursing care after clinical rehabilitation. 


\section{References}

[1] Johnson RL, Gerhart KA, McCray J, Menconi JC, Whiteneck GG. Secondary conditions following spinal cord injury in a population-based sample. Spinal Cord 1998; 36(1): 45-50.

[2] Anson CA, Shepherd C. Incidence of secondary complications in spinal cord injury. International Journal of Rehabilitation Research 1996; 19(1): 55-66.

[3] Noreau L, Proulx P, Gagnon L, Drolet M, Laramee MT. Secondary impairments after spinal cord injury: a population-based study. American Journal of Physical Medicine and Rehabilitation 2000; 79(6): 526-35.

[4] Widerström-Noga EG, Felipe-Cuervo E, Broton JG, Duncan RC, Yezierski RP. Perceived difficulty in dealing with consequences of spinal cord injury. Archives of Physical Medicine and Rehabilitation 1999; 80(5): 580-6.

[5] Levi R, Hultling C, Seiger A. The Stockholm Spinal Cord Injury Study. 3. Health-related issues of the Swedish annual level-of-living survey in SCI subjects and controls. Paraplegia 1995; 33(12): 726-30.

[6] Harrison C, Kuric J. Community reintegration of SCI persons: problems and perceptions. SCI Nursing 1989; 6(3): 44-7.

[7] Brown DJ, Judd FK, Ungar GH. Continuing care of the spinal cord injured. Paraplegia 1987; 25(3): 296-300.

[8] Cyr LB. Sequelae of SCI after discharge from the initial rehabilitation program. Rehabilitation Nursing 1989; 14(6): 326-9,337.

[9] Levi R, Hultling C, Nash MS, Seiger A. The Stockholm spinal cord injury study: 1. Medical problems in a regional SCI population. Paraplegia 1995; 33(6): 308-15.

[10] McKinley WO, Jackson AB, Cardenas DD, DeVivo MJ. Long-term medical complications after traumatic spinal cord injury: a regional model systems analysis. Archives of Physical Medicine and Rehabilitation 1999; 80(11): 140210.

[11] Cox RJ, Amsters DI, Pershouse KJ. The need for a multidisciplinary outreach service for people with spinal cord injury living in the community. Clinical Rehabilitation 2001; 15(6): 600-6. 
[12] Dunn M, Love L, Ravesloot C. Subjective health in spinal cord injury after outpatient healthcare follow-up. Spinal Cord 2000; 38(2): 84-91.

[13] Glidden MM. Spinal cord injury and case management. Topics in Spinal Cord Injury Rehabilitation 1999; 4 (4): 16-23.

[14] Fine PR, Better SR, Engstrand JL. The operation of a hospital based specialty home health team: activities and associated costs. Rehabilitation Nursing 2000; 25(2): 70-75.

[15] Mattson J. Case management: a historical and future perspective of its influence on outcome for persons who have sustained spinal cord injury. Topics in Spinal Cord Injury Rehabilitation 1999; 4 (4): 30-37.

[16] Rawl SM, Easton KL, Kwiatkowski S, Zemen D, Burczyk B. Effectiveness of a nurse-managed follow-up program for rehabilitation patients after discharge. Rehabilitation Nursing 1998; 23(4): 204-9.

[17] Leih P, Salentijn C. Verpleegkundige diagnoses: Betekenis, classificatie en vragen (Nursing diagnoses: Meaning, classification and questions). Verpleegkunde 1991; 6: 3-10.

[18] Chenitz WC, Swanson JM. From practice to grounded theory, qualitative research in nursing. Menlo Park, California: Addison-Wesley Publishing Company; 1986.

[19] De Boer D, Plagge E. Verpleegkundige diagnoses bij personen met een dwarslaesie na ontslag uit het revalidatiecentrum (Nursing diagnoses of spinal cord injured patients after discharge from clinical rehabilitation). Unpublished nursing science master thesis University of Groningen, the Netherlands; 2001.

[20] Pye CG. Nursing diagnosis in long-term spinal cord injury. In: Classification of nursing diagnosis: proceedings of the eleventh conference. Glendale, California.; 1995.

[21] Gordon M. Nursing diagnosis, process and application. Third ed. St. Louis, Missouri: Alison Miller; 1994. 


\section{Health problems of persons with spinal cord injury living in the Netherlands}

Published in:

Disability and Rehabilitation 2005; 27(22): 1381-1389

Jos Bloemen-Vrencken, Marcel Post, Jos Hendriks, Elly de Reus, and Luc de Witte 


\section{Abstract}

Purpose: To investigate the prevalence of health problems among persons with spinal cord injury (SCI) living in the Netherlands, to identify the problems experienced as most important, and to analyse the experienced impact of these most important problems on daily activities and social life.

Method: Postal survey among all members of the Dutch Association of SCI Patients. The questionnaire focused on 26 health problems: 13 secondary impairments, eight problems of daily living and five psychosocial problems.

Results: The respondents (response rate $45.5 \%, 454$ persons) experienced an average of eight health problems. The most frequently occurring problems regarded bladder and bowel regulation, spasms, pain, oedema and sexuality. Except for oedema, these problems were also most often cited as the most important. The most disabling condition for both daily and social activities was pain. Few significant relationships were found between the prevalence of health problems and the level, completeness and duration of the injury or gender.

Conclusion: Persons with SCI living in the community experience many health problems and limitations in daily activities and social life due to these problems. The occurrence of these problems does not diminish with increasing time after injury. This strongly emphasises the need for follow-up care.

Keywords: Health problems, SCI. 


\section{Introduction}

During the last few decades, life expectancy for people with spinal cord injury (SCI) has increased considerably [2-5]. Due to advances in post-injury care management, early death from medical complications after SCI, such as respiratory insufficiency, renal failure, or septicaemia, has decreased greatly $[5,6]$. Consequently, issues regarding long-term management have become increasingly important [3-7].

From previous studies it is known that, once discharged, persons with SCI are confronted with problems that negatively affect functioning. Reported problems include physical problems like pain [8-14], spasms [5, 8-11, 13, 14], bladder and bowel problems $[5,9,10,13,14]$. The literature also mentions transportation and financial problems $[6,8,14,15]$, difficulties in care management $[15,16]$, feelings of sadness $[14,16]$ and lack of adequate housing $[8,15,16]$. Since there are so many problems, several reports $[3,17-26]$ indicate the necessity of continuing care after discharge from inpatient rehabilitation.

In the Netherlands, after discharge from inpatient rehabilitation, care for spinal cord injured patients is transferred from the rehabilitation centre to primary health care. However, SCI is a rare condition with an incidence of traumatic SCI of 12.1 per million per year [27]. Consequently primary health care professionals only sporadically see patients with SCI in their practice. Therefore, these professionals might not have much opportunity to expand their knowledge about the specific care these patients need [19]. The professionals in rehabilitation centres, on the other hand, are limited in their possibilities to give follow-up care, due to the limited payment they receive from health service insurers for this kind of care. Subsequently, until recently, life-long care for persons with SCI is still underdeveloped in the Netherlands. The Dutch Association of SCI Patients, the iRv (Institute for Rehabilitation Research) and the Rehabilitation Centre Hoensbroeck therefore decided to develop a follow-up care programme to support patients and professionals involved in making the transfer from inpatient rehabilitation to primary health care. To focus this programme on the most important problems from a patient's perspective, the present exploratory study was initiated. The main purpose was to investigate the prevalence of health problems among members of the Dutch patients' association, to identify the problems experienced as most important, and to analyse the experienced impact of these most important problems on daily activities and social life. We also wanted to study the relationships between the occurrence of health problems and respondent/injury characteristics. The results should help to decide on which problems the follow-up care programme should focus. 


\section{Methods}

\section{Data collection}

A questionnaire was sent to all members of the Dutch Association of SCI Patients. Beside some personal and lesion characteristics (see table 1) the questionnaire focused on the prevalence of health problems, the most important health problems and their impact on daily and social life, secondary impairments typical for SCI and self-care ability.

\section{Health problems}

The main part of the questionnaire focused on 26 health problems that individuals with SCI might experience. This health problem-list, shown in table 2, consisted of 13 secondary impairments, eight problems of daily living and five psychosocial problems. Item formulation to the respondents was as shown in table 2, although the headings 'secondary impairments', 'problems of daily living', and 'psychosocial problems' were not used in the patients' version. The list resulted from earlier research [26], clinical experience and expert consultation with leading rehabilitation physiatrists, nurses, researchers in this field and experienced patients. For each health problem, the respondents were asked to indicate whether or not they had faced this problem during the previous 12 months. They were also invited to describe problems experienced that were not mentioned in the list.

\section{Health problems experienced as being most important and their impact on daily and social life}

The respondents had to select a maximum of five most important health problems out of all problems experienced. For each of the most important problems the respondents were asked:

- to state the frequency of occurrence;

- to indicate whether this problem caused no, some, moderate, considerable or complete impediment for their social activities (such as work, sports, hobbies, going out);

- to indicate whether this problem caused no, some, moderate, considerable or complete impediment for their activities of daily living (such as eating, bathing, grooming, transfers).

\section{Additional questions about secondary impairments typical for SCI}

In order to describe some secondary impairments typical for SCI in more detail, additional questions were asked about the type, location, and seriousness of these problems (i.e. regarding difficulties with breathing / respiratory tract, bladder and bowel regulation, pressure sores, pain and spasms). 


\section{Self-care ability}

Self-care ability was measured using the Dutch questionnaire version of the Barthel Index (BI), which reliability and validity have been shown to be good [28]. The BI rates the degree of independence from help by others in performing activities of daily living. It consists of 10 items of which seven concern activities of daily living (bathing, dressing, feeding, toilet use, grooming, bladder and bowels). The three remaining items concern mobility: transfers, climbing stairs and indoor/outdoor mobility. The total range of the $\mathrm{BI}$ is between 0 and 20 and is interpreted as: 0-4 'very disabled'; 5-9 'severely disabled'; 10-14 'moderately disabled'; 15-19 'mildly disabled' and 20 'independent' [28]. In our sample the reliability of the BI was high (Cronbach's alpha was 0.85$)$.

Persons who were unable to write were invited to make use of a digital/computerised version of the questionnaire, which could be obtained on their own request. To improve the response rate, a reminder was sent four weeks after the questionnaire was mailed.

\section{Statistical analysis}

Descriptive analyses were performed to describe the prevalence and the experienced importance of health problems, and the experienced impact of these problems on daily activities and social life. To detect associations between the occurrence of health problems and subject characteristics, chi-square tests of independence were performed. For this purpose, the subjects were grouped as follows:

- Tetraplegia (C1-T1) versus paraplegia (T2-S5). The self-reported highest motor level was taken as criterion.

- Complete versus incomplete injury. Some respondents reported a complete injury together with a partial injury at a higher level; in the analysis they were treated as having a complete injury.

- Duration of injury was trichotomised as in the study of Levi [29]: 0 till 5 years (about 25\% of the respondents), 5 till 19 years (about 50\%) and over 19 years $(25 \%)$;

- Male versus female.

The level of statistical significance was set at $\mathrm{p}<0.05$.

\section{Results}

\section{Respondents}

The questionnaire was sent to all 997 members of the patient association, of whom $454(45.5 \%)$ responded. Table 1 shows the general characteristics of the response group. Time after injury varied between half a year and 62.6 years, and age varied between 18 and 82 years. Only eight respondents asked and used the 
digital/computerised version of the questionnaire. We were not able to compare the response group with the non-response group regarding the characteristics mentioned in table 1, since these data were not available.

Table 1 Subject characteristics $(\mathrm{N}=454)$

\begin{tabular}{ll}
\hline Age, mean [yrs] (SD) & $\mathbf{4 7 . 7}(\mathbf{1 3 . 4})$ \\
Time since injury, mean [yrs] (SD) & $13.3(10.9)$ \\
Married or cohabitating [\%] & 65.9 \\
Living on one's own [\%] & 25.6 \\
Gender, male [\%] & 65.0 \\
Paid work [\%] & 43.4 \\
Level and type of injury [\%] & \\
Complete tetraplegia & 20.0 \\
Incomplete tetraplegia & 14.0 \\
Complete paraplegia & 46.7 \\
Incomplete paraplegia & 19.3 \\
Cause of injury [\%] & \\
Traffic accident & 32.7 \\
Sports, recreation & 18.9 \\
Fall & 9.6 \\
Accident at working place & 8.9 \\
Gunshot or stab wounds & 0.4 \\
Medical interventions & 8.7 \\
Disease & 9.8 \\
Other & 10.9 \\
Barthel Index, mean (SD) & \\
Total group & $12.2(4.6)$ \\
Complete tetraplegia & $8.1(4.4)$ \\
Incomplete tetraplegia & $10.3(5.5)$ \\
Complete paraplegia & $13.5(3.3)$ \\
Incomplete paraplegia & $14.5(3.8)$ \\
\hline
\end{tabular}

\section{The prevalence of health problems}

Table 2 presents the prevalence of the health problems investigated. The second column shows how often each problem was mentioned as one of the five most important problems. The respondents faced an average of eight health problems per person. Per problem category, the averages per person were: 4.6 secondary impairments (out of 13 possible); 2.0 problems of daily living (out of eight possible) and 1.3 psychosocial problems (out of five possible). Only seven respondents $(1.5 \%)$ experienced no secondary impairments at all, whereas about one third of all respondents experienced no problems of daily living (30.2\%) and no psychosocial problems (38.1\%). Among the six problems most often mentioned, five were secondary impairments. In rank order these were: problems of bladder (70.9\%) and 
Table 2 Experienced health problems during the previous year $(\mathrm{N}=454)$

\begin{tabular}{|c|c|c|c|c|}
\hline \multirow[t]{2}{*}{ Problem areas } & \multicolumn{2}{|c|}{$\begin{array}{r}\text { Number of } \\
\text { respondents } \\
\text { who } \\
\text { experienced } \\
\text { this problem }\end{array}$} & \multicolumn{2}{|c|}{$\begin{array}{l}\text { Number o } \\
\text { respondents wh } \\
\text { mentioned this } \\
\text { problem in top } 5 \\
\text { most importan }\end{array}$} \\
\hline & $\mathbf{N}$ & $\%$ & $\mathbf{N}$ & $\%$ \\
\hline \multicolumn{5}{|l|}{ Secondary impairments } \\
\hline Bladder regulation (incontinence, urinary tract infections, e.g.) & 322 & 70.9 & 235 & 51.8 \\
\hline Bowel regulation (incontinence, diarrhoea, constipation, e.g.) & 277 & 61.0 & 189 & 41.6 \\
\hline Spasms & 257 & 56.6 & 150 & 33.0 \\
\hline Pain & 251 & 55.3 & 182 & 40.1 \\
\hline Oedema (accumulation of liquid in the legs) & 220 & 48.5 & 72 & 15.9 \\
\hline Having pressure sores or preventing them & 163 & 35.9 & 94 & 20.7 \\
\hline Increasing weight & 146 & 32.2 & 62 & 13.7 \\
\hline Excessively sweating & 128 & 28.2 & 40 & 8.8 \\
\hline $\begin{array}{l}\text { Contractures (decreased joint mobility due to reduction of } \\
\text { muscle length) }\end{array}$ & 102 & 22.5 & 33 & 7.3 \\
\hline $\begin{array}{l}\text { Breathing / respiratory tract (shortness of breath, infection of } \\
\text { respiratory tract, e.g.) }\end{array}$ & 87 & 19.2 & 32 & 7.0 \\
\hline $\begin{array}{l}\text { Calcification or the growth of bone around joints below the } \\
\text { level of the injury (neurogenic heterotopic ossification) }\end{array}$ & 58 & 12.8 & 19 & 4.2 \\
\hline Low blood pressure & 52 & 11.5 & 11 & 2.4 \\
\hline Thrombosis (blood clots in blood vessel) & 14 & 3.1 & 3 & 0.7 \\
\hline \multicolumn{5}{|l|}{ Problems of daily living } \\
\hline $\begin{array}{l}\text { Handicap management (extra time needed for personal care } \\
\text { and arranging all kind of things due to the SCI) }\end{array}$ & 172 & 37.9 & 67 & 14.8 \\
\hline $\begin{array}{l}\text { Activities of daily living (eating, personal care, dressing, } \\
\text { transfers, moving forward) }\end{array}$ & 143 & 31.5 & 46 & 10.1 \\
\hline $\begin{array}{l}\text { Facilities, equipments, housing (e.g. problems to arrange } \\
\text { them or not having them) }\end{array}$ & 135 & 29.7 & 57 & 12.6 \\
\hline Functioning in unadapted environments & 127 & 28.0 & 40 & 8.8 \\
\hline Domestic work (e.g. cooking, cleaning, shopping) & 125 & 27.5 & 27 & 5.9 \\
\hline $\begin{array}{l}\text { Leisure time activities (association, club, sports, social } \\
\text { activities as going to the movies and going out for dinner) }\end{array}$ & 97 & 21.4 & 23 & 5.1 \\
\hline Work & 69 & 15.2 & 26 & 5.7 \\
\hline $\begin{array}{l}\text { Communication (writing, reading, phoning, environmental } \\
\text { control devices) }\end{array}$ & 34 & 7.5 & 7 & 1.5 \\
\hline \multicolumn{5}{|l|}{ Psychosocial problems } \\
\hline Sexuality & 178 & 39.2 & 102 & 22.5 \\
\hline $\begin{array}{l}\text { Dependency (having difficulties being dependent on personal } \\
\text { help) }\end{array}$ & 160 & 35.2 & 83 & 18.3 \\
\hline Asking for help, standing up for oneself, being assertive & 96 & 21.1 & 38 & 8.4 \\
\hline Adaptability, having difficulties to cope with the handicap & 91 & 20.0 & 46 & 10.1 \\
\hline Relational problems (within family or circle of acquaintances) & 63 & 13.9 & 27 & 5.9 \\
\hline Other problems (open-ended question) & 71 & 15.6 & 56 & 12.3 \\
\hline
\end{tabular}


bowel regulation $(61.0 \%)$, spasms (56.6\%), pain (55.3), and oedema (48.5\%). The next most frequently occurring health problem concerned sexuality (psychosocial problem category). Problems with handicap management occurred most frequently in the category of problems of daily living.

\section{Additional information about secondary impairments typical for SCI}

The respondents $(\mathrm{n}=454)$ reported the following details about secondary impairments.

\section{Bladder problems}

Almost half of the respondents reported one or more urinary tract infections (45.6\%). Problems with incontinence (such that clothes get wet) were mentioned by $38.1 \%$, being dependent on help from others was mentioned as a problem by $12.3 \%$, inadequate incontinence management supplies by $6.2 \%$, difficulties to catheterise by $5.1 \%$ and other problems by $7.9 \%$.

\section{Bowel problems}

Almost one third of the respondents reported constipation (31.9\%) and incontinence (30.6\%). Diarrhoea was mentioned by $20.5 \%$; dependence on personal help from others by $18.1 \%$; inadequate incontinence management supplies by $1.3 \%$ and other problems by $7.9 \%$.

\section{Spasms}

Spasms were experienced as a problem during transfers (40.7\%), sleep (39.2\%), wheelchair propulsion (37.0\%), washing/dressing (32.4\%), and other $(16.3 \%)$.

\section{Pain}

Of all respondents $43.0 \%$ experienced pain below the level of the injury, 39.6\% reported pain in muscles and joints and $27.8 \%$ reported pain at the level of the injury. The seriousness of the pain was indicated as follows: little (16.2\%), moderate $(31.1 \%)$, serious $(35.9 \%)$, very serious $(16.8 \%)$.

\section{Pressure sores}

A quarter of the respondents reported a superficial wound (26.4\%), 19.8\% reported redness of the skin and $12.8 \%$ reported a deep wound. The most frequently reported pressure sores were located at the buttock (25.1\%), coccyx (24.3\%) and heel (19.8\%).

\section{Breathing problems}

The respondents reported the following problems: difficulties to cough up sputum $(13.4 \%)$, breathlessness $(10.6 \%)$, respiratory tract infection $(7.5 \%)$, continuous mechanical ventilation $(0.2 \%)$ and help from others needed to remove sputum $(0.2 \%)$. 


\section{The problems experienced as being most important and their impact on daily and social life}

The respondents indicated an average of four most important problems. The rankings of the most frequent and the most important problems were almost equal. The most important problems were once again reported as bladder regulation $(51.8 \%)$ and bowel regulation $(41.6 \%)$, pain $(40.1 \%)$, spasms $(33.0)$, and sexuality $(22.5 \%)$. Pressure sores were also frequently $(20.7 \%)$ mentioned as most important. Other problems were mentioned among the most important by less than $20 \%$. Especially for oedema there was a large difference between the number of respondents who experienced the problem $(48.5 \%)$ and the number of respondents who considered the problem to be one of the most important $(15.9 \%)$.

For each problem mentioned in the top five most important problems, additional questions were asked about the frequency of occurrence and the experienced impact on daily activities and social life. The results for the six most frequently mentioned important problems are depicted in table 3.

Table 3 The six problems listed most frequently among the top five most important problems: frequency of occurrence, the impact on daily and social activities

\begin{tabular}{|c|c|c|c|c|c|c|}
\hline & $\begin{array}{r}\text { Bladder } \\
\mathrm{N}=235\end{array}$ & $\begin{array}{r}\text { Bowel } \\
\mathrm{N}=189\end{array}$ & $\begin{array}{r}\text { Pain } \\
\mathrm{N}=182\end{array}$ & $\begin{array}{r}\text { Spasms } \\
\mathrm{N}=150\end{array}$ & $\begin{array}{r}\text { Sexuality } \\
N=102\end{array}$ & $\begin{array}{r}\text { Pressure sores } \\
\mathrm{N}=92\end{array}$ \\
\hline Frequency of problem & $\%$ & $\%$ & $\%$ & $\%$ & $\%$ & $\%$ \\
\hline Daily/continuously & 45.5 & 28.6 & 91.2 & 86.7 & 59.8 & - \\
\hline 1-6 times a week & 9.8 & 30.7 & 6.6 & 8.0 & 15.7 & - \\
\hline 1-3 times a month & 9.8 & 19.6 & 0.5 & 1.3 & 5.9 & - \\
\hline$<1$ time a month & 31.1 & 19.6 & 1.6 & 0.7 & 5.9 & - \\
\hline Missing & 3.8 & 1.6 & 0.0 & 3.3 & 12.7 & - \\
\hline \multicolumn{7}{|c|}{ Impact on social activities } \\
\hline None & 14.5 & 14.8 & 5.5 & 19.3 & 62.7 & 20.7 \\
\hline Some & 28.1 & 26.5 & 14.3 & 29.3 & 5.9 & 20.7 \\
\hline Moderate & 26.8 & 31.2 & 38.5 & 26.7 & 9.8 & 21.7 \\
\hline Considerable & 23.0 & 24.9 & 36.3 & 18.0 & 12.7 & 17.4 \\
\hline Complete & 6.4 & 2.6 & 5.5 & 6.0 & 1.0 & 19.6 \\
\hline Missing & 1.3 & 0.0 & 0.0 & 0.7 & 7.8 & 0.0 \\
\hline \multicolumn{7}{|l|}{ Impact on daily activities } \\
\hline None & 28.5 & 23.8 & 9.9 & 12.0 & 72.5 & 19.6 \\
\hline Some & 29.8 & 34.4 & 21.4 & 30.0 & 1.0 & 28.3 \\
\hline Moderate & 27.2 & 24.9 & 36.3 & 29.3 & 10.8 & 16.3 \\
\hline Considerable & 9.8 & 15.3 & 28.0 & 22.7 & 4.9 & 25.0 \\
\hline Complete & 3.0 & 1.1 & 4.4 & 4.7 & 1.0 & 10.9 \\
\hline Missing & 1.7 & 0.5 & 0.0 & 1.3 & 9.8 & 0.0 \\
\hline
\end{tabular}


Pain appeared to be the most often occurring and most disabling condition for both daily activities and social life. As many as $91.2 \%$ of the respondents with pain experienced it daily/continuously. About two thirds of the respondents (68.7\%) with pain experienced it as a moderate, considerable or complete impediment to their ADL, while $80.3 \%$ experienced the same degree of impediment to social activities. The second most frequent problem was spasms $(86.7 \%$ experienced it daily/continuously). After pain, spasms caused the greatest impact on daily activities whereas bladder and bowel regulation caused the greatest impact on social life. Problems with regard to sexual life were common, but had less impact on daily activities and social life. The impact of pressure sores on daily and social activities was almost equal.

\section{Prevalence of health problems in relationship with injury and subject characteristics}

\section{Level of the injury}

Among respondents with tetraplegia, significantly higher prevalence rates were found for several secondary impairments: spasms $(\mathrm{p}<0.01)$, breathing problems $(\mathrm{p}<0.01)$, low blood pressure $(p<0.01)$ and contractures $(p<0.05)$. ADL, being dependent on help from others and communication, also caused significantly $(\mathrm{p}<0.01)$ more often problems among respondents with tetraplegia. Pain, on the other hand, occurred significantly $(\mathrm{p}<0.05)$ more often among respondents with paraplegia.

\section{Completeness of the injury}

Respondents with a complete SCI experienced significantly more often pressure sores $(\mathrm{p}<0.01)$ and heterotopic ossification $(\mathrm{p}<0.05)$. Respondents with an incomplete SCI experienced more frequently spasms $(\mathrm{p}<0.01)$, contractures $(\mathrm{p}<0.05)$ and adaptability problems $(\mathrm{p}<0.01)$.

\section{Gender}

Sexual problems occurred significantly $(\mathrm{p}<0.01)$ more often in men than in women. Work-related problems also occurred significantly $(\mathrm{p}<0.05)$ more often in men. Problems regarding adaptation to the injury $(\mathrm{p}<0.01)$, domestic work $(\mathrm{p}<0.05)$, and pain $(p<0.05)$, on the other hand, occurred significantly more often in women than in men.

\section{Duration of the injury}

Table 4 shows the prevalence of health problems in relation to the duration of the SCI. 
Table 4 Prevalence of health problems in relationship with the duration of the injury

\begin{tabular}{|c|c|c|c|}
\hline & $\begin{array}{r}<5 \text { years } \\
\mathrm{N}=118\end{array}$ & $\begin{array}{r}5-19 \text { years } \\
\mathrm{N}=215\end{array}$ & $\begin{array}{r}>19 \text { years } \\
\mathrm{N}=112\end{array}$ \\
\hline \multicolumn{4}{|l|}{ Secondary impairments } \\
\hline Bladder regulation & 66.9 & 71.6 & 73.2 \\
\hline Bowel regulation & 66.9 & 59.5 & 58.0 \\
\hline Spasms & 55.9 & 57.7 & 55.4 \\
\hline Pain & 61.9 & 55.8 & 46.4 \\
\hline Oedema & 46.6 & 45.6 & 58.0 \\
\hline Pressure sores $*$ & 36.4 & 30.7 & 47.3 \\
\hline Increasing weight & 34.7 & 31.2 & 31.3 \\
\hline Excessively sweating & 25.4 & 28.8 & 28.6 \\
\hline Contractures $*$ & 22.0 & 18.1 & 32.1 \\
\hline Breathing / respiratory tract & 19.5 & 18.6 & 19.6 \\
\hline Heterotopic ossification & 11.9 & 12.1 & 15.2 \\
\hline Low blood pressure & 7.6 & 11.6 & 15.2 \\
\hline Thrombosis & 1.7 & 4.7 & 1.8 \\
\hline \multicolumn{4}{|l|}{ Problems of daily living } \\
\hline Handicap management & 43.2 & 37.7 & 33.0 \\
\hline ADL & 33.9 & 27.9 & 36.6 \\
\hline Facilities / equipments & 34.7 & 26.0 & 29.5 \\
\hline Functioning in unadapted environments $* *$ & 36.4 & 20.5 & 32.1 \\
\hline Domestic work & 34.7 & 23.3 & 27.7 \\
\hline Leisure time & 23.7 & 18.6 & 24.1 \\
\hline Work ** & 27.1 & 13.5 & 7.1 \\
\hline Communication & 7.6 & 8.8 & 4.5 \\
\hline \multicolumn{4}{|l|}{ Psychosocial problems } \\
\hline Sexuality $*$ & 50.0 & 34.0 & 37.5 \\
\hline Dependency $*$ & 45.8 & 32.1 & 28.6 \\
\hline Asking for help & 23.7 & 19.5 & 21.4 \\
\hline Adaptability $* *$ & 41.5 & 13.5 & 10.7 \\
\hline Relational & & & \\
\hline Problems & 18.6 & 11.6 & 11.6 \\
\hline Other problems & 16.9 & 13.5 & 16.1 \\
\hline
\end{tabular}

** $\mathrm{p}<0.01$

$* \mathrm{p}<0.05$

Seven out of 26 problems showed significant relationships with the duration of the injury. The prevalence of problems regarding work $(\mathrm{p}<0.01)$, adaptation to the injury $(p<0.01)$, dependency $(p<0.05)$ and sexuality $(p<0.05)$ decreased significantly with the duration of the injury. The prevalence of pressure sores, contractures, and problems regarding functioning in unadapted environments showed a significant $(p<0.05)$ nonlinear relationship with the duration of the injury. The lowest prevalence was found among respondents who had their SCI between 5 and 19 years. The highest prevalence of pressure sores and contractures was found among respondents who had 
had their injury for more than 19 years. The highest prevalence of problems regarding functioning in unadapted environments was found among respondents who had their injury for less than five years. The prevalence of bladder problems, heterotopic ossification, and low blood pressure also seem to increase with the duration of the injury, but not significantly.

\section{Discussion}

The present study investigated the prevalence and severity of health problems among members of the Dutch Association of SCI Patients and the impact of these problems on daily and social functioning. The results show that the respondents experience an average of eight health problems. The occurrence of these problems did not significantly diminish with increasing time after injury. The most frequently occurring problems were those of bladder and bowel regulation, spasms, pain, oedema and sexuality. The most disabling condition for both daily and social activities was pain. The reported impact of bladder and bowel problems on social activities was considerable higher compared to the reported impact on daily activities.

Differences in methodology (design, data collection and time frame), hamper comparisons of our results to those of other studies. Nevertheless, the main conclusion confirms those of previous studies, e.g. that health problems frequently occur in persons with SCI in the period after inpatient rehabilitation. The study of Noreau et al. [5] was most comparable to ours, because prevalence data were collected over a period of 12 months and the respondents were comparable to our respondents with respect to age, time since injury, level of injury and type of injury. Compared to Noreau et al., we found lower percentages of people with urinary tract infections ( $46 \%$ versus 56\%) and low blood pressure (11\% versus 33\%), but we found higher percentages of people with spasms (57\% versus $40 \%$ ) and pressure sores $(36 \%$ versus $28 \%$ ). The prevalence of thrombosis was comparable (3\% versus $4 \%$ ).

The percentages of respondents in this study reporting bladder (38.1\%) and bowel $(30.6 \%)$ incontinence, such that clothes got wet, were high when comparing them to the relatively low percentages of respondents who report inadequate incontinence management supplies (bladder 6.2\% and bowel 1.3\%). These results probably indicate that there are quite a number of respondents, with an inadequate bladder and bowel management, who do not have the expectation of incontinence management supplies being able to improve its manageability. Since the availability and reimbursement of incontinence management supplies until recently were good in the Netherlands, the results also might indicate that a number of respondents are not aware of recent developments of bladder and bowel management practices (e.g. colonic cleansing), pharmacology, equipments, and surgery (e.g. Indiana pouch, colostomy). Anyway, our 
findings emphasise the importance of regular reviews of bladder and bowel management after discharge from rehabilitation.

Our findings regarding the perceived difficulty dealing with consequences of SCI agreed with those of Widerström-Noga et al. [14]. In their study, the decreased ability to walk or move and to control bladder and bowel, as well as decreased sexual function, pain and spasms were found to be the most difficult consequences of SCI. Except for the decreased ability to walk or move, the respondents of our study also considered these problems to be most important. The results concerning the perceived impact of these problems on daily activities and social life confirm the importance of these problems.

The reported impact of bladder and bowel problems on social activities was considerably higher than the reported impact on daily activities. This finding contrasts to the results of Hicken [30], who showed that persons with SCI who were not dependent regarding their bladder management did not differ in their reported social integration compared to persons that were independent. However, independent of the actual incidence of accidents, persons with SCI may experience problems in their social life because of their fear of accidents and subsequent social embarrassment.

Our results about relationships between the prevalence of health problems and injury characteristics show similarities with the results of other studies. Spasms and low blood pressure occur more frequently among persons with tetraplegia [5, 14]. Pressure sores were found to occur more frequently among persons with a complete lesion $[5,7,29,31]$. In our study pain occurred more often in persons with paraplegia. Just as in the study of McColl et al. [23] pain occurred significantly more often in women than in men. However, the literature about pain prevalence is not unequivocal: some investigators have found no relations between level and completeness of injury and pain while others have found a greater incidence of pain among persons with either tetraplegia or paraplegia [32].

Given that life expectancy for people with SCI has increased considerably, we found it essential to assess the influence of the duration of injury on the occurrence of health problems. We found, just as other investigators [2, 6-8, 29, 31, 32], significant relations between the prevalence of pressure sores and the duration of the injury. In general, the occurrence of these problems did not significantly diminish with increasing time after injury, suggesting that health problems occur and need attention in the long-term too (after 10-15 years).

Our study has some important limitations. Firstly, this study concerned a selected group of persons with SCI who were members of the Dutch Association of SCI Patients. This patient organisation includes relatively few persons with incomplete SCI. However, we only found a few significantly relationships between the occurrence of health problems and the completeness of the injury. Therefore, if we had used a representative sample, the results would probably not have differed much. Secondly, our study suffered from a relatively low response rate $(45.5 \%)$, possibly caused by the use of a long and complicated questionnaire; the timing of the study (holiday period) 
and perhaps some research participation fatigue, because several studies have taken place among this population in the past few years. This low response rate may have triggered mainly responses from persons with serious injuries or who were suffering from health problems. Consequently, the prevalence of health problems could be overestimated in our study.

In a previous study [26], we explored the occurrence of nursing problems in a small sample of persons with SCI discharged from inpatient rehabilitation. The presence of a wide variety of problems implied that there was an important need for follow-up care. The present study further emphasises the need for follow-up care, since health problems and limitations in daily activities and social life due to these problems occur in a substantial proportion of persons with SCI in both the short and the long-term. Follow-up care should focus on the prevention, early identification, treatment and/or management of health problems and their consequences for daily activities and social life. Given our results special attention should be paid to pain, spasms, pressure sores, and problems regarding bladder, bowel and sexuality.

\section{Acknowledgement}

The study was supported by: ZonMw, the Netherlands Organisation for Health Research and Development, Rehabilitation programme, grant no. 01432030. 


\section{References}

[1] Post MWM, Bloemen-Vrencken JHA, de Witte LP. Health problems and care needs of Dutch patients with spinal cord injuries living in the community. In: Poster presented at the 1st joint meting of ASIA and IMSOP; 2002; Vancouver; 2002.

[2] Charlifue SW, Weitzenkamp DA, Whiteneck GG. Longitudinal outcomes in spinal cord injury: aging, secondary conditions, and well-being. Archives of Physical Medicine and Rehabilitation 1999, 80(11): 1429-34.

[3] Dunn M, Love L, Ravesloot C. Subjective health in spinal cord injury after outpatient healthcare follow-up. Spinal Cord 2000, 38(2): 84-91.

[4] Levi R, Hultling C, Seiger A. The Stockholm Spinal Cord Injury Study. 3. Health-related issues of the Swedish annual level-of-living survey in SCI subjects and controls. Paraplegia 1995, 33(12): 726-30.

[5] Noreau L, Proulx P, Gagnon L, Drolet M, Laramee MT. Secondary impairments after spinal cord injury: a population-based study. American Journal of Physical Medicine and Rehabilitation 2000, 79(6): 526-35.

[6] Anson CA, Shepherd C. Incidence of secondary complications in spinal cord injury. International Journal of Rehabilitation Research 1996, 19(1): 55-66.

[7] McKinley WO, Jackson AB, Cardenas DD, DeVivo MJ. Long-term medical complications after traumatic spinal cord injury: a regional model systems analysis. Archives of Physical Medicine and Rehabilitation 1999, 80(11): 140210.

[8] Johnson RL, Gerhart KA, McCray J, Menconi JC, Whiteneck GG. Secondary conditions following spinal cord injury in a population-based sample. Spinal Cord 1998, 36(1): 45-50.

[9] Levi R, Hultling C, Nash MS, Seiger A. The Stockholm spinal cord injury study: 1. Medical problems in a regional SCI population. Paraplegia 1995, 33(6): 308-15.

[10] Meyers AR, Bisbee A, Winter M. The 'Boston model' of managed care and spinal cord injury: a cross-sectional study of the outcomes of risk-based, prepaid, managed care. Archives of Physical Medicine and Rehabilitation 1999, 80(11): 1450-6. 
[11] Post MW, de Witte LP, van Asbeck FW, van Dijk AJ, Schrijvers AJ. Predictors of health status and life satisfaction in spinal cord injury. Archives of Physical Medicine and Rehabilitation 1998, 79(4): 395-401.

[12] Richards JS, Waites K, Chen YY, Kogos S, Schmitt MM. The epidemiology of secondary conditions following spinal cord injury. Topics in Spinal Cord Injury Rehabilitation 2004, 10(1): 15-29.

[13] Walter JS, Sacks J, Othman R, Rankin AZ, Nemchausky B, Chintam R, et al. A database of self-reported secondary medical problems among VA spinal cord injury patients: its role in clinical care and management. Journal of Rehabilitation Research and Development 2002, 39(1): 53-61.

[14] Widerström-Noga EG, Felipe-Cuervo E, Broton JG, Duncan RC, Yezierski RP. Perceived difficulty in dealing with consequences of spinal cord injury. Archives of Physical Medicine and Rehabilitation 1999, 80(5): 580-6.

[15] Harrison C, Kuric J. Community reintegration of SCI persons: problems and perceptions. SCI Nursing 1989, 6(3): 44-7.

[16] Cyr LB. Sequelae of SCI after discharge from the initial rehabilitation program. Rehabilitation Nursing 1989, 14(6): 326-9, 337.

[17] Brown DJ, Judd FK, Ungar GH. Continuing care of the spinal cord injured. Paraplegia 1987, 25(3): 296-300.

[18] Cox RJ, Amsters DI, Pershouse KJ. The need for a multidisciplinary outreach service for people with spinal cord injury living in the community. Clinical Rehabilitation 2001, 15(6): 600-6.

[19] Dryden DM, Saunders LD, Rowe BH, May LA, Yiannakoulias N, Svenson LW, et al. Utilization of health services following spinal cord injury: a 6-year follow-up study. Spinal Cord 2004, 42(9): 513-25.

[20] Fine PR, Better SR, Engstrand JL. The operation of a hospital based specialty home health team: activities and associated costs. The official Journal of the Association of Rehabilitation Nurses 1978, 3(1): 5-11.

[21] Glidden MM. Spinal cord injury and case management. Topics in Spinal Cord Injury Rehabilitation 1999, 4(4): 16-23.

[22] Mattson J. Case management: a historical and future perspective of its influence on outcome for persons who have sustained spinal cord injury. Topics in Spinal Cord Injury Rehabilitation 1999, 4(4): 30-37. 
[23] McColl MA, Charlifue S, Glass C, Lawson N, Savic G. Aging, gender, and spinal cord injury. Archives of Physical Medicine and Rehabilitation 2004, 85(3): 363-7.

[24] Middleton JW, Lim K, Taylor L, Soden R, Rutkowski S. Patterns of morbidity and rehospitalisation following spinal cord injury. Spinal Cord 2004, 42(6): $359-67$.

[25] Rawl SM, Easton KL, Kwiatkowski S, Zemen D, Burczyk B. Effectiveness of a nurse-managed follow-up program for rehabilitation patients after discharge. Rehabilitation Nursing 1998, 23(4): 204-9.

[26] Bloemen-Vrencken JH, de Witte LP. Post-discharge nursing problems of spinal cord injured patients: on which fields can nurses contribute to rehabilitation? Clinical Rehabilitation 2003, 17(8): 890-8.

[27] van Asbeck FW, Post MW, Pangalila RF. An epidemiological description of spinal cord injuries in The Netherlands in 1994. Spinal Cord 2000, 38(7): 4204.

[28] Post MWM, van Asbeck FWA, van Dijk AJ, Schrijvers AJP. Een Nederlandse interview-versie van de Barthel Index onderzocht bij dwarslaesiepatienten (Dutch interview version of the Barthel Index evaluated in patients with spinal cord injuries). Nederlands tijdschrift voor Geneeskunde 1995, 139: 1376-80.

[29] Levi R, Hultling C, Seiger A. The Stockholm Spinal Cord Injury Study: 2. Associations between clinical patient characteristics and post-acute medical problems. Paraplegia 1995, 33(10): 585-94.

[30] Hicken BL, Putzke JD, Richards JS. Bladder management and quality of life after spinal cord injury. American Journal of Physical Medicine and Rehabilitation 2001, 80(12): 916-22.

[31] National Spinal Cord Injury Statistical Center. Annual Statistical Report. Birmingham: University of Alabama, 2004.

[32] Rintala DH, Loubser PG, Castro J, Hart KA, Fuhrer MJ. Chronic pain in a community-based sample of men with spinal cord injury: prevalence, severity, and relationship with impairment, disability, handicap, and subjective wellbeing. Archives of Physical Medicine and Rehabilitation 1998, 79(6): 604-14. 



\section{Health behaviour of persons with spinal cord injury}

Accepted for publication in:

Spinal Cord

Jos Bloemen-Vrencken, Luc de Witte, Marcel Post, and Wim van den Heuvel 


\section{Abstract}

Study design: Postal survey.

Objective: To describe the health behaviour of persons with spinal cord injury (SCI) living in the community and the relationships between health behaviour, respondent/injury characteristics, and health-related variables: the presence and number of secondary impairments, re-admissions in rehabilitation centre and hospital, and perceived health.

Setting: Members of the Dutch Association of SCI Patients.

Method: The frequency of health behaviours, that delay or prevent secondary impairments, was assessed by means of a 22 item, self-report questionnaire. The questionnaire was also focused on 13 secondary impairments.

Results: The frequency of engaging in health behaviour varied considerably between the respondents. Variance was observed between and within the health behaviours measured. The respondents did not frequently engage in pressure relief methods when sitting/driving in their wheelchair. Almost no statistical differences were observed between the health behaviour of subgroups of respondents based on respondent/injury characteristics. However, the total health behaviour scores increased significantly with increasing age and pressure sore prevention was significantly more applied in persons with a complete lesion. Health behaviour was significantly more applied in respondents who had one or more secondary impairments.

Conclusion: Since secondary impairments are prevalent among persons with SCI and education on a healthy lifestyle is a core component of every rehabilitation programme, it is of great importance to rigorously test the efficacy of health behaviours promoted during rehabilitation. Therefore, longitudinal research is recommended.

Keywords: Health behaviour, secondary impairments, SCI, and rehabilitation. 


\section{Introduction}

A spinal cord injury (SCI) very often results in an everlasting complete or incomplete muscle paralysis, sensory loss, and autonomous dysfunction below the level of the injury. During rehabilitation, patients receive education and training to give them sufficient skills and knowledge about the injury to deal with its consequences in daily life. Among other topics, much attention is paid to a healthy lifestyle and the prevention of secondary impairments [1]. However, persons with SCI nevertheless often experience secondary impairments after discharge from rehabilitation [2-9]. In response to this observation, several Dutch rehabilitation centres have developed follow-up care interventions [10]. Education and training about health maintenance and prevention also is an important component of these interventions. In order to be able to evaluate the effectiveness of this education and training, it is important that the health behaviour of persons with SCI be assessed.

This study is aimed at describing the health behaviour of persons with SCI living in the community and the relationships between health behaviour and respondent/injury characteristics. The results should give insight into the health behaviour and differences in health behaviour that may exist in different groups of persons with SCI living in the community, and may help to distinguish for whom training and education regarding a healthy lifestyle is very important. The second aim was to describe the relationships between health behaviour and health-related variables: the presence and number of secondary impairments, re-admissions in rehabilitation centre and hospital, and perceived health. Assuming that at least part of secondary impairments can be prevented, it might be expected that there is a negative relationship between 'good' health behaviour and the presence of secondary impairments. The better the health behaviour of persons with SCI, the fewer secondary problems they might experience. On the other hand, a positive relationship between good health behaviour and good perceived health was expected.

\section{Methods}

\section{Data collection}

A questionnaire was sent to all members of the Dutch Association of SCI Patients. The questionnaire focused on health behaviour, secondary impairments, perceived health and self-care ability.

Persons who were unable to write were invited to make use of a digital/computerised version of the questionnaire, which could be obtained on request. A reminder was sent four weeks after the questionnaire was mailed. 


\section{Health behaviour}

The Spinal Cord Injury Lifestyle Scale (SCILS) of Pruitt and colleagues [11] was used as a basis for our health behaviour scale. The SCILS is a 25 item, self-report questionnaire designed to assess the frequency of behaviours specific to SCI health maintenance and behaviours that promote general health for the avoidance of secondary impairments. The SCILS was adapted, since some items were formulated rather generally (i.e. 'I am aware of and try to reduce my risk for heart disease'), and some items were not applicable for all persons with SCI (i.e. 'I change my catheters as often as I have been directed to'). Also some adaptations were needed to suit the scale to Dutch SCI rehabilitation practice.

A panel of clinicians (physiatrists, occupational therapists, physiotherapists, social workers, psychologists, and nurses), researchers, and experienced patients adapted the SCILS. Changes were made especially with regard to genitourinary health behaviour aspects. Initially, a list of 31 descriptions of health behaviours resulted, containing 10 items that also were included in the SCILS and 21 new items. For all items the respondents were asked to state the frequency of occurrence (never, sometimes, often, always).

Using the data from our current study, the possibilities for item elimination and clustering of items into subscales were examined using a combination of content, reliability and factor analysis (Principal Component Analysis with Varimax rotation). Forty-four out of 454 respondents had $10 \%$ or more missing values and were not taken into account in the analyses. Firstly, five items were eliminated because of lack of discriminative ability since $85 \%$ or more of the respondents gave exactly the same answer to these items (topics were: frequency of having stool, finishing a cure of antibiotics, prevention of skin burns, having medicines and 'caring supplies' in stock, and the use of soft drugs). The factor analysis did not reveal distinctive and reliable subscales, although there were eight items regarding the prevention of pressure sores with a reliability coefficient of 0.80 (see item 1-8 in table 2). Reliability analysis led to a health behaviour scale consisting of 22 items (see table 2 ) and elimination of four items on the basis of low $(\leq 0.20)$ corrected item-total correlations (topics were: standing and walking exercises, bladder emptying, abstinence from smoking and use of alcohol). Cronbach's alpha for the 22 items was 0.80 , implying that the items were interrelated and measure the same underlying construct i.e. preventive health behaviour.

The scores of each item were summarised using 0 for 'never', 1 for 'sometimes', 2 for 'often', and 3 for 'always'. A total health behaviour score was calculated by summing up the scores of each item. The total score range is from 0 (never performing any health behaviour) up to 66 (always performing all health behaviours).

\section{Secondary impairments}

The questionnaire included questions about 13 secondary impairments: bladder problems, bowel problems, spasms, pain, oedema, pressure sores, increasing weight, 
excessive sweating, contractures, breathing/respiratory tract problems, neurogenic heterotopic ossification, low blood pressure, and thrombosis. For each secondary impairment, the respondents were asked to indicate whether or not they had faced this problem during the previous 12 months [12]. A sum score was computed indicating the number of secondary impairments $(0-13)$.

\section{Perceived health}

Perceived health was measured using the General Health scale of the SF-36 [13]. This scale consists of five questions about overall health, the person's own health compared to others, and one's vulnerability to becoming ill. The total score of this scale is between 0 (very poor health) and 100 (perfect health).

\section{Self-care ability}

Self-care ability was measured using the Dutch questionnaire version of the Barthel Index (BI), the reliability and validity of which have been shown to be good [14]. The BI rates the degree of independence from help by others in performing activities of daily living. It consists of 10 items concerning activities of daily living (bathing, dressing, feeding, toilet use, grooming, bladder and bowels) and mobility: transfers, climbing stairs and walking/wheelchair driving. The total score of the BI is between 0 and 20 and is interpreted as: 0-4 'very disabled'; 5-9 'severely disabled'; 10-14 'moderately disabled'; 15-19 'mildly disabled' and 20 'independent' [14]. In our sample the reliability of the BI was high (Cronbach's alpha 0.85).

\section{Statistical analysis}

\section{Description of health behaviour}

To describe the health behaviour of the respondents, descriptive analyses were used. Total health behaviour scores were calculated for the following subgroups:

- Male versus female;

- Tetraplegia (C1-T1) versus paraplegia (T2-S5). The self-reported highest motor level was taken as the level of injury;

- Complete versus incomplete injury. Some respondents reported a complete injury together with a partial injury at a higher level, in the analysis they were treated as having a complete injury;

- Duration of injury was trichotomised, 0 till 5 years (about 25\% of the respondents), 5 till 19 years (about 50\%), and over 19 years (about 25\%);

- Age of injury was trichotomised, 18 till 35 years (about 25\% of the respondents), 35 till 55 years (about 50\%), and over 55 years (about 25\%). 
To describe the health behaviour in relation with health-related variables, the respondents were grouped as follows:

- The number of secondary impairments was trichotomised. Grouping was: 0 till 4 impairments (about 25\% of the respondents), 4 till 6 impairments (about $50 \%$ ), and over 6 impairments (about 25\%);

- The presence of bladder problems, bowel problems, pain, spasms, and/or pressure sores during the past 12 months. These problems had been identified as being the most important secondary impairments in persons with SCI [12];

- Experienced general health was trichotomised. Grouping was: 0 till 45 (about $25 \%$ of the respondents), 45-75 (about 50\%), and over 75 (about 25\%);

- Being re-admitted in a rehabilitation centre since primary rehabilitation or not;

- Being re-admitted in a hospital since primary rehabilitation or not.

\section{Associations}

The health behaviour score was treated as a variable of ordinal level. To detect associations between health behaviour, respondent/injury characteristics and healthrelated variables, Mann-Whitney U tests and Spearman correlations (age, duration of SCI, number of secondary impairments, perceived health) were calculated. The level of statistical significance was set at $\mathrm{p}<0.05$.

\section{Results}

\section{Respondents}

The questionnaire was sent to 997 members of the patient association, of whom 454 responded (45.5\%). There were 410 respondents, who had less than $10 \%$ missing values in the 31 health behaviour items. Table 1 shows their general characteristics. Time after injury varied between half a year and 62.6 years, and age varied between 18 and 82 years. Only eight respondents used the digital/computerised version of the questionnaire. The response group could not be compared with the non-response group regarding the characteristics mentioned in table 1 , since these data were not available. 
$\underline{\text { Table } 1 \text { Subject characteristics }(\mathrm{N}=410)}$

\begin{tabular}{lrl}
\hline Age, mean [yrs] (SD) & $46.9(13.2)$ \\
Time since injury, mean [yrs] (SD) & $13.6(10.7)$ \\
Married or cohabitating [\%] & 64.9 \\
Living on one's own [\%] & 25.6 \\
Gender, male [\%] & 66.1 \\
Level and type of injury [\%] & \\
Complete tetraplegia & 21.0 \\
Incomplete tetraplegia & 13.1 \\
Complete paraplegia & 47.9 \\
Incomplete paraplegia & 17.9 \\
Cause of injury [\%] & 34.0 \\
Traffic accident & 19.7 \\
Sports, recreation & 9.6 \\
Fall & 8.4 \\
Accident at working place & 0.2 \\
Gunshot or stab wounds & 8.4 \\
Medical interventions & 9.4 \\
Disease & 10.3 \\
Other & \\
Barthel Index, mean (SD) & $12.1(4.6)$ \\
Total group & $8.3(4.4)$ \\
Complete tetraplegia & $9.4(5.1)$ \\
Incomplete tetraplegia & $13.6(3.2)$ \\
Complete paraplegia & \\
Incomplete paraplegia & \\
&
\end{tabular}

\section{Health behaviour and relationships with respondent/injury characteristics}

Table 2 presents the scores on all 22 items. There were four health behaviours that were often or always applied by more than $85 \%$ of all respondents. These were 'skin care in case of incontinence' (item 8), 'examination of the cause of pressure sores' (item 4), and 'taking the (right amount of) prescribed medicines' (item 18 and 19). The least applied health behaviours were 'monitoring blood pressure' (item 17), 'limiting fat and cholesterol intake' (item 16), and 'pressure relief methods like weight shifts' (item 3). More than $80 \%$ of the respondents did not check their blood pressure on a regular basis and more than half of the respondents almost never engaged in the health behaviours item 3 and 16. The percentage of respondents that 'often' or 'always' engaged in the remaining health behaviours varied from 61.4 to 79.7. In sum, the scores within and between the items varied considerably. 
Table 2 Health behaviour scale and health behaviour scores per item $(n=410)$. Range per item 0-3 (neveralways).

\begin{tabular}{|c|c|c|c|c|c|}
\hline Item & & $\begin{array}{r}\text { Never } \\
(\%) \\
\end{array}$ & $\begin{array}{r}\text { Some- } \\
\text { times } \\
(\%) \\
\end{array}$ & $\begin{array}{r}\text { Often } \\
(\%) \\
\end{array}$ & $\begin{array}{r}\text { Always } \\
(\%) \\
\end{array}$ \\
\hline 1 & $\begin{array}{l}\text { I take care not to develop skin breakdown or areas of } \\
\text { redness, when I am sleeping. }\end{array}$ & 11.3 & 16.2 & 13.5 & 59.0 \\
\hline 2 & $\begin{array}{l}\text { I check my skin daily on areas of redness or breakdown or I } \\
\text { have checked my skin daily. }\end{array}$ & 10.0 & 28.6 & 21.3 & 40.1 \\
\hline 3 & $\begin{array}{l}\text { I do some type of pressure relief every } 30 \text { minutes any time I } \\
\text { am sitting or driving in my wheelchair (by changing my } \\
\text { position or lifting myself). }\end{array}$ & 22.9 & 29.7 & 26.5 & 20.9 \\
\hline 4 & $\begin{array}{l}\text { If I have a skin breakdown, I would try to find out how it } \\
\text { occurred. }\end{array}$ & 4.4 & 8.9 & 12.3 & 74.3 \\
\hline 5 & $\begin{array}{l}\text { I am careful not to bump my legs, feet, or buttocks when } \\
\text { doing transfers. }\end{array}$ & 7.8 & 12.5 & 22.3 & 57.4 \\
\hline 6 & $\begin{array}{l}\text { I am aware of the condition of my anti-pressure sores } \\
\text { devices. }\end{array}$ & 11.7 & 16.3 & 25.3 & 46.7 \\
\hline 7 & $\begin{array}{l}\text { If I have a skin breakdown/pressure sore, I would be careful } \\
\text { not to put weight on it (I would not sit or lie on it). }\end{array}$ & 9.6 & 18.0 & 20.6 & 51.8 \\
\hline 8 & $\begin{array}{l}\text { In case of incontinence, I would take care to have my skin } \\
\text { dried as soon as possible. }\end{array}$ & 3.2 & 5.7 & 17.6 & 73.4 \\
\hline 9 & $\begin{array}{l}\text { I am careful to keep my joints flexible (I regularly do range of } \\
\text { motion exercises or have these exercises done). }\end{array}$ & 12.2 & 18.6 & 25.2 & 44.0 \\
\hline 10 & $\begin{array}{l}\text { I do exercises that enhance my muscle strength (possibly with } \\
\text { help of my physiotherapist). }\end{array}$ & 12.7 & 18.5 & 26.8 & 42.0 \\
\hline 11 & If my urine looks turbid or smells, I would have it examined. & 11.1 & 24.8 & 17.2 & 46.9 \\
\hline 12 & I drink at least 2 litres a day. & 5.1 & 21.0 & 27.6 & 46.3 \\
\hline 13 & $\begin{array}{l}\text { In case I have symptoms of autonomic dysreflexia (sweating, } \\
\text { headache, red complexion, and high blood pressure), I would } \\
\text { examine why I have these symptoms (e.g. full bladder, full } \\
\text { bowel or clothes that are too tight). }\end{array}$ & 17.1 & 13.4 & 18.4 & 51.1 \\
\hline 14 & $\begin{array}{l}\text { In case of 'hard' stool, I take care to drink more, to eat more } \\
\text { fibres or take more laxantia. }\end{array}$ & 12.5 & 13.8 & 16.5 & 57.2 \\
\hline 15 & I take care that my weight doesn't increase. & 9.3 & 23.2 & 32.4 & 35.1 \\
\hline 16 & $\begin{array}{l}\text { I limit the amount of fat and cholesterol in my diet (for } \\
\text { example, I limit red meats, dairy products). }\end{array}$ & 29.3 & 25.1 & 29.8 & 15.9 \\
\hline 17 & $\begin{array}{l}\text { I monitor my blood pressure on a regular basis or I have it } \\
\text { monitored regularly. }\end{array}$ & 51.0 & 32.0 & 11.7 & 5.4 \\
\hline 18 & I always take the medicines that are prescribed. & 1.5 & 4.4 & 15.6 & 78.5 \\
\hline 19 & I always take that amount of medicines that is prescribed. & 1.7 & 4.0 & 16.9 & 77.4 \\
\hline 20 & $\begin{array}{l}\text { In case I have physical complaints I would consult a doctor } \\
\text { (e.g. in case of skin breakdown, bladder infection, } \\
\text { pneumonia, a changing level of spasms, increasing symptoms } \\
\text { of autonomic dysreflexia, or an increasing level of pain). }\end{array}$ & 1.5 & 23.4 & 28.3 & 46.8 \\
\hline 21 & $\begin{array}{l}\text { I will always make clear my wishes regarding the way I would } \\
\text { like to receive care. }\end{array}$ & 2.2 & 11.1 & 23.0 & 63.7 \\
\hline 22 & $\begin{array}{l}\text { When I leave my home, I always take my medicines and/ or } \\
\text { 'caring supplies' with me. }\end{array}$ & 6.1 & 10.8 & 13.5 & 69.5 \\
\hline
\end{tabular}


Table 3 presents the median total scores for the whole group of respondents and for subgroups based on respondent/injury characteristics. Few differences were observed between health behaviour of subgroups of respondents. However, the total health behaviour scores increased significantly with increasing age (Spearman correlation 0.24). Pressure sore prevention (item 1-8) was significantly $(\mathrm{p}<0.01)$ more implemented by persons with a complete lesion (median sumscore item 1-8: complete lesions 19.0, incomplete lesions 16.0).

Table 3 Health behaviour in relation with respondent/injury characteristics $(n=410)$

\begin{tabular}{lc}
\hline & Median total score \\
\hline Median total score & 46.0 \\
Interquartile range & 12.3 \\
Range & $18-66$ \\
Gender & 47.0 \\
Man & 45.0 \\
Woman & \\
Level of injury & 48.0 \\
Tetraplegia & 46.0 \\
Paraplegia & \\
Type of injury & 47.0 \\
Complete injury & 44.0 \\
Incomplete injury & \\
Duration of SCI & 47.0 \\
$\leq 5$ years & 46.0 \\
$5-19$ years & 46.0 \\
$>19$ years & \\
Age & $43.0 * *$ \\
$\leq 35$ years & $47.0 * *$ \\
$35-55$ years & $48.0 * *$ \\
$>55$ years &
\end{tabular}

\section{Health behaviour and relationships with health-related variables}

Table 4 presents the prevalence of secondary impairments investigated. On average the respondents experienced 4.6 secondary impairments. The most frequently occurring secondary impairments were: bladder and bowel problems, spasm, pain, and oedema. Only six respondents $(1.5 \%)$ experienced no secondary impairments at all. 
Table 4 Experienced secondary impairments during the previous year $(N=410)$

\begin{tabular}{lrr}
\hline & $\mathbf{N}$ & $\mathbf{\%}$ \\
\hline Bladder problems (incontinence, urinary tract infections, e.g.) & 297 & 72.4 \\
Bowel problems (incontinence, diarrhoea, constipation, e.g.) & 254 & 62.0 \\
Spasms & 234 & 57.1 \\
Pain & 224 & 54.6 \\
Oedema (accumulation of liquid in the legs) & 204 & 49.8 \\
Having pressure sores or preventing problems & 154 & 37.6 \\
Increasing weight & 125 & 30.5 \\
Excessively sweating & 113 & 27.6 \\
Contractures (decreased joint mobility due to reduction of muscle length) & 93 & 22.7 \\
Breathing / respiratory tract problems (shortness of breath, infection of respiratory & 78 & 19.0 \\
tract, e.g.) & & \\
Calcification or the growth of bone around joints below the level of the injury & 53 & 12.9 \\
(neurogenic heterotopic ossification) & 46 & 11.2 \\
Low blood pressure & 14 & 3.4 \\
Thrombosis (blood clots in blood vessel) & & \\
\hline
\end{tabular}

Table 5 presents the health behaviour scores in relation with health-related variables. Most times, the total health behaviour scores were slightly higher for respondents in poorer health. A significant but weak correlation (0.17) existed between the number of secondary impairments and the total health behaviour score. The more secondary impairments respondents had, the better their health behaviour scores were. Significant relationships also existed between the presence of pressure sores and the total health behaviour score and the sumscore of the pressure sore prevention health behaviours (median sumscore item 1-8: no pressure sores 17.0, pressure sores 19.0, $\mathrm{p}<0.01)$. Health behaviour was significantly more frequently implemented by respondents who had been readmitted in a hospital since their primary rehabilitation. There was no significant relationship between health behaviour and perceived health.

\section{Discussion}

This study shows that the frequency of applying health behaviour by persons with SCI living in the community varies considerably between individuals. Variance was observed between and within the health behaviours measured. In our opinion, it is notable that the respondents did not frequently apply pressure relief methods when sitting/driving in their wheelchair (item 3). The importance of this health behaviour is emphasised during clinical rehabilitation. Pressure sore prevention was significantly more applied in persons with a complete lesion. Probably this is explained by the fact that persons with complete lesions have a higher risk to develop pressure sores [4-6, $15,16]$. It is also notable that the total health behaviour score tends to increase significantly with increasing age, while Pruitt et al. [11] found no relationship between the total SCILS score and age. 
Table 5 Health behaviour in relation with health-related variables $(n=410)$

\begin{tabular}{|c|c|}
\hline & Median total score \\
\hline Median total score & 46.0 \\
\hline Interquartile range & 12.3 \\
\hline Range & $18-66$ \\
\hline \multicolumn{2}{|l|}{ Number of secondary impairments in previous 12 months } \\
\hline$<4$ & $44.0^{* *}$ \\
\hline $4-6$ & $46.0^{* *}$ \\
\hline$>6$ & $48.0^{* *}$ \\
\hline \multicolumn{2}{|l|}{ Secondary impairments in previous 12 months } \\
\hline No pressure sores & $45.0^{* *}$ \\
\hline Pressure sores & $48.0^{*}$ \\
\hline No bladder problems & 47.0 \\
\hline Bladder problems & 46.0 \\
\hline No bowel problems & 45.0 \\
\hline Bowel problems & 47.0 \\
\hline No pain & 46.0 \\
\hline Pain & 47.0 \\
\hline No spasm & 47.0 \\
\hline Spasm & 46.0 \\
\hline \multicolumn{2}{|l|}{ Re-admissions } \\
\hline Not readmitted in rehab centre since primary rehabilitation & 46.0 \\
\hline Readmitted in rehab centre since primary rehabilitation & 47.0 \\
\hline Not readmitted in hospital since primary rehabilitation & $44.0^{*}$ \\
\hline Readmitted in hospital since primary rehabilitation & $47.0^{*}$ \\
\hline \multicolumn{2}{|l|}{ General health SF-36 range 0-100 } \\
\hline$\leq 45$ & 48.0 \\
\hline $45-75$ & 45.0 \\
\hline$>75$ & 45.0 \\
\hline
\end{tabular}

Most striking are our results regarding the relationships between health behaviour scores and health-related variables. A negative relationship was expected between health behaviour and the presence of secondary impairments. The better the health behaviour of persons with SCI, the fewer secondary problems were expected. The present study shows the opposite: health behaviour scores were higher for respondents who had one or more secondary impairments. This may indicate that persons with secondary impairments modified their health behaviour to prevent these secondary impairments in future. Another explanation may be that the health behaviours as measured do not have much impact on the occurrence of secondary impairments. Some of the secondary impairments in our list are more likely to be influenced by health behaviour, for example increasing weight or pressure sores, than others, for example neurogenic heterotopic ossification or pain. It might also be that 
certain health behaviours are only relevant for persons 'at risk', for example pressure relief might only be relevant for persons with complete injuries. Pruitt [11] also did not observe a positive relationship between health behaviour and the number of secondary impairments, while other researchers [17-20] demonstrated that there were no significant relationships between the occurrence of pressure sores and the traditional protective behaviours for pressure ulcers, such as weight shifts or skin checks.

The possible explanations for our observation that health behaviour was more frequently applied by persons with more secondary impairments are in sharp contrast with each other and lead to contrasting implications for rehabilitation practice. In case health behaviour has a positive effect on the prevention of secondary impairments, but persons with SCI only tend to engage in it after the occurrence of secondary impairments, the attention for education and training on health behaviour should be intensified. Rehabilitation professionals then need to focus on developing effective methods of persuading persons with SCI to take more responsibility for their health behaviour and to deliver information and education at a time when persons with SCI feel ready for it and recognise the relevance [21]. Currently, education is institutionally based and acute rehabilitation oriented. Rehabilitation professionals also might need to expand their education regarding health behaviour in the long-term to persons who are living in the community. In case that protective health behaviour is only relevant in persons 'at risk', there seems to be no need to teach everything to everyone but is it important to identify groups that are at risk for certain secondary conditions and to teach them the skills necessary to prevent these conditions. Also, the effect of education and resulting health behaviours should in that case only be tested in such specific risk-groups. In case health behaviour as measured does not have any impact at all on the occurrence of secondary conditions, it is not necessary to spend so much effort to the education on health behaviour during rehabilitation, implying immense consequences for the content of most rehabilitation programmes.

Due to the cross-sectional study design it is not possible to say whether or not persons with SCI only started the health behaviour measured after the occurrence of problems. Since education on a healthy lifestyle is a core component of literally every rehabilitation programme and secondary impairments are prevalent, it is of great importance to rigorously test the efficacy of health behaviours promoted during rehabilitation. Therefore, longitudinal research is recommended to study what persons with SCI know about health behaviour; when, why and what health behaviours they practice; and the impact of health behaviour on the prevalence of secondary impairments.

\section{Acknowledgement}

The study was supported by: ZonMw, the Netherlands Organisation for Health Research and Development, Rehabilitation programme, grant no. 01432030. 


\section{References}

[1] Wyatt DA, White GW. Reducing secondary conditions for spinal cord injured patients: pilot testing a risk assessment and feedback instrument. Topics in Spinal Cord Injury Rehabilitation 2000; 6(1): 9-22.

[2] Anson CA, Shepherd C. Incidence of secondary complications in spinal cord injury. International Journal of Rehabilitation Research 1996; 19(1): 55-66.

[3] Johnson RL, Gerhart KA, McCray J, Menconi JC, Whiteneck GG. Secondary conditions following spinal cord injury in a population-based sample. Spinal Cord 1998; 36(1): 45-50.

[4] Levi R, Hultling C, Nash MS, Seiger A. The Stockholm spinal cord injury study: 1. Medical problems in a regional SCI population. Paraplegia 1995; 33(6): 308-15.

[5] McKinley WO, Jackson AB, Cardenas DD, DeVivo MJ. Long-term medical complications after traumatic spinal cord injury: a regional model systems analysis. Archives of Physical Medicine and Rehabilitation 1999; 80(11): 140210.

[6] Noreau L, Proulx P, Gagnon L, Drolet M, Laramee MT. Secondary impairments after spinal cord injury: a population-based study. American Journal of Physical Medicine and Rehabilitation 2000; 79(6): 526-35.

[7] Richards JS, Waites K, Chen YY, Kogos S, Schmitt MM. The epidemiology of secondary conditions following spinal cord injury. Topics in Spinal Cord Injury Rehabilitation 2004; 10(1): 15-29.

[8] Walter JS, Sacks J, Othman R, Rankin AZ, Nemchausky B, Chintam R, et al. A database of self-reported secondary medical problems among VA spinal cord injury patients: its role in clinical care and management. Journal of Rehabilitation Research and Development 2002; 39(1): 53-61.

[9] Widerström-Noga EG, Felipe-Cuervo E, Broton JG, Duncan RC, Yezierski RP. Perceived difficulty in dealing with consequences of spinal cord injury. Archives of Physical Medicine and Rehabilitation 1999; 80(5): 580-6. 
[10] Bloemen-Vrencken JH, de Witte LP, Post MW, Pons C, van Asbeck FW, van der Woude LH, et al. Effects of a Dutch follow-up care model for spinal cord injured patients on health problems, re-admissions, and quality of care. Submitted for publication 2005.

[11] Pruitt SD, Wahlgren DR, Epping-Jordan JE, Rossi AL. Health behavior in persons with spinal cord injury: development and initial validation of an outcome measure. Spinal Cord 1998; 36(10): 724-31.

[12] Bloemen-Vrencken JHA, Post MW, Hendriks JM, De Reus EC, De Witte LP. Health problems of persons with spinal cord injury living in the Netherlands. Disability and Rehabilitation 2005; 27(22): 1381-9.

[13] Ware JE, Jr., Sherbourne CD. The MOS 36-item short-form health survey (SF-36). I. Conceptual framework and item selection. Medical Care 1992; 30(6): 473-83.

[14] Post MWM, van Asbeck FWA, van Dijk AJ, Schrijvers AJP. Dutch interviewversion of the Barthel Index validated for persons with Spinal Cord Injury [in Dutch]. Nederlands Tijdschrift voor Geneeskunde 1995; 139: 1376-80.

[15] Byrne DW, Salzberg CA. Major risk factors for pressure ulcers in the spinal cord disabled: a literature review. Spinal Cord 1996; 34(5): 255-63.

[16] National Spinal Cord Injury Statistical Center. Annual Statistical Report. Birmingham: University of Alabama; 2004.

[17] Garber SL, Rintala DH, Don Rossi C, Hart KA, Fuhrer MJ. Reported pressure ulcer prevention and management techniques by persons with spinal cord injury. Archives of Physical Medicine and Rehabilitation 1996; 77(8): 744-749.

[18] Krause JS, Vines CL, Farley TL, Sniezek J, Coker J. An exploratory study of pressure ulcers after spinal cord injury: relationship to protective behaviors and risk factors. Archives of Physical Medicine and Rehabilitation 2001; 82(1): 10713.

[19] Krause JS, Broderick L. Patterns of recurrent pressure ulcers after spinal cord injury: identification of risk and protective factors 5 or more years after onset. Archives of Physical Medicine and Rehabilitation 2004; 85(8): 1257-64.

[20] Raghavan P, Raza WA, Ahmed YS, Chamberlain MA. Prevalence of pressure sores in a community sample of spinal injury patients. Clinical Rehabilitation 2003; 17(8): 879-84. 
[21] Potter PJ, Wolfe DL, Burkell JA, Hayes KC. Challenges in educating individuals with SCI to reduce secondary conditions. Topics in Spinal Cord Injury Rehabilitation 2004; 10(1): 30-40. 

5

\section{Follow-up care for persons with spinal cord injury living in the community: a systematic review of interventions and their evaluation}

Published in:

Spinal Cord 2005; 43: 462-475

Jos Bloemen-Vrencken, Luc de Witte, and Marcel Post 


\section{Abstract}

Study design: Systematic review.

Objectives: (1) To describe and compare follow-up care programmes, performed by rehabilitation centres, for persons with spinal cord injury (SCI) and (2) to describe the effects of these programmes regarding the occurrence of secondary impairments, wellbeing, the quality and costs of care.

Methods: A systematic literature search was conducted in MEDLINE (1972-2003) and CINAHL (1982-2003). Publications were selected about medical and/or nursing follow-up care to SCI patients living in the community performed by or with rehabilitation facilities for SCI patients. The aim of the follow-up care should be a decrease of secondary impairments, an improvement of well-being, an improvement of the quality and/or a decrease of the costs of care.

Results: The search resulted in 24 papers. The descriptions of the programmes in these papers were sometimes rather scattered, vague or brief. The most important methods were telemedicine (six programmes; of which five were performed in the same rehabilitation centre), outpatient consulting hours (six programmes), home visits (three programmes), and case management (one programme). Eight other programmes combined several methods (i.e. outpatient consulting hours, home visits, peer teaching and support, outings, ongoing support, therapy from several care disciplines, SCI education, providing SCI expertise and support to community health care providers, coordination of care with community nursing agencies). In all, 16 programmes have been evaluated to some degree. In general the quality of the studies was low. Most evaluations were pre-experimental in design. Only three were quasiexperimental, and two programmes were experimental in design. Although several studies claimed positive effects, it was not possible to draw conclusions on the effect of follow-up care on the occurrence of secondary impairments, well-being, the quality and costs of care.

Conclusion: There is a need for the development, the publication and the welldesigned evaluation of follow-up care programmes for persons with SCI.

Keywords: Follow-up care, long-term care, spinal cord injuries. 


\section{Introduction}

Since persons with spinal cord injury (SCI) are confronted with all kinds of short- and long-term problems in functioning after discharge from initial rehabilitation, the need for continuing care for persons with SCI living in the community has been emphasised in several reports [1-8].

Until recently follow-up care provided by the Dutch rehabilitation centres has consisted of periodical outpatient visits to a physiatrist. During these visits a comprehensive assessment of total functioning is performed and, if necessary, interventions or other support is given. After discharge from clinical rehabilitation, daily medical and nursing care for persons with SCI is usually given by primary care professionals. As a result of the low prevalence of persons with SCI, primary health care professionals only sporadically have persons with SCI in their practice. Consequently, they do not often have much opportunity to gain sufficient knowledge and experience about the specific care these patients need. As a result of this and the high prevalence of health problems, rehabilitation teams want to extend their role in follow-up care to persons with SCI living in the community.

In order to be able to learn from other initiatives regarding follow-up care, this systematic review was initiated. At present there is no systematic overview of the content of follow-up care programmes and the effects on the prevalence of health problems.

The purpose of this paper is to provide an overview of published follow-up care programmes provided by rehabilitation centres to persons with SCI after their inpatient and outpatient rehabilitation. This study is focused on medical and nursing follow-up care, since most problems SCI patients experience are within the scope of the medical and nursing profession. The second objective is to describe the effects of these published follow-up care programmes on the occurrence of secondary impairments, well-being, the quality and costs of care. 


\section{Method}

\section{Search strategy}

Publications were selected from the MEDLINE (1972-2003) and CINAHL (19822003) databases. In all search strategies we combined several terms for spinal cord injuries (i.e. tetraplegia, paraplegia, spinal cord injuries) with a broad range of keywords related to follow-up care (i.e. follow-up care, long-term care, aftercare, continuity-of-patient care, patient-discharge, outpatient care, ambulatory-carefacilities, primary-health care, home care, home rehabilitation, community care, disease management, shared care). The search strategy is described in figure 1. The definition of a keyword given in the thesaurus list of the databases was used to determine whether a keyword was appropriate to use in the search strategy. Only publications written in Dutch, English or German were taken into consideration.

Figure 1: Search strategy

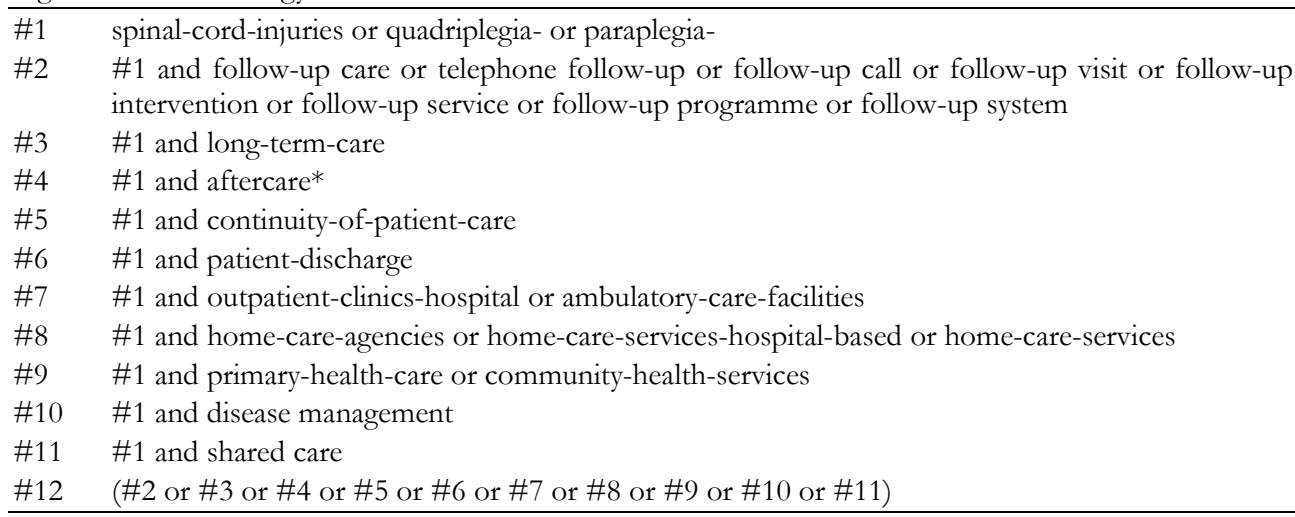

\section{Selection procedure}

A publication was selected if it described medical and/or nursing follow-up care to persons with SCI living in the community after their inpatient- and outpatient rehabilitation. The aim of the follow-up care should be a decrease of secondary impairments, an improvement of well-being, an improvement of the quality and/or a decrease of the costs of care. Furthermore it should describe follow-up care performed by or in cooperation with rehabilitation facilities for SCI patients.

The first phase of the selection was performed by three investigators (LW, MP and JB) by reading the titles and, if available, the abstracts of all the initially identified publications. All publications selected by at least two of the three investigators were obtained and studied by the first investigator (JB) in order to determine whether the 
inclusion criteria mentioned indeed were applicable. In case of doubt on selection of a publication, the other investigators were consulted.

\section{Assessment of selected follow-up care interventions}

The follow-up care programmes were systematically described with respect to the aims, target population, method, responsible care disciplines, and content of the follow-up care. If there was a control/comparison group, the content of the treatment the persons in this group received was also described.

Follow-up care programmes that had been evaluated were described with respect to design, number of patients, outcome measures, and results. The studies were categorised as experimental, quasi-experimental or pre-experimental, according to the classification as described by Polit and Hungler [9]. In this classification an experiment is defined as a study in which the investigator controls (manipulates) the independent variable and randomly assigns subjects to different conditions. Quasi-experiments involve manipulation but lack a comparison group or randomisation. In quasiexperiments efforts are made to introduce controls to compensate in part for the absence of one or both of these important characteristics. Pre-experiments do not include controls to compensate for the absence of either randomisation or a control group.

\section{Results}

\section{Results of the search strategy}

The search for publications resulted in almost 800 titles of which 99 were selected by at least two of the three researchers as being possibly relevant. The types of these 99 publications varied. Only a minority had a scientific format, including an abstract, introduction, methods, results, discussion, and conclusion section. Also some letters to an editor, a job description, and a research abstract were included. Sometimes it was hard to decide whether or not to include a publication, because, for example, the information about the follow-up care was too brief. Finally, 24 of the 99 initially selected publications were included in this review.

The reasons for not including the remaining 75 publications varied. Seventeen publications focused on the care during rehabilitation and discharge-preparation, 10 publications focused on the importance of follow-up care, but did not describe a programme, eight publications described or evaluated care provided by primary care professionals only, two described inpatient care programmes for patients readmitted due to pressure sores, two publications reported health problems after discharge, and the remaining 35 publications were excluded for all kinds of reasons (e.g. publications focusing on the importance of good education materials, a well organised continuum 
of care, health problems after discharge, case descriptions not dealing with follow-up care provided by the rehabilitation centre).

\section{Intervention characteristics}

Table 1 displays the aims, methods used, care disciplines responsible, and content of the follow-up care programmes identified.

\section{Principle methods of the follow-up care programmes}

Five methods of follow-up care could be identified from the descriptions in the selected articles:

- telemedicine, the use of telecommunications technology that either delivers or supports the delivery of health services and education via long distance [10-15]. Five of these six projects were performed by the same rehabilitation centre, i.e. Shepherd Centre, Atlanta, USA. Since both the content and to some extent the aims were different for each follow-up care programme, all these projects were included in this review.

- outpatient consulting hours providing physicals, reviews of daily functioning and support in case of health problems [16-21];

- home visits [22-24];

- case management, involving the coordination of care within, between, and beyond the acute and rehabilitation programmes, extending care and coordination to the community and managing the reemerging needs of the population over time [25];

- miscellaneous types of follow-up care consisting of several of the following methods: outpatient consulting hours, home visits, peer teaching and support, outings, ongoing support, therapy from several care disciplines, SCI education, providing SCI expertise and support to community health care providers, coordination of care with community nursing agencies [26-33].

\section{Aims of follow-up care programmes}

Prevention and/or treatment of secondary impairments was the most frequently mentioned aim of the follow-up care programmes. Two thirds of the follow-up care programmes included this in their aims [10-14, 16-18, 22, 24-30]. Six follow-up care programmes solely aimed at the prevention and/or treatment of a specified secondary impairment: pressure sores [10-13, 17], and urinary tract infections [16]. Beside this, several of these programmes also had a broader aim like the promotion of well-being and community reintegration [12, 18, 22, 25, 26, 28-30].

In several publications $[13,18-22,28,29,32]$ the aim of the follow-up care was not stated explicitly, although in most cases an aim could be derived from the text. 


\section{Target population of follow-up care programmes}

The target population in all follow-up care programmes was persons with SCI recently discharged from rehabilitation and living in the community. Some care programmes also involved inpatients $[17,25,31,33]$. The follow-up care programme described by Beck [26] was designed for persons with tetraplegia and their long-term health care providers. Several care programmes regarded persons with SCI and their partners or families [19, 21-25, 27, 32, 33].

\section{Responsible care disciplines}

Almost half of the follow-up care programmes were performed by nurses [10-14, 16, 22, 24-26, 33]. The remaining programmes were performed by several care disciplines. In the follow-up programme described by Pollack [31], the participants had coresponsibility in the performance. The follow-up care programmes described by Dover [17], Lapierre [20], and Dinsdale [28] were performed in collaboration with primary health care providers. Several follow-up care programmes $[15,21,23-26,28$, 30] paid attention to the coordination of care with community care agencies/providers, e.g. by providing SCI expertise, support and communication of information regarding assessments and treatment plans.

\section{Content of the follow-up care programmes}

The degree in which the content of the follow-up care programmes were described was very diverse. The content of patient-caregiver contacts or education were for instance sometimes elaborated, and sometimes not. Sometimes it was hard to distinguish the difference between the follow-up programme and usual care. Sometimes the description of the content of follow-up care described rather scattered, vague, and brief.

Except for the follow-up care described by Steinberg [32], the programmes did not include home therapy or home health aid, for simple nursing procedures such as baths, enemas, etc. Most follow-up care programmes had a supportive, consultative and educative character. 


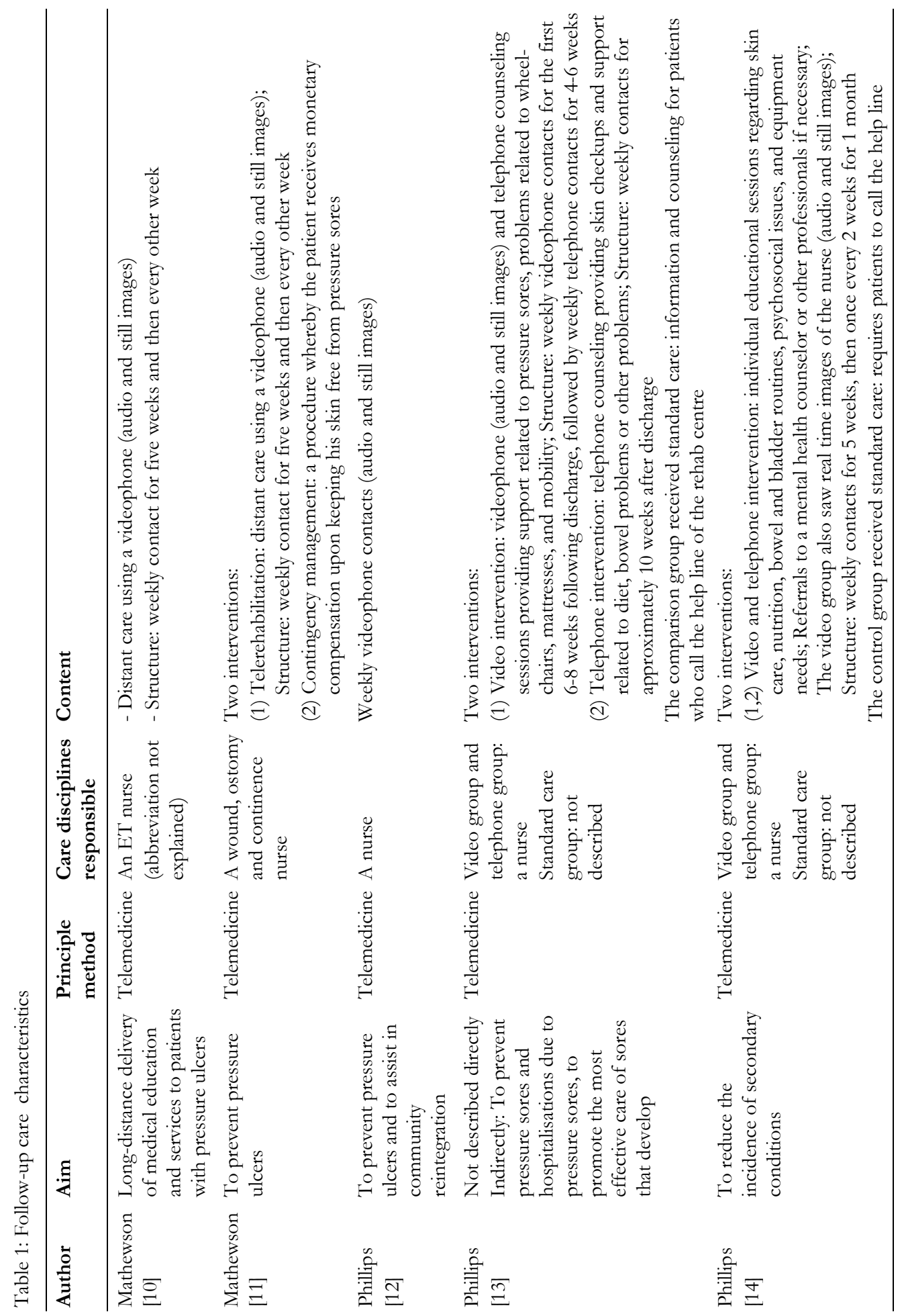




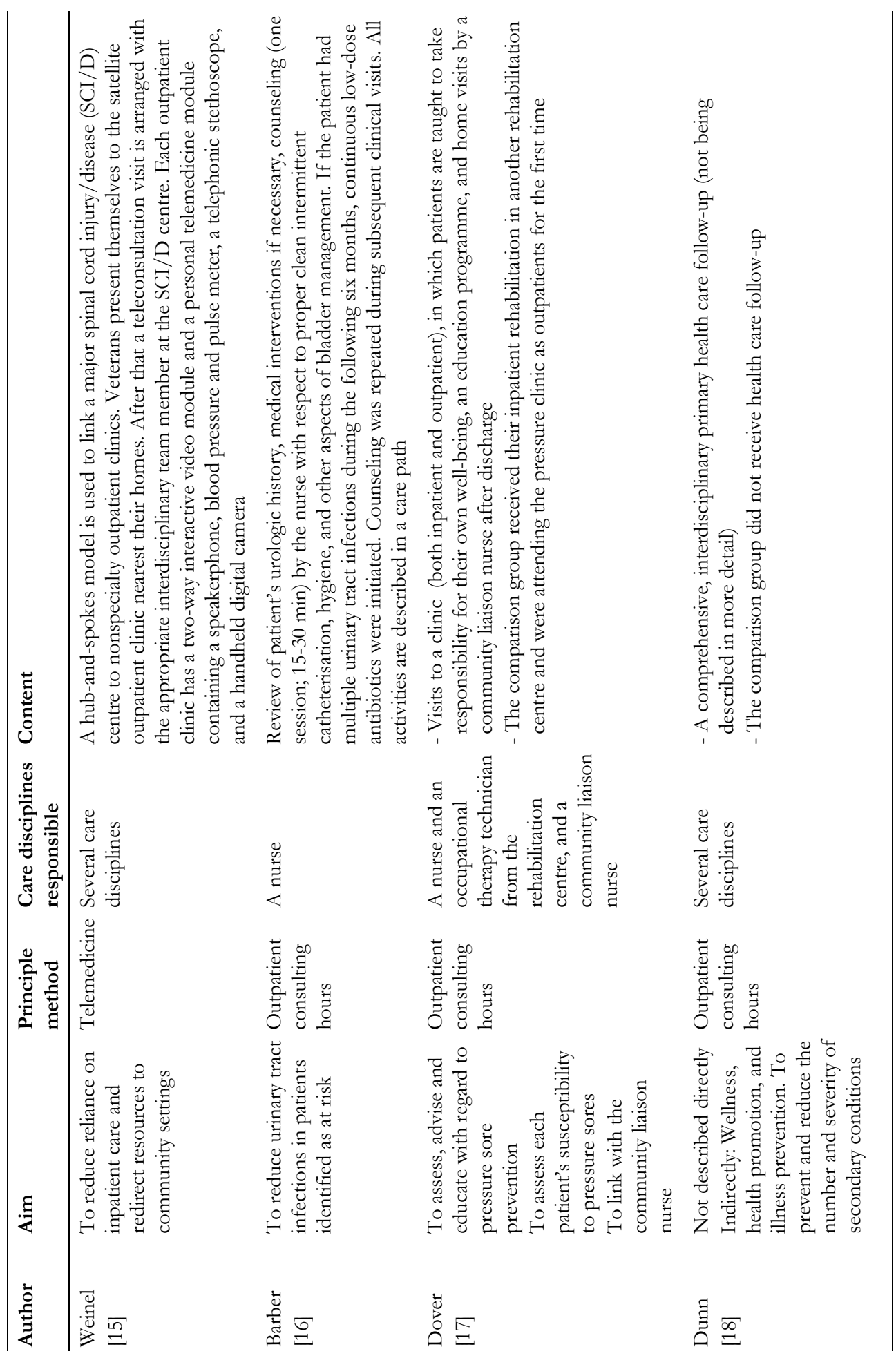




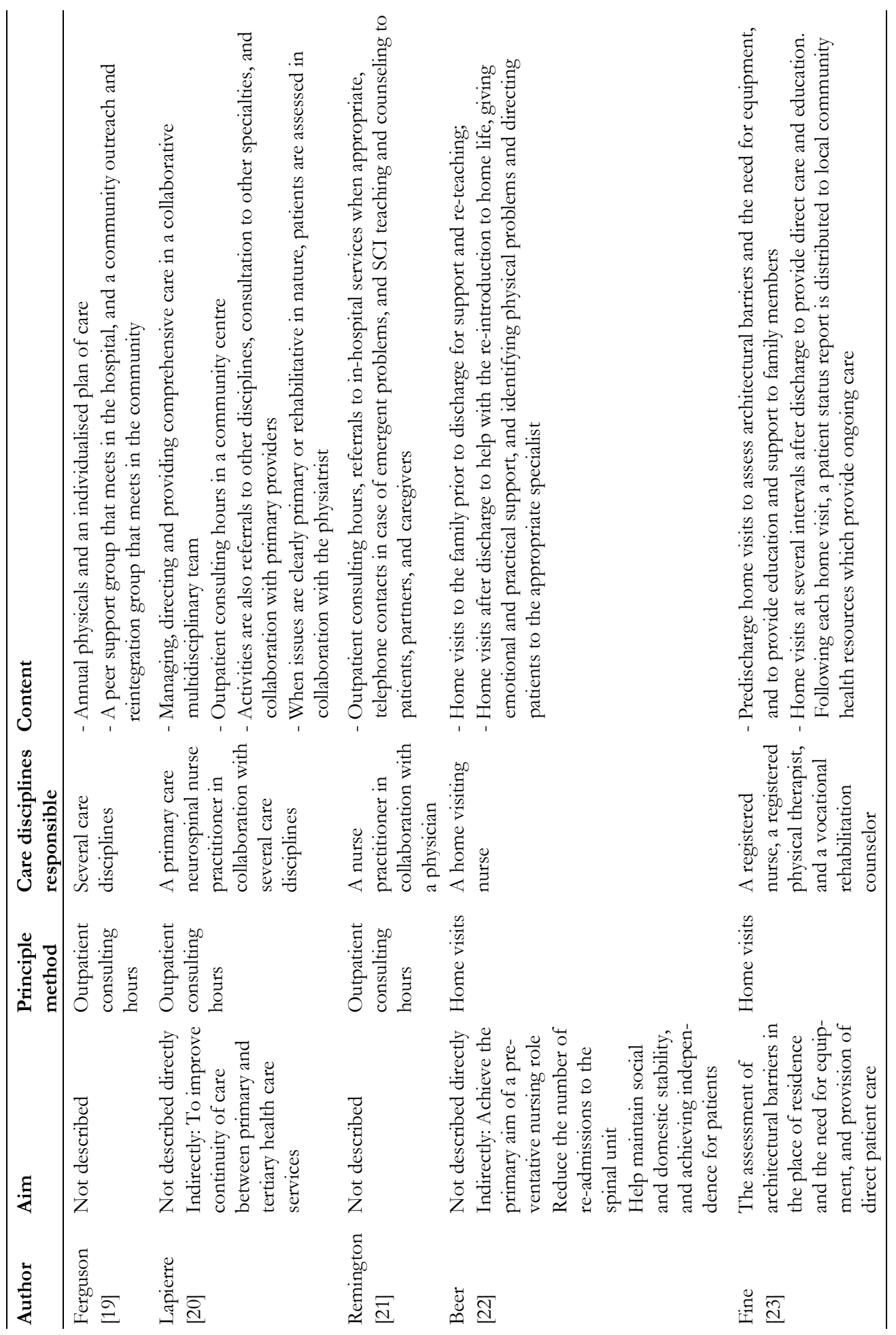




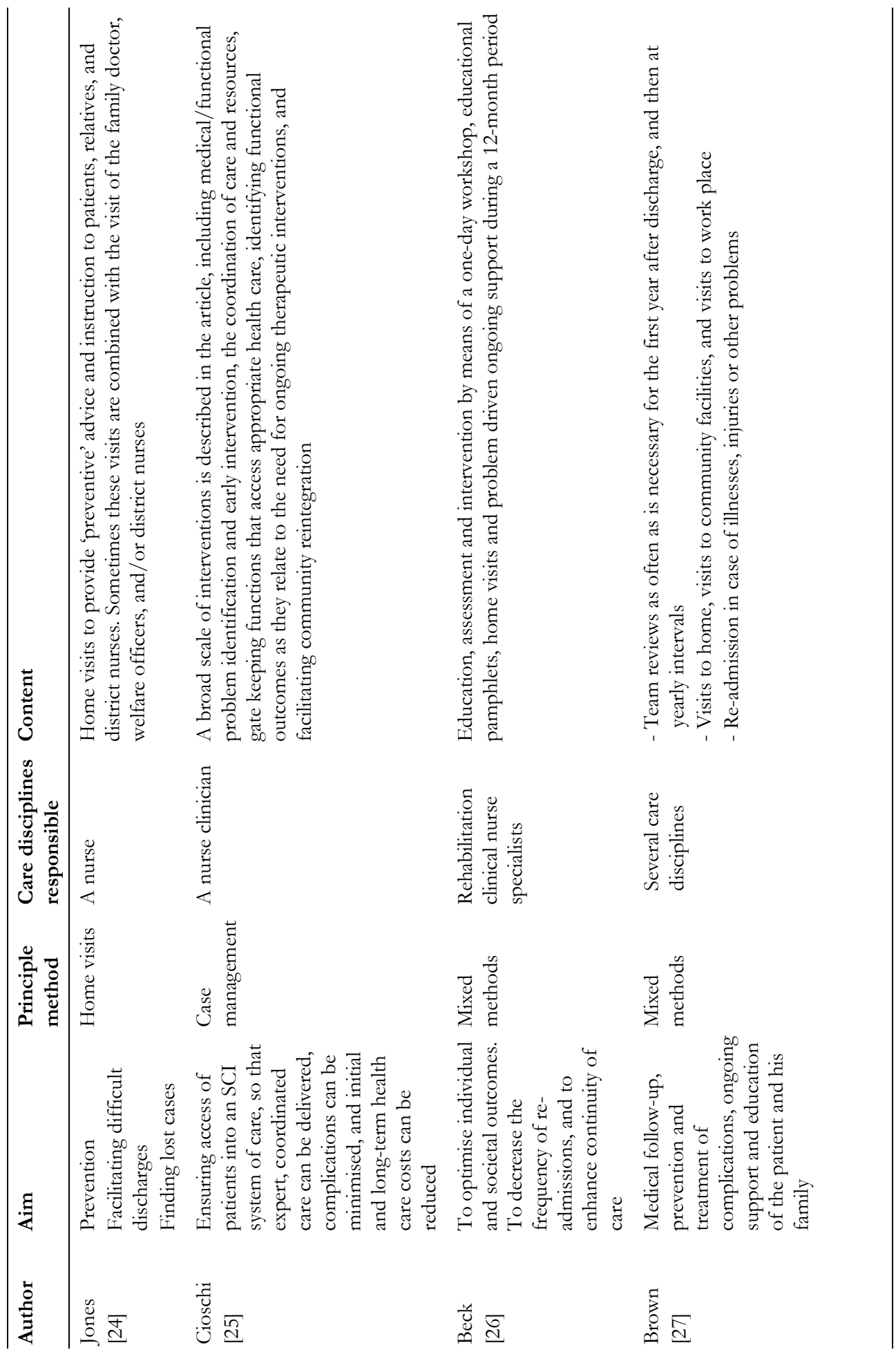




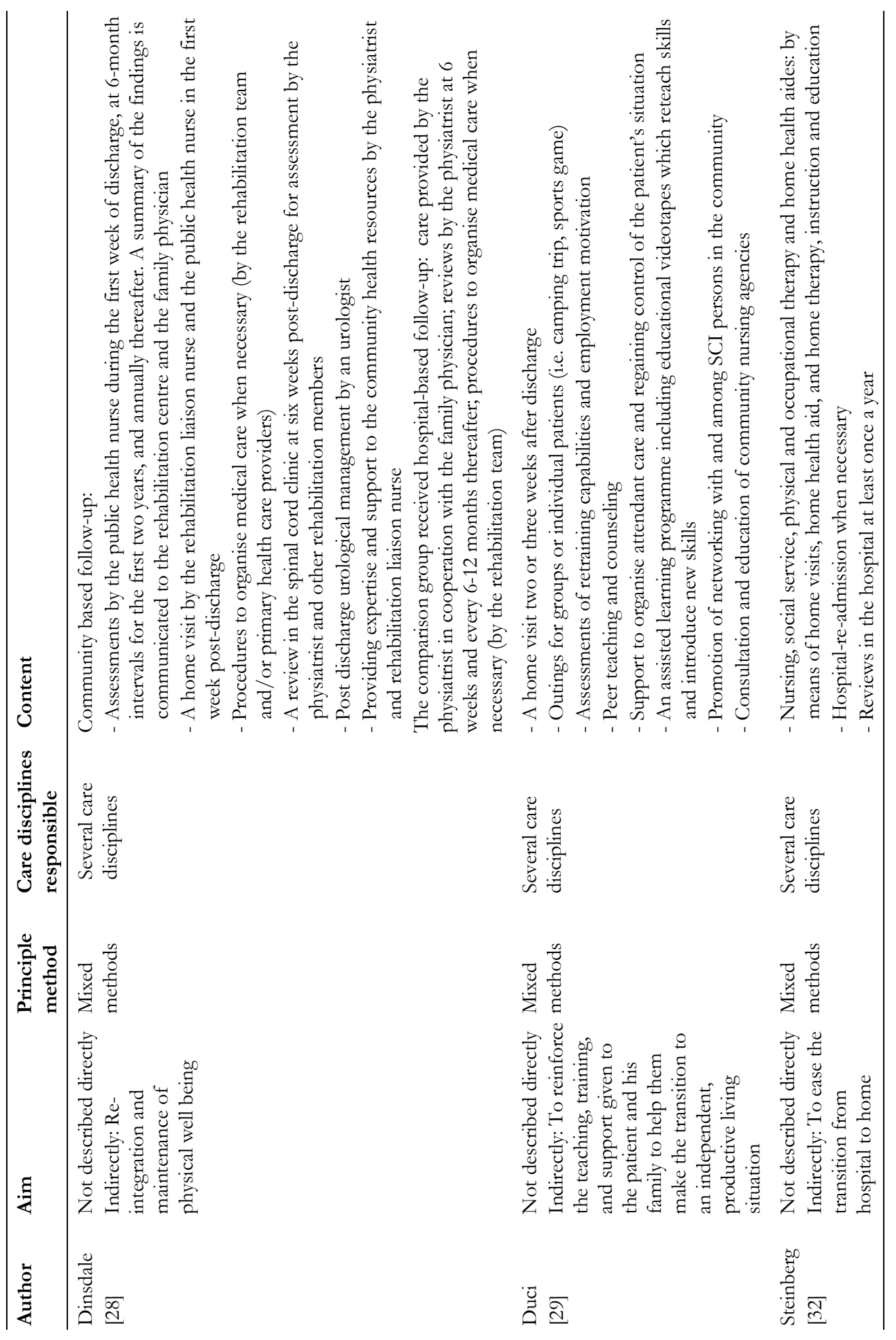




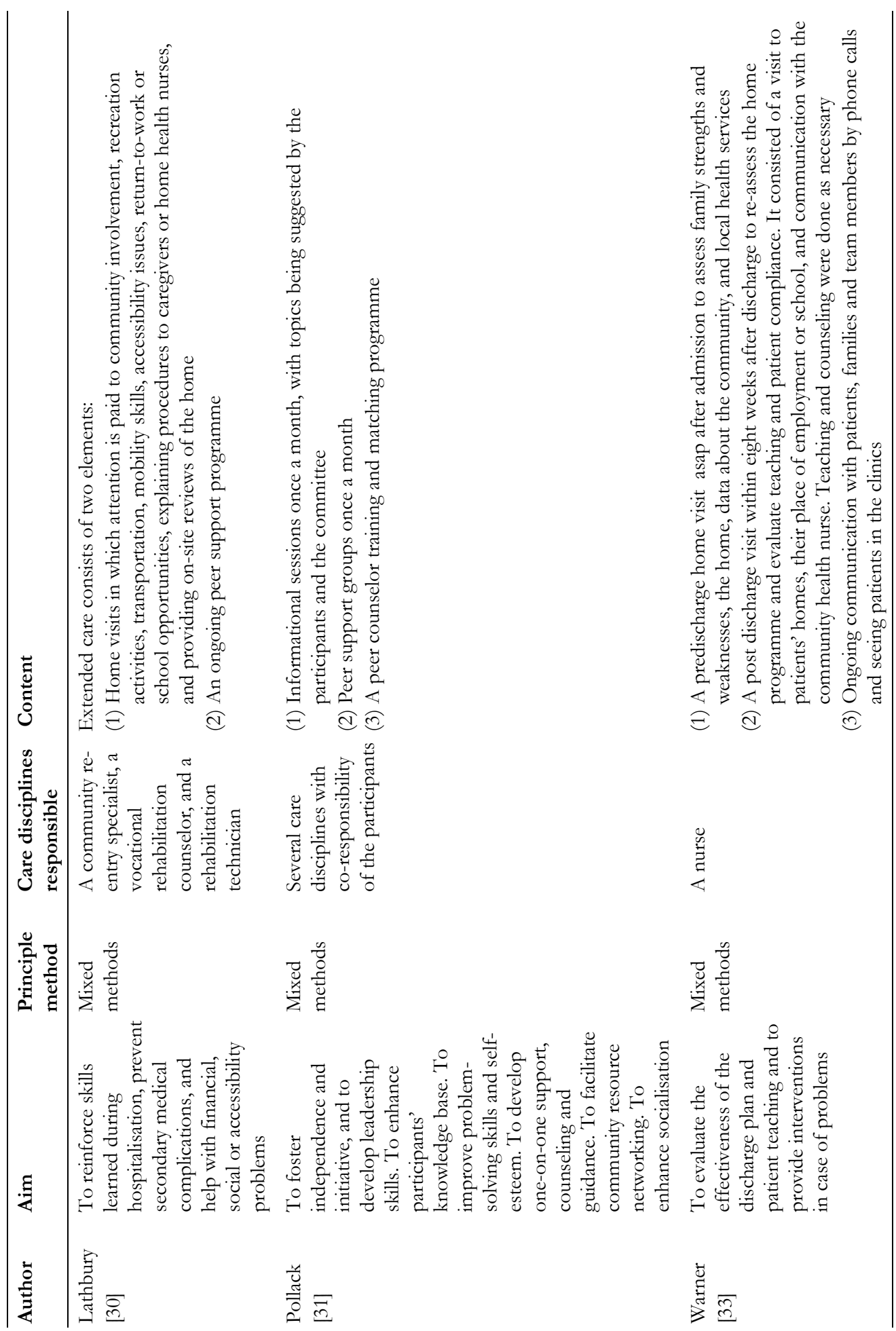




\section{Evaluation characteristics}

Table 2 describes the design, number of patients, outcome measures, and outcomes of the studies that evaluated follow-up care programmes. In all, 16 out of the 24 followup care programmes had been evaluated to some degree.

\section{Designs of evaluation}

In all, 11 evaluations were pre-experimental [10, 12, 16, 20, 22-25, 30-32], three studies were quasi-experimental $[13,17,18]$, and two studies were experimental in design [14, 28].

\section{Number of patients}

The number of patients included in the evaluation studies varied from 1 through 519 persons with SCI. Four evaluations of follow-up care did not mention the number of patients [20, 22, 24, 31].

\section{Outcome measures}

Several publications did not define the outcome measures in a methodology section $[10,12,16,17,20,24,26,32]$. The outcome measures of these publications, mentioned in table 2 , have been derived from the descriptions of the results. Almost all studies used posttest-only measurements. In a few studies, partly pretest-posttest measurements were performed [16, 26, 32]. Five types of outcome measures could be identified from the descriptions in the selected articles:

(a) the incidence and/or improvement of secondary impairment(s) [10, 13, 16-18];

(b) health care utilisation: for example, the number and duration of hospital readmissions, and the number of follow-up care contacts [10, 12-14, 17, 22-24, 26, 28, 32, 33];

(c) costs of the care [10,23];

(d) satisfaction with the care [12, 20, 26];

(e) other outcome measures: for example, self-reported health, independence, knowledge, and the level of functioning [12-14, 18, 24, 26, 28, 31-33].

Legenda to table 2

* In the 'outcome measures' column:

$\mathrm{a}=$ the incidence and/or improvement of secondary impairment(s)

$\mathrm{b}=$ health care utilisation

$\mathrm{c}=$ costs of the care

$\mathrm{d}=$ patients' satisfaction with the care

$\mathrm{e}=$ outcome measurement as described in the table

** In the 'outcomes' column the numbers also refer to the above mentioned outcome measures, per outcome measure the results are given 


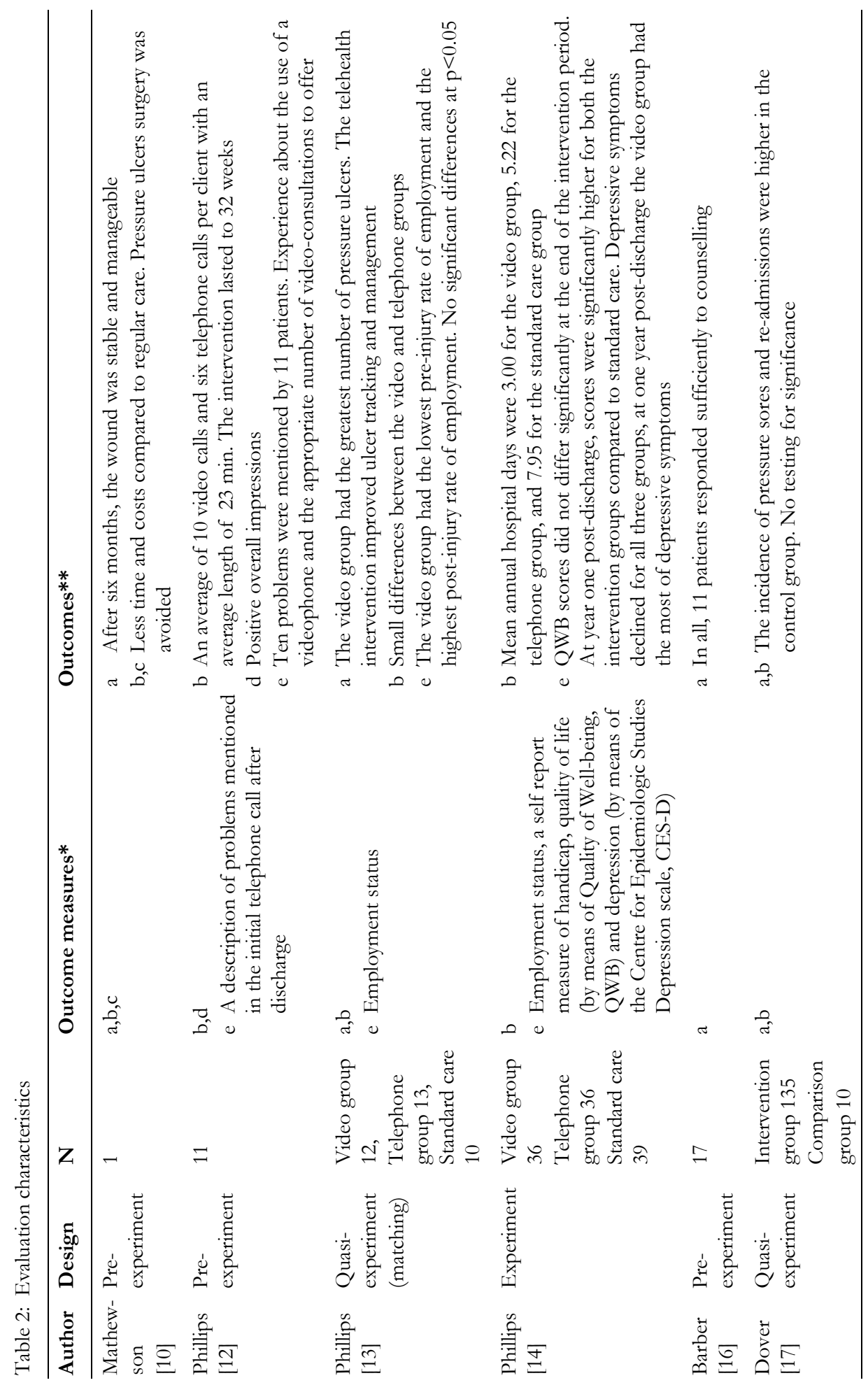




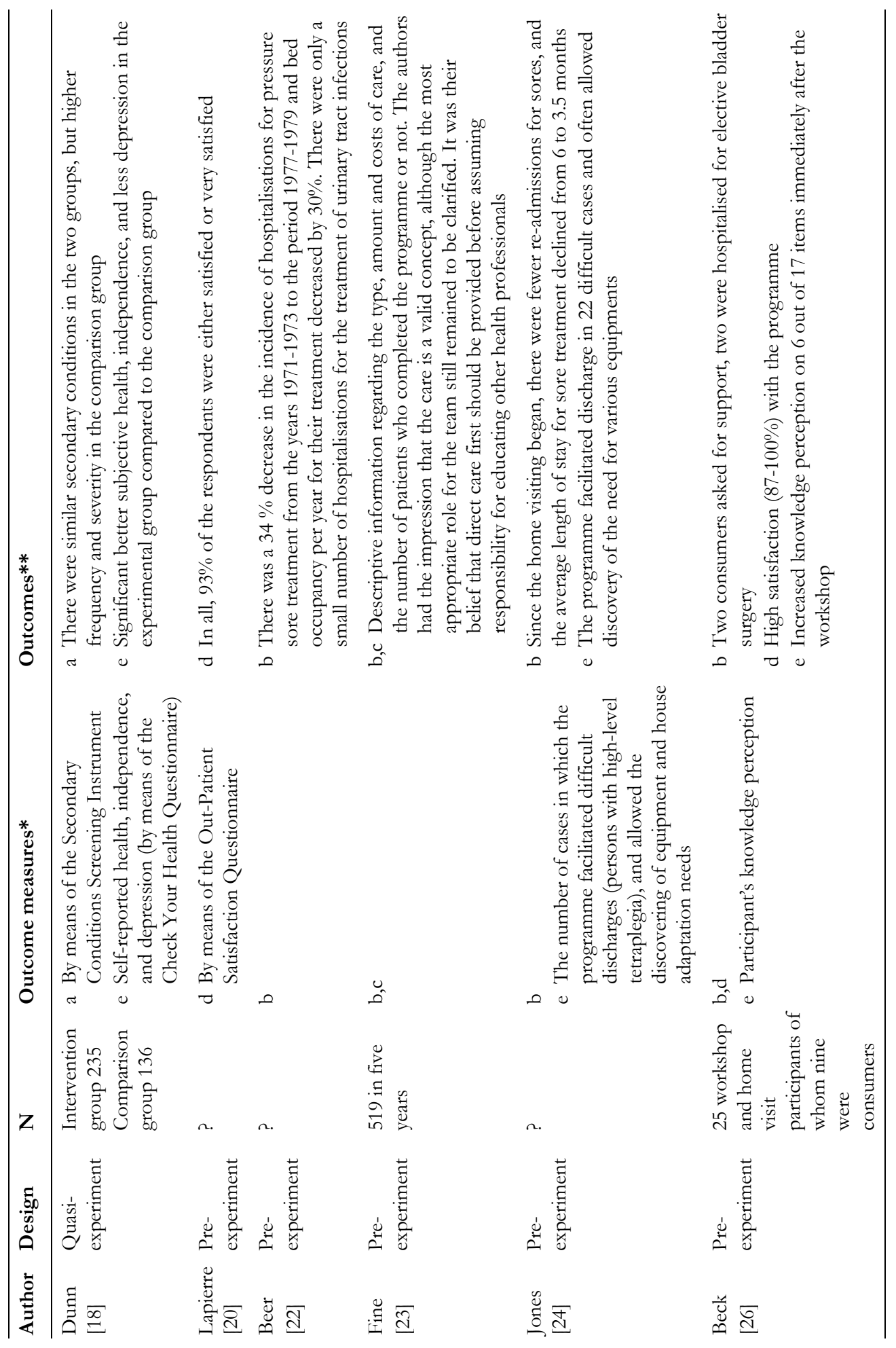




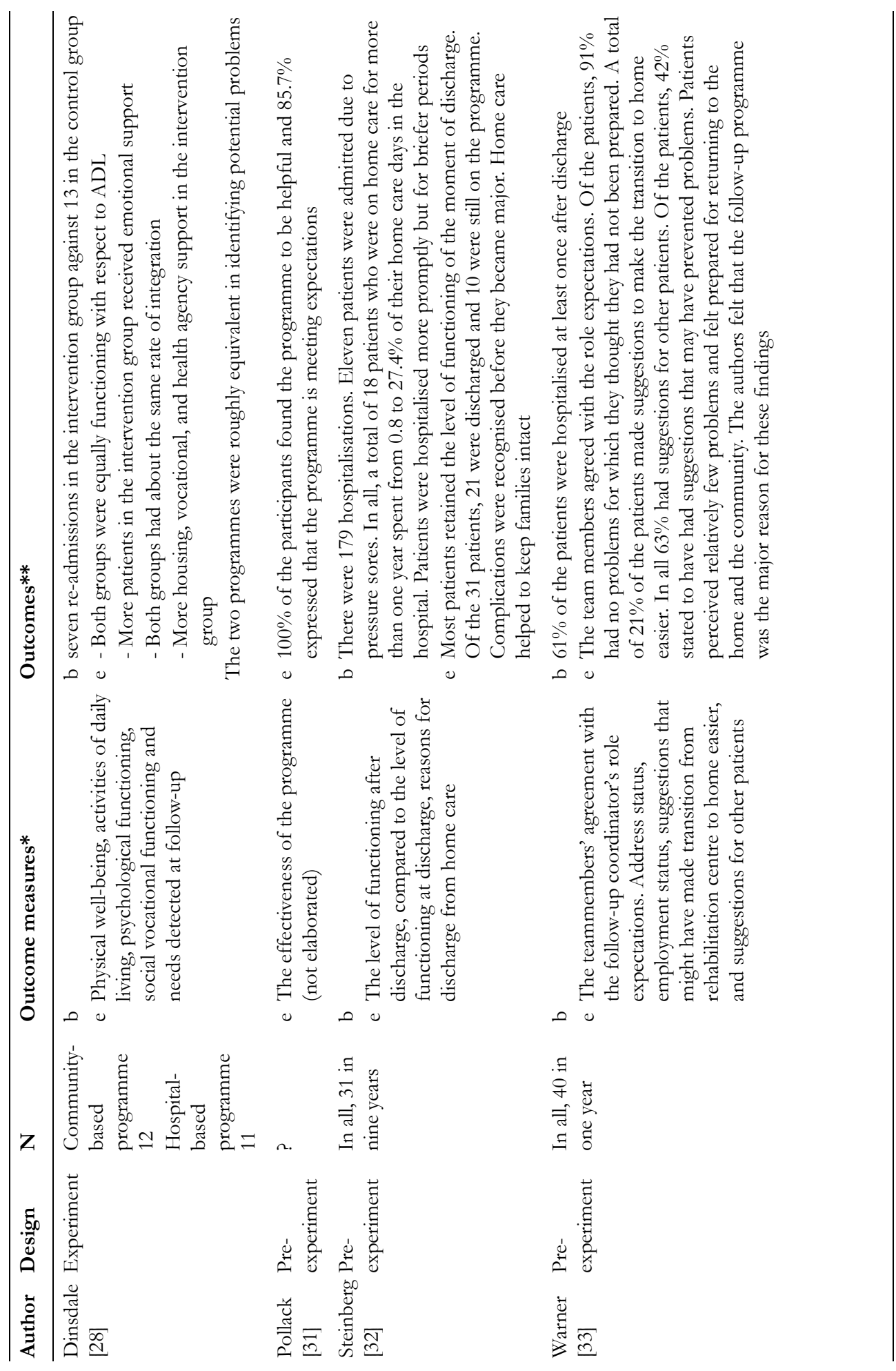




\section{Results of the evaluations}

Most pre-experimental studies claimed positive effects of the follow-up care, although it was sometimes hard to derive this from the results presented. As a result of the preexperimental design, the results of the evaluations are not included in the evaluation here. The following effects were found in the quasi-experiments and experiments:

- incidence and/or improvement of secondary impairments: improvements were found in two $[17,18]$ of the three studies investigating the effects on this variable. In one of these studies [17] there was no test for significance. Phillips [13] found a higher incidence of pressure sores in the intervention group, but stated that the follow-up care appeared to improve ulcer tracking and management.

- health care utilisation: three $[14,17,28]$ out of four studies investigating the effects on this variable found a decline of health care utilisation, although no information was provided about the statistical testing of the findings. The remaining study [13] reported more hospitalisations in the intervention groups compared with the comparison group, although this difference was not significant.

- other outcomes: Phillips [13] found a higher post-injury employment rate in the intervention group, although this difference was not significant. Dunn [18] reported significantly better subjective health, independence and less depression in the experimental group. In another study Phillips [14] found, at one-year post-discharge, significantly higher scores of the quality of well-being in both the intervention groups. On the other hand, at one-year post-discharge, the video group had more depressive symptoms than the telephone or standard care group. Dinsdale [28] found no differences with respect to ADL, integration (school and work), and needs detected at follow-up. But more emotional, housing, vocational and health agency support was used in the intervention group.

\section{Discussion}

The literature search provided only a small number of descriptions of follow-up care programmes. The description of the content of these programmes sometimes was rather scattered, vague and brief. Five methods of follow-up care were identified: telemedicine, outpatient consulting hours, home visits, case management, and mixed types of follow-up care.

In all, 16 out of the 24 follow-up care programmes have been evaluated to some degree. Health care utilisation was the most frequently studied outcome measure, followed by the incidence and/or improvement of secondary impairment(s). Only a 
small number of studies paid attention to the effects of follow-up care on the satisfaction with the care, the cost of care, health and independence. In general, the quality of the evaluation studies was low. Most evaluations were pre-experimental in design. Only three were quasi-experimental, and two were experimental in design. Although several studies found positive effects, it was not possible to draw general conclusions on the effect of follow-up care on the occurrence of secondary impairments, well-being, the quality and costs of care. It can be concluded that the effectiveness of follow-up care programmes for persons with SCI remains far from proven.

The results of this review may, however, be limited for several reasons. First, it may be questioned whether all possible relevant articles were detected. However, we searched the MEDLINE and CINAHL databases, made use of a combination of $\mathrm{MeSH}$ (indexing terms) and text words that covered a wide range of the research field, tried other search strategies too, and studied all publications initially selected by at least two of the three researchers, including publications without abstracts. We are therefore reasonably confident that we didn't miss relevant publications that should have been included in this review.

Second, the review may possibly be subject to 'publication bias', implying that several existing follow-up care programmes and their evaluations might not have been described in the literature. Since we have got to know several follow-up programmes in practice that were not included in our study, we assume the presence of publication bias.

Thirdly, 18 out of the 24 publications included in this study were from the USA, two were from Canada $[20,28]$, two from the UK [17, 24], and two from Australia $[22,27]$. Therefore the results cannot be translated to other countries. The obvious difference between the number of follow-up care programmes performed in the USA compared to those in other parts of the world, such as North-West Europe, may be explained by the fact that the content of follow-care programmes in Europe might have not been communicated in English or German. Another reason for the high percentage of US follow-up care programmes may be the difference regarding the duration of inpatient rehabilitation. Since the duration of inpatient rehabilitation in the USA is relatively short, the need for follow-up care in the USA may be higher.

All this contributes to the most important conclusion of this review: there is a need for the development, the publication and the well-designed evaluation of follow-up care programmes for persons with SCI. We encourage rehabilitation centres, specialised in the rehabilitation of persons with SCI, to take the initiative to organise follow-up care, preferably in cooperation with primary care professionals and/or patient organisations. Since primary care professionals rarely have sufficient knowledge and experience about the specific care persons with SCI need (due to the low prevalence of persons with SCI), it is important that the expertise of specialised rehabilitation centres is in some way or another available for persons with SCI living in the community and that these centres should take the initiative in organising follow- 
up care. Cooperation with primary care professionals is preferable, since they are the persons first and foremost to deliver care at home. From our review we learned that follow-up care programs vary widely with regard to aim and methods. To facilitate comparisons of design and results of such programs, we propose a rough classification system, based on three dimensions:

(1) Classification according to the aim of follow-up care:

- specific aim like preventing or treating one or more secondary complications;

- generic aim like the promotion of quality of life, participation and community reintegration;

- combination of the aims mentioned above.

(2) Classification according to the method of follow-up care:

- preventive activities directly aimed at individual patients or patient groups;

- therapeutic activities directly aimed at individual patients or patient groups;

- activities aimed at the promotion of continuity of care;

- combination of the methods mentioned above.

(3) Classification according to the localisation of the care:

- at the patient's home;

- in the rehabilitation centre;

- both at the patient's home and in the rehabilitation centre making use of communication technologies;

- combination of methods mentioned above.

With regard to the evaluation of follow-up care programmes we think it is important to evaluate the follow-up care with regard to its effectiveness (effects on the prevalence on secondary impairments). Furthermore attention should also be paid to the effects regarding the efficiency (costs and health care utilisation) and the effects on quality of care (satisfaction and continuity).

\section{Acknowledgement}

The study was supported by: ZonMw, the Netherlands Organisation for Health Research and Development, Rehabilitation programme, grant no. 01432030. 


\section{References}

[1] Anson CA, Shepherd C. Incidence of secondary complications in spinal cord injury. International Journal of Rehabilitation Research 1996; 19(1): 55-66.

[2] Bloemen-Vrencken JH, de Witte LP. Post-discharge nursing problems of spinal cord injured patients: on which fields can nurses contribute to rehabilitation? Clinical Rehabilitation 2003; 17(8): 890-8.

[3] Bloemen-Vrencken JHA, Post MWM, Hendriks J, De Reus ECE, de Witte LP. Health problems of persons with spinal cord injury living in the Netherlands. Disability and Rehabilitation 2005; 27(22): 1381-1389.

[4] Cox RJ, Amsters DI, Pershouse KJ. The need for a multidisciplinary outreach service for people with spinal cord injury living in the community. Clinical Rehabilitation 2001; 15(6): 600-6.

[5] Ernst JL, Thomas LM, Hahnstadt WA, Piskule AA. The self-identified longterm care needs of persons with SCI. SCI Psychosocial Process 1998; 1: 127132.

[6] Glidden MM. Spinal cord injury and case management. Topics in Spinal Cord Injury Rehabilitation 1999; 4 (4): 16-23.

[7] Mattson J. Case management: a historical and future perspective of its influence on outcome for persons who have sustained spinal cord injury. Topics in Spinal Cord Injury Rehabilitation 1999; 4 (4): 30-37.

[8] Rawl SM, Easton KL, Kwiatkowski S, Zemen D, Burczyk B. Effectiveness of a nurse-managed follow-up program for rehabilitation patients after discharge. Rehabilitation Nursing 1998; 23(4): 204-9.

[9] Polit DF, Hungler BP. Nursing Research: Principles and Methods. 4th ed. Philadelphia: Lippincott Company; 1991.

[10] Mathewson C, Adkins VK, Lenyoun MA, Schmidt AM, Jones ML. Using telemedicine in the treatment of pressure ulcers. Ostomy Wound Manage 1999; 45(11): 58-62. 
[11] Mathewson C, Adkins VK, Jones ML. Initial experiences with telerehabilitation and contingency management programs for the prevention and management of pressure ulceration in patients with spinal cord injuries. Journal of Wound, Ostomy, and Continence Nursing 2000; 27(5): 269-71.

[12] Phillips VL, Temkin AJ, Vesmarovich SH, Burns R. A feasibility study of video-based home telecare for clients with spinal cord injuries. Journal of Tekenedicine and Telecare 1998; 4(4): 219-23.

[13] Phillips VL, Temkin A, Vesmarovich S, Burns R, Idleman L. Using telehealth interventions to prevent pressure ulcers in newly injured spinal cord injury patients post-discharge. Results from a pilot study. Int J Technol Assess Health care 1999; 15(4): 749-55.

[14] Phillips VL, Vesmarovich S, Hauber R, Wiggers E, Egner A. Telehealth: reaching out to newly injured spinal cord patients. Public Health Reports 2001; 116(Suppl 1): 94-102.

[15] Weinel D. The Sunshine Network Teleconsultation Initiative for SCI Veterans in Community Settings. SCI Nursing 2000; 17(1): 22-3.

[16] Barber DB, Woodard FL, Rogers SJ, Able AC. The efficacy of nursing education as an intervention in the treatment of recurrent urinary tract infections in individuals with spinal cord injury. SCI Nursing 1999; 16(2): 54-6.

[17] Dover H, Pickard W, Swain I, Grundy D. The effectiveness of a pressure clinic in preventing pressure sores. Paraplegia 1992; 30(4): 267-72.

[18] Dunn M, Love L, Ravesloot C. Subjective health in spinal cord injury after outpatient healthcare follow-up. Spinal Cord 2000; 38(2): 84-91.

[19] Ferguson I. Growing a SCI support clinic -- in the VA health care system. SCI-Psychosocial-Process 2000; 13(3): 129-32.

[20] Lapierre NM. Innovative approach in rehabilitation nursing: providing primary care to tertiary care patients. Canadian Journal of Nursing Leadership 1999; 12(4): 23-4.

[21] Remington H. How successful has a nurse-managed outpatient SCI clinic been in your hospital? SCI Nursing 1991; 8(1): 30.

[22] Beer NI. The role of the home visiting nurse in the total education programme of spinal cord injured persons. Paraplegia 1984; 22(5): 311-5. 
[23] Fine PR, Better SR, Engstrand JL. The operation of a hospital based specialty home health team: activities and associated costs. The official Journal of the Association of Rehabilitation Nurses 1978; 3(1): 5-11.

[24] Jones HW. A follow-up service-supplemented by domicillary visits. Paraplegia 1972; 10(2): 111-4.

[25] Cioschi HM, Goodman CL. A lifetime case management model for persons with spinal cord injury. Journal of Case Management 1994; 3(3): 117-23.

[26] Beck LA, Scroggins LM. Optimizing health of individuals with tetraplegia. SCI Nursing 2001; 18(4): 181-6.

[27] Brown DJ, Judd FK, Ungar GH. Continuing care of the spinal cord injured. Paraplegia 1987; 25(3): 296-300.

[28] Dinsdale S, Thurber D, Hough E, Rencz S. Community based monitoring for spinal man. Canadion Journal of Public Health 1981; 72(3): 195-8.

[29] Duci B, Saperstein I. SCI home care: transitional rehabilitation as a component of follow-up care. SCI Nursing 1986; 3(1): 6-9.

[30] Lathbury K. The road ahead--managing a spinal cord injury. Case Manager 2000; 11(3): 55-7.

[31] Pollack SF, Zuger RR, Walsh J. Moving Out Services for Education and Support (MOSES): a model program for individuals with spinal cord injury. SCI Nursing 1992; 9(3): 79-82.

[32] Steinberg FU. The management of patients with spinal cord injury by a hospital-based home care programme. Paraplegia 1975; 12(4): 256-50.

[33] Warner BH, Taylor SK. Follow-up care evaluation: patient perspective. Rehabilitation Nursing 1982; 7(6): 13-6, 24. 



\section{Transmural care in the rehabilitation sector:}

implementation experiences with a transmural care model for people with spinal cord injury

Published in:

International Journal of Integrated Care 2005; 5, www.ijic.org

Jos Bloemen-Vrencken, Luc de Witte, Jeanny Engels, Wim van den Heuvel, and Marcel Post 


\begin{abstract}
Purposes: The purpose of this article is first to describe the development and content of a transmural care model in the rehabilitation sector, which aims to reduce the number and severity of health problems of people with spinal cord injury (SCI) and to improve the continuity of care. Second, the purpose is to describe the applicability and implementation experiences of a transmural care model in the rehabilitation sector.
\end{abstract}

Methods: The transmural care model was developed in cooperation with the Dutch Association of SCI Patients, community nurses, general practitioners, rehabilitation nurses, rehabilitation managers, physiatrists and researchers. The core component of the care model consists of a transmural nurse, who 'liaises' between people with SCI living in the community, primary care professionals and the rehabilitation centre. The transmural care model provides a job description containing activities to support people with SCI and their family/partners and activities to promote continuity of care.

The transmural care model was implemented in two Dutch rehabilitation centres. The following three aspects, as experienced by the transmural nurses, were evaluated: the extent to which the care model was implemented; enabling factors and barriers for implementation; strength and weakness of the care model.

Results: The transmural care model was not implemented in all its details, with a clear difference between the two rehabilitation centres. Enabling factors and barriers for implementation were found at three levels: (1) the level of the individual professional (e.g. competencies, attitude and motivation), (2) the organisational and financing level (e.g. availability of facilities and finances), and (3) the social context (the opinion of colleagues, managers and other professionals involved with the care). The most important weakness experienced was that there was not enough time to put all the activities into practice. The strength of the care model lies in the combination of support of patients after discharge, support of and cooperation with primary care professionals, and feedback of experiences to the clinical rehabilitation teams.

Conclusion: We recommend further improving and implementing the care model and encourage other care professionals and researchers to share their implementation experiences of follow-up care innovations for people with SCI.

Keywords: Transmural care, follow-up care, process evaluation, SCI. 


\section{Introduction}

The National Council for Public Health care described transmural care as follows: 'Health care, geared to the needs of the patient, provided on the basis of co-operation and co-ordination between general and specialised caregivers, with shared responsibility and specification of delegated responsibilities' [1]. Since its introduction in the early 1990s, transmural care has become very popular in the Netherlands, considering the number of running transmural projects. Transmural care is most often directed towards bridging the gap between different levels of care providers, for example between primary care and secondary care. It evolved as a reaction to perceived deficits in the organisation of health care: patients as well as care providers felt there was not enough continuity, caused by deficient coordination between primary and secondary health care. The care process of patients was interrupted when they moved from one health care provider to the next. By bridging the gap between different health care providers, the effectiveness, quality and efficiency of health care could be improved [2]. The transmural care concept is not often used outside the Netherlands [3].

However, problems with continuity of care are not specific to the Netherlands, but occur in many other countries too $[4,5]$. Here, integrated care is a more common term for activities aiming at improving continuity of care [4-6]. Integrated care deals with the integration of health care, social care and related services. It is more comprehensive than transmural care since transmural care generally does not include the whole care process of patients and is focused on one or two crucial transition steps between different types of health care providers [2].

In the Netherlands, the care needs of a specific chronic patient group often form the point of departure for transmural care innovations [3]. However, in the rehabilitation sector such projects are sparse. This article describes the development and content of a transmural care model for people with spinal cord injury (SCI), and the experiences with its implementation in two rehabilitation centres. People with SCI who are living in the community often have health problems, such as bladder and bowel problems, spasms, pain, and pressure sores [7]. However, due to the low prevalence of people with SCI, it is difficult for primary care professionals to gain enough knowledge and experience about the specific care these patients require. Therefore, there is a strong need for effective interventions aimed at the prevention of such health problems after discharge [8-14].

A transmural care model could improve the continuity of care and reduce the number and severity of health problems of people with SCI living in the community.

The aim of this paper therefore is to study whether the transmural care concept is applicable in the rehabilitation sector. More explicitly, it aims to provide insight into 
(1) the extent to which the transmural care model was implemented; (2) enabling factors and barriers for implementation; and (3) the experienced strength and weakness of the transmural care model.

Experiences with the implementation of follow-up care for people with SCI have hardly ever been described [15], but are in our opinion very important for health care professionals who are involved in the care for people with SCI and who may wish to use the transmural care model or develop a similar intervention. A process evaluation is also important to be able to interpret the results of an outcomes evaluation [16], in which the effects on the number and severity of health problems of people with SCI after discharge from clinical rehabilitation will be studied.

\section{Development and content of the transmural care model}

A project group was set up to support and guide the development of the transmural care model and its implementation. This group comprised representatives of the Dutch Association of SCI Patients, researchers (JE, MP, LdW, JB), and managers, physiatrists and nurses of the participating rehabilitation teams. The project group established a working group for the development of the transmural care model. The working group consisted of two representatives of the Dutch Association of SCI Patients, two community nurses, one general practitioner, three rehabilitation nurses from two rehabilitation centres and three researchers. A protocol for the transmural care model was developed, based on results of research performed earlier [7, 9], and the practical and theoretical experience of the members of the working group.

The resulting model was presented for feedback to the rehabilitation teams of the two participating rehabilitation centres, the Dutch College of General Practitioners and the Dutch Association of Community Nurses.

The core component of the transmural care model consists of a transmural nurse, who 'liaises' people with SCI living in the community, primary care professionals and the rehabilitation centre. The transmural nurse is member of the clinical rehabilitation team (she also works as a nurse at the spinal cord unit) and is engaged for eight hours a week to perform the four main tasks:

- to support people with SCI and their partner/family with their health problems, which come within the scope of the nursing discipline;

- to support primary care professionals with the specific care for people with SCI;

- to promote continuity of care between primary care professionals and the rehabilitation team;

- to give feedback and take initiatives for improvements in care to the rehabilitation team, based on the experiences with patients. 
The transmural care model provides a job description for the transmural nurses, which contains activities to support people with SCI and their family/partners and activities to promote continuity of care (described in table 1).

Table 1: Job description of the transmural nurses

\section{Activities to support people with SCI}

1 To introduce the transmural care before discharge from clinical rehabilitation and to explore the needs of follow-up care, and to make agreements about this (Patients with SCI are free to decide whether or not to make use of the transmural care).

2 To give advice and support after discharge from clinical rehabilitation depending on the needs and the complexity of care by means of (at 3 weeks, 3, 6, 9 and 12 months after discharge):

2.1 telephone consultations on the initiative of the transmural nurse;

2.2 consultations in the rehabilitation centre (in addition to the periodical outpatient visit to the physiatrist);

2.3 home visits in case of health problems;

2.4 telephone consulting hours (consultation of the transmural nurse on the initiative of people with SCI).

3 To organise peer meetings after discharge.

Activities to promote continuity of care

4 To introduce the so-called 'care compass'; a little book which contains individual advice of caregivers to the patient, an overview of health services, and info sheets concerning several consequences and complications of SCI. The patient 'owns' the care compass, but it is also meant to support the caregiving by family/partners and professional caregivers.

5 To organise telephone consulting hours for primary care professionals.

6 To organise a meeting at the patient's home before discharge with the patient, the primary care professionals of all care disciplines involved with the care after discharge, and the transmural nurse to transfer care, in case of complex care.

7 To inform primary care professionals about the transmural care (content and accessibility).

8 To organise presentations to primary care professionals to inform them about SCI, prevention of secondary impairments and the specific care people with SCI need.

9 To organise presentations to the rehabilitation team to inform them about experiences with people with SCI after discharge and to make proposals for improvement in the clinical care, on the basis of the experiences with patients.

In all the contacts mentioned at 1 and 2 an assessment list is used to structure the discussion of total functioning.

The transmural nurses had to link their activities closely to the care structures in the rehabilitation centre and the primary care. In the model this entails three consequences. Patients would have as much autonomy as possible to organise their own care after discharge. Second, primary care professionals are the people first and foremost to deliver care at home; and third, the transmural care nurses would not take over tasks from caregivers in the rehabilitation centre. 


\section{The process evaluation: Methods}

\section{Intervention}

In order to test the robustness of the transmural care model, the model was implemented in two Dutch rehabilitation centres (De Hoogstraat in Utrecht and Rehabilitation Centre Hoensbroeck in Hoensbroek, abbreviated here as DH and $\mathrm{RCH}$ ). $\mathrm{DH}$ is situated in an urban area in the middle of the country, and $\mathrm{RCH}$ in a semi-urban region in south of the Netherlands. Compared with DH, RCH admits patients from a larger area, including patients from Belgium. In general there are no large differences regarding the content of the clinical care in the two rehabilitation centres except that, compared with $\mathrm{RCH}$, in $\mathrm{DH}$ the patients are stimulated slightly more to take responsibility for their own care. Before the start of the project, the nurses of the inpatient SCI department of RCH were more involved with follow-up care than the nurses of the inpatient SCI department of DH. In RCH the physiatrist referred patients attending the outpatient consulting hour to the nurses of the inpatient SCI department in the case of nursing problems. In DH, these patients were referred to the nurse of the day hospital.

All people with SCI discharged during a study period of 18 months were entitled to use the transmural care for at least one year after discharge. The total intervention period lasted 30 months. During the intervention period two researchers (JE, JB) met the transmural nurses every three months to support them with the implementation of the transmural care model and to help fine-tune their care to the needs of the clients. During this period two health care insurers agreed to finance the implementation of the intervention.

\section{Participants}

The process evaluation was performed among the transmural nurses of the two 'experimental' rehabilitation centres, and all people with SCI who were discharged from clinical rehabilitation during the study period of 18 months.

\section{Measures}

In each rehabilitation centre, the following three aspects of the intervention process were evaluated:

(1) The extent to which all the activities of the transmural care model were performed. With regard to the individual support of people with SCI (activities 1 and 2 in table 1), four aspects will be elaborated:

- the number of the different types of contacts;

- the time spent on the contacts;

- the number and types of health problems for which interventions were applied;

- the number and type of interventions applied during the contacts.

(2) Enabling factors and barriers for the implementation of the transmural care model. 
(3) The experienced strength and weakness of the transmural care.

Data regarding these three aspects were collected in the following ways:

- structured registration forms administered by the nurses during the intervention period (aspect 1);

- interviews with the transmural nurses about their experiences with the intervention every three months during the intervention period of 30 months (aspects 1,2,3);

- participation of members of the research team in the three-monthly meetings of the nurses in which the implementation of the transmural care was discussed (aspects 1,2,3).

\section{Analysis}

The statistical package for the social sciences (SPSS) was used to describe the number and the content of the contacts the transmural nurses had with their clients (registration forms). The interviews with the transmural nurses were tape-recorded and the full text was transcribed. All transcriptions were analysed to identify all the experiences the transmural nurses had regarding the implementation of the different aspects of the transmural care model, enabling factors and barriers for the implementation, and the experienced strength and weakness of the transmural care.

\section{The process evaluation: Results}

\section{Participants}

We included 134 people with SCI, who had the possibility to use the transmural care during at least one year after discharge. There were 86 people from DH and 48 from $\mathrm{RCH}$. The general characteristics of the response group are shown in table 2.

$\mathrm{DH}$ had a total of three transmural nurses during the intervention period. For practical reasons $\mathrm{DH}$ chose to have two nurses to perform the transmural care together. In this centre there were several changes in transmural nurses. The three nurses formed two pairs to give the transmural care. One pair gave the transmural care for nine months, while the other pair did so for about three months. During the remaining 18 months of the intervention period a single transmural nurse performed the transmural care. The reasons for the changes were not related to the transmural care. RCH chose to have one transmural nurse to perform the transmural care. During the intervention period, there were two transmural nurses. One nurse gave the transmural care for six months and the other for a period of two years. All nurses can be considered experienced, since they had all worked for several years at a spinal cord department. 
Table 2: Subject characteristics

\begin{tabular}{lrrr} 
& $\begin{array}{r}\text { DH } \\
\mathbf{N}=\mathbf{8 6}\end{array}$ & $\begin{array}{r}\text { RCH } \\
\mathbf{N}=\mathbf{4 8}\end{array}$ & $\begin{array}{r}\text { Total group } \\
\mathbf{N}=\mathbf{1 3 4}\end{array}$ \\
\hline Age, mean [yrs] (SD) & $48.4(15.1)$ & $44.9(16.4)$ & $47.2(15.6)$ \\
Men [\%] & 59.3 & 56.3 & 58.2 \\
Level and type of injury [\%] & & & \\
Complete tetraplegia & 12.8 & 20.8 & 15.7 \\
Incomplete tetraplegia & 17.4 & 18.8 & 17.9 \\
Complete paraplegia & 37.2 & 35.4 & 36.6 \\
Incomplete paraplegia & 29.1 & 25.0 & 27.6 \\
Missing & 3.5 & 0.0 & 2.2 \\
Cause of injury [\%] & & & \\
$\quad$ Traumatic & 62.8 & 66.7 & 64.2 \\
Non-traumatic & 20.9 & 20.8 & 20.9 \\
Combination traumatic and non-traumatic & 5.8 & 12.5 & 8.2 \\
$\quad$ Missing & 10.5 & 0.0 & 6.7 \\
Two or more times hospitalised in the & 37.2 & 33.3 & 35.8 \\
rehabilitation centre [\%] & & & \\
\hline
\end{tabular}

\section{The extent to which the transmural care was implemented}

In the first half of table 1 (activities 1,2 and 3) there are listed the activities to support people with SCI. Table 3 displays the type and number of contacts (activities 1 and 2) the transmural nurses had with people with SCI for each rehabilitation centre and the total patient group.

\section{Activity 1 The introduction of the transmural care before discharge}

The transmural care was not introduced to several patients before discharge. The transmural nurses mentioned that they regularly had to introduce the transmural care after discharge in cases where they had not been timely informed about the discharge or where the discharge occurred too suddenly. Especially in $\mathrm{DH}$ there was a considerable number of patients $(31.4 \%)$ who wanted to organise their care after discharge autonomously and to contact the transmural nurse on their own initiative if necessary.

\section{Activity 2 Advice and support after discharge}

In both rehabilitation centres telephone consultations on the initiative of the transmural nurse (activity 2.1) were the most frequently used method to support patients after discharge (almost $75 \%$ of all patients received this type of support), while home visits (activity 2.3) were the method of support least used (less than $2 \%$ of all patients). The methods of support (activities 2.1-2.4) were more varied in RCH. In all contacts all transmural nurses used the assessment list to discuss the patients' functioning. Beside the types of support mentioned in the transmural care model 
(activity 2.1 to 2.4), e-mail contact was also used in both rehabilitation centres. Sometimes these e-mails also contained digital photos of pressure sores.

Table 3: Type and number of contacts with patients

\begin{tabular}{|c|c|c|c|}
\hline & DH & RCH & Total group \\
\hline & {$[\%] \quad(n)$} & {$[\%] \quad(n)$} & {$[\%] \quad(n)$} \\
\hline Type of contacts relative to number of patients & $\mathbf{N}=86$ & $\mathrm{~N}=48$ & $\mathbf{N}=134$ \\
\hline 1 Introduction of care before discharge & $65.1(56)$ & 75.0 & $68.7(92)$ \\
\hline 2.1 Telephone consultations on transmural nurse's initiative & $67.4(58)$ & $83.3(40)$ & 73.1 (98) \\
\hline 2.2 Consultations in the rehabilitation centre after discharge & $8.1 \quad(7)$ & $54.2(26)$ & 24.6 (33) \\
\hline 2.3 Home visits & $1.2 \quad(1)$ & $8.3 \quad(4)$ & $3.7 \quad(5)$ \\
\hline 2.4 Telephone consultation on patient's initiative & 14.0 & 27.1 & $18.7(25)$ \\
\hline E-mail on patient's initiative & $3.5 \quad(3)$ & $2.1 \quad(1)$ & $3.0 \quad(4)$ \\
\hline E-mail on transmural nurse's initiative & (3) & 0.0 & $2.2 \quad(3)$ \\
\hline Missing type of contact & $2.3 \quad(2)$ & $12.5 \quad(6)$ & $6.0 \quad(8)$ \\
\hline Number of contacts per patient & $N=86$ & $\mathrm{~N}=48$ & $\mathbf{N}=134$ \\
\hline Patients with zero to two contacts & $17.4 \quad(15)$ & $8.3 \quad(4)$ & $14.2(19)$ \\
\hline Patients with three to four contacts & $30.2(26)$ & 27.1 & $29.1(39)$ \\
\hline Patients with five or more contacts & 20.9 (18) & 52.1 & 32.1 (43) \\
\hline $\begin{array}{l}\text { Patients choosing to organise their care autonomously and } \\
\text { to contact the transmural nurse on their own initiative }\end{array}$ & $31.4(27)$ & $12.5 \quad(6)$ & $24.6 \quad(33)$ \\
\hline Type of contacts relative to total number of contacts & $\mathrm{N}=241$ & $\mathbf{N}=253$ & $\mathrm{~N}=494$ \\
\hline 1 Introduction of care before discharge & $23.2(56)$ & $14.2(36)$ & $18.6(92)$ \\
\hline 2.1 Telephone consultations on transmural nurse's initiative & $64.3(155)$ & $48.6(123)$ & $56.3(278)$ \\
\hline 2.2 Consultations in the rehabilitation centre after discharge & (7) & $18.6(47)$ & 10.9 (54) \\
\hline 2.3 Home visits & $0.4 \quad(1)$ & $2.8 \quad(7)$ & $1.6 \quad(8)$ \\
\hline 2.4 Telephone consultation on patient's initiative & $5.4(13)$ & 11.9 & $8.7 \quad(43)$ \\
\hline E-mail on patient's initiative & (3) & $0.4 \quad(1)$ & $0.8 \quad(4)$ \\
\hline E-mail on transmural nurse's initiative & (3) & 0.0 & $0.6 \quad(3)$ \\
\hline Missing type of contact & (3) & $3.6 \quad(9)$ & $2.4(12)$ \\
\hline
\end{tabular}

Although the transmural care protocol was not very conclusive with respect to the number of contacts and other activities the transmural nurses had to perform, it indicated an average of about six contacts during the first year after discharge (including the introduction of the care before discharge and five contacts after discharge). Only $32 \%$ of all patients received all the number of contacts indicated in the transmural care model and $43 \%$ of all patients had four contacts or less. The RCH transmural nurses had relatively more contacts with the patients than the DH transmural nurses. In DH the number of patient contacts was not influenced by the fact that the nurse of the day hospital was occasionally involved in the follow-up care of patients. From the start of the project patients discharged from their primary rehabilitation directly approached the transmural nurses in case of questions/problems. Patients who had been hospitalised twice or more sometimes 
consulted the nurse of the day hospital, nearly always because of pressure sores. In both centres the transmural nurses spent an average of about 22 minutes per patient contact, including administration. In $\mathrm{RCH}$ the transmural contacts continued more often for more than one year after discharge, compared with DH (in RCH, 19 patients still had contact with the transmural nurse after one year of discharge, in $\mathrm{DH}$, five patients).

Table 4 displays the number and types of health problems for which the transmural nurses applied interventions. Pressure sores were the most common health problem for which interventions were applied, followed by bowel and bladder problems. The percentage of patients suffering from pain, bladder and bowel problems was considerably higher in $\mathrm{RCH}$, as were the overall percentage of patients suffering of problems after discharge (DH: 47\%, $\mathrm{RCH}$ : 67\%) and the number of interventions per patient. The category 'other problems' included all kinds of both physical and psychosocial issues.

Table 4: The number and type of health problems for which interventions were applied

\begin{tabular}{|c|c|c|c|c|c|c|}
\hline \multirow[t]{3}{*}{$\begin{array}{l}\text { Problems for which } \\
\text { interventions were applied }\end{array}$} & \multicolumn{2}{|c|}{$\begin{array}{c}\mathrm{DH} \\
\mathrm{N}=86\end{array}$} & \multicolumn{2}{|c|}{$\begin{array}{c}\mathrm{RCH} \\
\mathrm{N}=48\end{array}$} & \multicolumn{2}{|c|}{$\begin{array}{c}\text { Total group } \\
\mathrm{N}=134\end{array}$} \\
\hline & patients & times & patients & times & patients & times \\
\hline & $\% \quad(n)$ & $\% \quad(n)$ & $\% \quad(n)$ & (n) & $\% \quad(n)$ & $\% \quad(n)$ \\
\hline Pressure sores & $22.1(19)$ & $31.5(29)$ & $29.2(14)$ & $36.2 \quad(59)$ & $24.6(33)$ & $34.5(88)$ \\
\hline Bowel problems & $11.6(10)$ & $20.7(19)$ & $25.0(12)$ & $14.1 \quad(23)$ & $16.4(22)$ & $16.5(42)$ \\
\hline Bladder problems & $9.3(8)$ & $13.0(12)$ & $25.0(12)$ & $9.8 \quad(16)$ & $14.9(20)$ & $11.0(28)$ \\
\hline Pain & $7.0(6)$ & $7.6 \quad(7)$ & 18.8 (9) & $8.6 \quad(14)$ & $11.2(15)$ & $8.2(21)$ \\
\hline $\begin{array}{l}\text { Facilities, equipment, housing } \\
\text { (e.g.: problems to arrange them } \\
\text { or not having them) }\end{array}$ & $5.8 \quad(5)$ & $6.5(6)$ & 6.3 (3) & $3.7 \quad(6)$ & $6.0 \quad(8)$ & $4.7(12)$ \\
\hline $\begin{array}{l}\text { Difficulties to tune care to the } \\
\text { needs }\end{array}$ & $7.0 \quad(6)$ & $7.6(7)$ & 8.3 (4) & $3.1 \quad(5)$ & $7.5(10)$ & $4.7(12)$ \\
\hline Other problems & $12.0 \quad(8)$ & $13.0(12)$ & $45.8(22)$ & $24.5 \quad(40)$ & $22.4(30)$ & $20.4(52)$ \\
\hline Total & $46.5(40)$ & $100.0(92)$ & $66.6(32)$ & $100.0(163)$ & $53.7(72)$ & $100.0(255)$ \\
\hline
\end{tabular}

Table 5 displays the number and type of interventions the transmural nurses applied. Instruction, advice and health education was the most frequently used intervention in both centres. According to the notes on the registration forms of all patient contacts, psychosocial support was given considerably more often in RCH compared to DH. In $81 \%$ of all cases the transmural nurses were able to apply an intervention themselves. In $19 \%$ they referred the patients to other caregivers for advice. In case they had to refer patients, they mostly referred them to caregivers from the rehabilitation centre. 
Table 5: The number and type of interventions that were applied

\begin{tabular}{|c|c|c|c|c|c|c|}
\hline \multirow[t]{3}{*}{ Type of interventions } & \multicolumn{2}{|r|}{$\begin{array}{r}\mathrm{DH} \\
\mathrm{N}=86\end{array}$} & \multicolumn{2}{|r|}{$\begin{array}{r}\mathrm{RCH} \\
\mathrm{N}=48\end{array}$} & \multicolumn{2}{|c|}{$\begin{array}{r}\text { Total group } \\
\mathbf{N}=134\end{array}$} \\
\hline & patients & times & Patients & times & patients & times \\
\hline & $\% \quad(n)$ & $\% \quad(n)$ & $\% \quad(n)$ & (n) & $\% \quad(n)$ & $\% \quad(n)$ \\
\hline $\begin{array}{l}\text { Instruction, advice, health } \\
\text { education }\end{array}$ & $45.3(39)$ & $71.3 \quad(77)$ & $66.7(32)$ & 54.1 (99) & $53.0(71)$ & $60.5(176)$ \\
\hline Psychosocial support & $2.3(2)$ & $2.8 \quad(3)$ & $35.4(17)$ & $24.0 \quad(44)$ & $14.2(19)$ & $16.2(47)$ \\
\hline $\begin{array}{l}\text { Advice for consultation caregi- } \\
\text { vers from the rehab. centre }\end{array}$ & $14.0(12)$ & 13.9 & $20.8(10)$ & 11.5 (21) & $16.4(22)$ & $12.4(36)$ \\
\hline $\begin{array}{l}\text { Advice for consultation } \\
\text { primary care professionals }\end{array}$ & $9.3(8)$ & 7.4 & $22.9(11)$ & $6.6 \quad(12)$ & $14.2(19)$ & $6.9 \quad(20)$ \\
\hline Other interventions & $5.8 \quad(5)$ & 4.6 & 8.3 (4) & $3.8 \quad(7)$ & $6.7(9)$ & $4.1 \quad(12)$ \\
\hline Total & $46.5(40)$ & $100.0(108)$ & $66.6(32)$ & $100.0(183)$ & $53.7(72)$ & $100.0(291)$ \\
\hline
\end{tabular}

\section{Activity 3 Peer meetings}

There were no peer meetings organised in either rehabilitation centre, although the nurses felt that patients would have appreciated it.

In the second half of table 1 (activities 4 to 9) there are listed the activities to promote continuity of care. Compared to the individual support of patients, little time was spent on the activities to promote continuity of care.

\section{Activity 4 The introduction of the care compass}

The care compass was introduced to almost all patients before discharge, but the transmural nurses felt that patients often did not use it in the way it intended. Patients for instance seldom asked the members of the rehabilitation team to write down personal advice.

\section{Activity 5 Telephone consulting hours for professional primary caregivers}

Primary care professionals relatively seldom undertook initiatives to contact the transmural nurses during the telephone consulting hours in case of questions and/or problems.

In both rehabilitation centres the transmural nurses had 19 contacts with primary care professionals, mostly community nurses, because of pressure sores, bladder and/or bowel problems in 11 patients.

\section{Activity 6 Transfer of care meetings}

'Transfer of care meetings' were not organised as described in the transmural care model. In the case of complex care, 'transfer of care' meetings were organised by nurses of the clinical rehabilitation team, as they had been before the start of the project. In contrast to the proposed 'transfer of care' meetings in the transmural care model, these meetings took place in the rehabilitation centre (instead of at the patient's home) and only the nursing discipline was involved (instead of all professional primary care disciplines involved with the patient after discharge). 


\section{Activity 7 Informing primary care professionals about the transmural care}

At the start of the project several community nursing services, regularly involved in the care for SCI patients, were informed about the project. After that, in both rehabilitation centres information flyers about the transmural care were sent to general practitioners and community nurses in the case of discharge. The patients were also motivated themselves to inform their caregivers after discharge about the care.

\section{Activity 8 Presentations to primary care professionals}

In both rehabilitation centres the transmural nurses gave about three presentations about SCI to community nursing services. In DH these presentations were at the request of the patients themselves, since they experienced a lack of knowledge regarding SCI. In RCH the presentations had a more informative character regarding the content of the care and the specific care needs of patients with SCI.

\section{Activity 9 Presentations to the rehabilitation team}

Presentations to the rehabilitation team to inform them about experiences with patients after discharge and to make proposals for improvements in the clinical care on the basis of these experiences occurred only very occasionally. This kind of information was mostly given informally. According to the experiences of the transmural nurses, awareness of the importance of follow-up care of both rehabilitation teams increased during the intervention period, as did their critical attitude towards the content of the clinical care. In DH this increase became concrete with the start of a project to improve the discharge preparation of patients.

Beside the activities of the transmural care model, the nurses also performed some other activities, such as giving a presentation to nurses in hospitals about SCI, gaining additional knowledge (i.e. by means of visiting conferences), and giving advice to patients, who had already been discharged for several years (i.e. patients who were not included in the research population). Especially the RCH transmural nurse paid a lot of attention to this patient group.

\section{Enabling factors and barriers for implementation}

For each aspect of the transmural care model, the transmural nurses mentioned several enabling factors and barriers for implementation, which could be grouped as follows:

\section{(1) Factors related to the level of the individual professional}

The knowledge, skills and competencies of the transmural nurses and the support to train these appeared to be important, i.e. knowledge regarding SCI and the organisation of the primary health care system, skills and competencies regarding patient-centred care, conversation techniques, networking, and being able to serve as a liaison, mediator and a pioneer. Combining the role of transmural nurse and member 
of the clinical nursing team also demanded certain competencies. The fact that the transmural nurses were very eager to learn and enthusiastic helped the implementation. Several transmural nurses also experienced a need for education during the course of the intervention period to train the competencies mentioned. The three-monthly meetings and the interviews with members of the research team were helpful in this respect. It helped the nurses to reflect on their activities, and to develop themselves regarding conversation techniques and to give care in a more patientcentred way. Too great a feeling of responsibility for the well-being of patients resulting in bringing up solutions and having a 'caring' attitude, sometimes hindered the transmural nurses in their work, especially in $\mathrm{RCH}$.

\section{(2) Factors related to the organisational and financing level}

At DH there was a stimulus to refer patients to the SCI nurse of the day hospital if nursing advice or instruction was needed after discharge. Such a procedure hindered the transmural nurses. This organisational structure had already been established for years, and, besides, the rehabilitation centre was able to claim expenses for those consultations (and not for the more 'preventive' consultations). Another limitation was caused by the fact that the members of both rehabilitation teams (except for the physiatrist) did not have the time or responsibility to pay attention to patients after discharge except when day hospital care was indicated. On the other hand, the transmural nurses mentioned that the combination of being a transmural nurse, a nurse at the spinal cord department, and a member of the rehabilitation team increased the possibilities to confer if problems arose that were outside the nursing scope and to give feedback about the transmural care (and the implications).

According to the transmural nurses, important working conditions appeared to be having a computer, a mobile phone and a consultation room at one's disposal, a work schedule in harmony with the transmural care, and being able to spend eight hours on the transmural care on one day. Especially during the first 10 months of the intervention period lack of these facilities hindered the performance of the $\mathrm{DH}$ transmural nurses. Besides, all nurses found the workload of the transmural care model far too high to accomplish in eight hours per week, which was the reason for the first transmural nurse at $\mathrm{RCH}$ to quit the project. E-mail contact and sending digital photos by email in case of pressure sores sometimes helped the transmural nurses to give support.

\section{(3) Factors related to the social context (the opinion of colleagues, managers and other}

\section{professionals involved with the care)}

It appeared very important that the intervention protocol matched the vision the centres had on rehabilitation. At $\mathrm{DH}$ the managers of the rehabilitation team instructed the transmural nurse to be very reserved regarding some transmural care activities (like home visits, consultations in the rehabilitation centre, and organising peer meetings). Partly, in their opinion, some activities were judged to be too 
patronising. Compared with $\mathrm{RCH}$, it was more strongly felt at $\mathrm{DH}$ that the patient should take responsibility for his/her own care, and should take the initiative to contact the transmural nurse if necessary. In their opinion the transmural nurses should not take the initiative for patient contacts.

\section{Experienced strength and weakness of the transmural care model}

In general the transmural nurses did not experience many weaknesses in the content of the transmural care model. The most important weakness was that there was not enough time to put all the activities into practice. Furthermore they experienced a certain tension between stimulating patients to organise their own care on the one hand, and protocol prescriptions on the other hand. Initiating contacts with patients on set moments and using an assessment list sometimes made the nurses feel they were patronising patients too much.

According to the transmural nurses, the strength of the transmural care lies in the possibility to give support to patients and primary care professionals after discharge. They also felt that their support was appreciated and that it created an opportunity to detect problems and to intervene in an early stage. The use of the assessment list contributed to the detection of problems that many patients more or less accepted as being normal when they had an SCI. The transmural nurses had the idea that they had been able to prevent re-admissions because of pressure sores. They also strongly believed that their advice regarding bowel problems increased the quality of life for several patients. Beside the support to patients after discharge, they were also able to use their experiences in their clinical activities. It helped them to prepare patients better for discharge and to communicate the implications of their experiences to the rehabilitation team.

\section{Discussion}

In this paper, we analysed the implementation of a transmural care model in two rehabilitation centres. We observed that, although all transmural nurses spent most of their time on the individual support of patients after discharge, only $32 \%$ of all patients received the number of contacts indicated in the protocol (6 contacts). At DH the number of contacts and the variation in types of contacts were less compared with $\mathrm{RCH}$. Pressure sores were the most common health problem for which interventions were applied, followed by bladder and bowel problems. The percentage of patients suffering from problems after discharge and the number of interventions per patient were lower in $\mathrm{DH}$.

Compared to the individual support of patients, in both rehabilitation centres little time was paid to activities to promote continuity of care (activities 4-9 in table 1). This contributes to our conclusion that the transmural care model was not implemented 
completely as planned, with a clear difference between the two centres. Possible explanations for these differences may be found in differences in the two study populations, and in the results regarding enabling factors and barriers. When comparing the study populations, the most eye-catching difference concerned the size. The fact that the transmural nurses of DH had to serve more patients in the same time certainly will have influenced the number and type of contacts after discharge. Sometimes, for instance, it was desirable, but in the nurse's opinion not feasible to visit a patient at home. It was also notable that there were significantly more patients in $\mathrm{DH}$ who let the transmural nurse know that they wished to organise their care autonomously and thus decided not to use the transmural care intensively. This last difference possibly might be caused by differences in: the 'natural' level of assertiveness of patients in the two different Dutch regions; and the attention the rehabilitation centres/transmural nurses have for training the patients to take responsibility for their own care. Comparison of the results regarding enabling factors and barriers, especially the vision on rehabilitation, the organisational and financing structure of the rehabilitation centre, and the working conditions, reveals that the DH transmural nurses experienced many more barriers compared with the RCH nurses.

Taking these findings into account, we recommend improving and further implementing the transmural care model. In our opinion and in the opinion of the transmural nurses, the combination of support of patients after discharge, support of and cooperation with primary care professionals, and feedback of experiences to the clinical rehabilitation teams, creates many opportunities to prevent and treat health problems and to improve the quality of care. To improve the model, it is most important to tailor the care more to the patients' needs. Instead of holding to six moments of contact during the first year of discharge, there should be more dialogue between the patients and the rehabilitation professionals about what, how and when. Secondly, the target population should be extended, since people who have already been discharged for several years, regularly experience health problems. In order to improve the implementation of this or other interventions in day-to-day rehabilitation practice, our implementation leads us to the following recommendations:

(1) The individual professionals should be provided with enough education on the competencies needed in their new function (regarding patient-centred care, conversation techniques, networking and the ability to serve as a liaison, mediator and pioneer).

(2) With respect to the organisational and financing level (e.g. availability of facilities and finances), enough time should be available to put the intervention into practice. In addition, the intervention should be embedded in the local organisational structure. Moreover, it should also be embedded in the payment system. In this respect we recommend that the effectiveness and the costs of the intervention are evaluated. 
(3) With regard to the social context, attention should be paid to creating support for the intervention at both managerial level and the level of professionals indirectly involved with the implementation.

A limitation of our study was, in our opinion, that the results concerning the content of the patient contacts were based on the nurses' records and not on a full record of what had been said and done. The nurses often may not have recorded giving psychosocial support as a separate intervention. Therefore, the number of problems and interventions described may be an underestimation of the actual number of problems and interventions applied. Despite this, and although our study was small and only included the experiences of the transmural nurses (and not those of the patients and other caregivers), our results may help other health care professionals and researchers who wish to use the transmural care model or to develop and implement a similar intervention. In line with Grol and Wensing [17], we found enabling factors and barriers for implementation at three levels: (1) the level of the individual professional (e.g. competencies, attitude and motivation), (2) the organisational and financing level (e.g. availability of facilities and finances), and (3) the social context (the opinion of colleagues, managers and other professionals involved with the care). We also found that the nursing discipline can have important input in the follow-up care of patients with spinal cord injuries. After all, pressure sores, bladder and bowel problems evidently fall in the scope of the nursing discipline. In our opinion, it is also possible to extend the transmural care model with other types of care, such as telemedicine. In our study, one method of telemedicine, i.e. using digital photos, was used spontaneously in case of pressure sores, but the literature reports more applications of telemedicine in the care for patients with SCI [18-23].

Finally, we would like to encourage health care professionals and researchers to share their implementation experiences, with regard to follow-up care innovations for people with SCI, in order to be able to improve the care for such people in the longterm. Our review [15] revealed only a small number of follow-up care innovations described in literature, in which little attention is paid to the evaluation.

\section{Acknowledgements}

We gratefully acknowledge the commitment of the transmural nurses, especially Conny di Bartolomeo and Rudy Sonsma.

The study was supported by: ZonMw, the Netherlands Organisation for Health Research and Development, Rehabilitation programme, grant no. 01432 030; and the health care insurance companies Agis and CZ. 


\section{References}

[1] National Board of Healthcare / Board of Hospital Provisions. Transmural Somatic Healthcare (in Dutch). Zoetermeer: Council for Public Health and Health care; 1995.

[2] Rosendal H. Comparative cohort studies in transmural care. Utrecht: Utrecht University; 2002.

[3] Temmink D, Francke AL, Kerkstra A, Abu-Saad HH. Dutch transmural nurse clinics for chronic patients: a descriptive study. Patient Education and Counseling 2000; 39(2-3): 177-84.

[4] Kodner DL. Following the logic of long-term care: toward an independent, but integrated sector. International Journal of Integrated Care (www.ijic.org) 2004; 4(1).

[5] Kodner DL, Spreeuwenberg C. Integrated care: meaning, logic, applications, and implications - a discussion paper. International Journal of Integrated Care (www.ijic.org) 2002; 2(3).

[6] Gröne O, Garcia-Barbero M. Integrated care. A position paper of the WHO European office for integrated care services. International Journal of Integrated Care (www.ijic.org) 2001; 1(3).

[7] Bloemen-Vrencken JHA, Post MWM, Hendriks J, De Reus ECE, de Witte LP. Health problems found in persons with spinal cord injury living in the Netherlands. Disability and Rehabilitation 200; 27(22): 1381-1389.

[8] Anson CA, Shepherd C. Incidence of secondary complications in spinal cord injury. International Journal of Rehabilitation Research 1996; 19(1): 55-66.

[9] Bloemen-Vrencken JHA, de Witte LP. Post-discharge nursing problems of spinal cord injured patients: on which fields can nurses contribute to rehabilitation? Clinical Rehabilitation 2003; 17(8): 890-8.

[10] Cox RJ, Amsters DI, Pershouse KJ. The need for a multidisciplinary outreach service for people with spinal cord injury living in the community. Clinical Rehabilitation 2001; 15(6): 600-6. 
[11] Ernst JL, Thomas LM, Hahnstadt WA, Piskule AA. The self-identified longterm care needs of persons with SCI. Spinal Cord Injury Psychosocial Process 1998; 1: 127-132.

[12] Glidden MM. Spinal cord injury and case management. Topics in Spinal Cord Injury Rehabilitation 1999; 4 (4): 16-23.

[13] Mattson J. Case management: a historical and future perspective of its influence on outcome for persons who have sustained spinal cord injury. Topics in Spinal Cord Injury Rehabilitation 1999; 4 (4): 30-37.

[14] Rawl SM, Easton KL, Kwiatkowski S, Zemen D, Burczyk B. Effectiveness of a nurse-managed follow-up program for rehabilitation patients after discharge. Rehabilitation Nursing 1998; 23(4): 204-9.

[15] Bloemen-Vrencken JH, de Witte LP, Post MW. Follow-up care for persons with spinal cord injury living in the community: a systematic review of interventions and their evaluation. Spinal Cord 2005; 43: 462-475.

[16] Haastregt van J. Preventing falls and mobility impairments in eldery people living in the community. Maastricht: Maastricht University; 2002.

[17] Grol R, Wensing M. Implementation. Effective change in patient care (in Dutch: Implementatie. Effectieve verandering in de patientenzorg.). Maarssen: Elsevier; 2001.

[18] Mathewson C, Adkins VK, Lenyoun MA, Schmidt AM, Jones ML. Using telemedicine in the treatment of pressure ulcers. Ostomy / Wound Management 1999; 45(11): 58-62.

[19] Mathewson C, Adkins VK, Jones ML. Initial experiences with telerehabilitation and contingency management programs for the prevention and management of pressure ulceration in patients with spinal cord injuries. Journal of Wound, Ostomy, and Continence Nursing 2000; 27(5): 269-71.

[20] Phillips VL, Temkin AJ, Vesmarovich SH, Burns R. A feasibility study of video-based home telecare for clients with spinal cord injuries. Journal of Telemedicine and Telecare 1998; 4(4): 219-23.

[21] Phillips VL, Temkin A, Vesmarovich S, Burns R, Idleman L. Using telehealth interventions to prevent pressure ulcers in newly injured spinal cord injury patients post-discharge. Results from a pilot study. International Journal of Technology Assessment in Health care 1999; 15(4): 749-55. 
[22] Phillips VL, Vesmarovich S, Hauber R, Wiggers E, Egner A. Telehealth: reaching out to newly injured spinal cord patients. Public Health Reports 2001; 116(Suppl 1): 94-102.

[23] Weinel D. The Sunshine Network Teleconsultation Initiative for SCI Veterans in Community Settings. Spinal Cord Injury Nursing 2000; 17(1): 22-3. 



\section{Effects of a Dutch follow-up} care model for spinal cord injured patients on health problems, re-admissions, and quality of care

Submitted for publication

Jos Bloemen-Vrencken, Luc de Witte, Marcel Post, Cees Pons, Floris van Asbeck, Luc van der Woude, and Wim van den Heuvel 


\section{Abstract}

Objective: To evaluate whether a Dutch follow-up care model reduces health problems and re-admissions, and improves the experienced quality of follow-up care of people with spinal cord injury (SCI) living in the community.

Design: Quasi-experiment with 12 months of follow-up.

Setting: Eight rehabilitation centres in the Netherlands.

Subjects: Patients who received transmural care in two 'experimental' rehabilitation centres were compared with a matched sample of patients having received 'usual follow-up care' in six other rehabilitation centres.

Intervention: The core component of the transmural care consists of a transmural nurse, who 'liaises' between people with SCI living in the community, primary care professionals and the rehabilitation centre. The transmural care model provides activities to support people with SCI and their family/partners and activities to promote continuity of care.

Main measures: The prevalence of pressure sores and urinary tract infections; the number and duration of re-admissions to hospital and rehabilitation centre due to pressure sores, bladder and bowel problems; the experienced quality of follow-up care.

Results: One year after discharge, no differences were found in health problems, readmissions to hospital and rehabilitation centre, and the experienced quality of followup care between the intervention and the usual follow-up care group.

Conclusion: Because health problems and re-admissions occur frequently after discharge, alternative strategies should be developed and evaluated. 


\section{Introduction}

People with spinal cord injury (SCI) who are living in the community often have health problems, such as bladder and bowel problems, spasms, pain, and pressure sores [1]. In the Netherlands, after discharge from inpatient rehabilitation, daily medical and nursing care for spinal cord injured patients is transferred from the rehabilitation centre to primary health care. However, SCI is a rare condition with an incidence of traumatic SCI of 10.4 per million per year who survive the acute stage in the Netherlands [2]. Consequently, primary health care professionals only sporadically see patients with SCI in their practice. Therefore, these professionals might not have much opportunity to expand their knowledge about the specific care these patients require. The professionals in rehabilitation centres, on the other hand, are limited in their possibilities to give follow-up care, due to the limited payment they receive from health service insurers for this kind of care. Consequently, until recently, life-long care for people with SCI was still ill-developed in the Netherlands. The need for effective interventions aimed at the prevention and early treatment of health problems after discharge has been frequently reported [1, 3-8].

We developed a transmural care model for people with SCI after discharge from rehabilitation to support patients and professionals involved in making the transfer from inpatient rehabilitation to primary health care. Transmural care refers to care given 'through the (virtual) walls' of the existing health care system and is most often directed toward bridging the gap between different levels of care providers [9]. The transmural care concept is not often used outside the Netherlands [10]. However, problems with continuity of care are not specific to the Netherlands, but occur in many other countries too $[11,12]$. Here, integrated care is a more common term which refers to the integration of healthcare, social care and related services [11-13]. It is more comprehensive than transmural care since transmural care generally does not include the whole care process of patients and is focused on one or two crucial transition steps between different types of healthcare providers [9].

The primary goal of our transmural care model was to reduce the number and severity of health problems. This quasi-experimental study aimed to determine whether people receiving this transmural care had better outcomes than people receiving 'usual' follow-up care. Pressure sores, bladder and bowel problems frequently occur and are important causes for re-admission in hospital and rehabilitation centres [14-16]. It was expected that the transmural care model could positively influence their prevention and treatment. Primary outcomes were the number of pressure sores and urinary tract infections, and the number of readmissions in hospital and rehabilitation centre due to pressure sores, bladder and bowel problems in the first year after discharge from inpatient rehabilitation. The 
secondary outcome was the patient's satisfaction with care, since it is recognised that the patient's perspective is as important and valid as the clinician's perspective in monitoring health care outcomes [17-20].

\section{Methods}

\section{Design}

The intervention study has a quasi-experimental longitudinal design. Participants were recruited from the Dutch research programme 'Physical strain, work capacity, and mechanisms of restoration of mobility in the rehabilitation of people with spinal cord injuries' (www.fbw.vu.nl/onderzoek/A4zon/ZONenglish, [21]). Patients who received the transmural care in two 'experimental' rehabilitation centres (De Hoogstraat and Hoensbroeck) were compared with patients who received 'usual follow-up care' in six other rehabilitation centres. For each subject in the experimental group, a subject in the control group was selected who was similar with regard to level and motor completeness of the SCI, gender and age. Effects of the transmural care programme were evaluated by comparison of outcomes in both groups one year after discharge from inpatient rehabilitation.

\section{Patients}

The transmural care could be used for at least one year after discharge by all spinal cord injured patients in the two 'experimental' centres, who had been discharged from January 2002 until July 2003. The effectiveness study, however, only included patients who were also included in the national research programme 'Physical strain, work capacity, and mechanisms of restoration of mobility in the rehabilitation of persons with spinal cord injuries'. For the patients to be included in the effectiveness study, the same inclusion criteria as in the above-mentioned research programme were applied:

- 18-65 years of age;

- SCI, both tetraplegia and paraplegia, ASIA impairment scale A-D, in some way wheelchair dependent;

- the injury itself is stable (no progressive disease);

- receiving rehabilitation treatment for the first time (no re-admissions).

Inclusion of 60 'experimental' patients and 60 'control' patients was expected.

\section{Intervention}

The intervention and usual follow-up care group differed with respect to the intensity of follow-up care given by the rehabilitation centre after conclusion of clinical rehabilitation. Day-to-day medical and nursing care in both groups is usually given by primary care professionals. 


\section{Usual follow-up care group}

The participants in the usual follow-up care group had the possibility to make use of periodical outpatient visits to the rehabilitation doctor of their rehabilitation centre. During these visits a comprehensive assessment of functioning is performed and, if necessary, interventions are applied or other forms of support are given.

\section{Intervention group}

In addition to the usual follow-up care by the rehabilitation doctor of the rehabilitation centre, the participants in the intervention group had the possibility to make use of transmural care, until at least one year after discharge. The core component of the transmural care consists of a transmural nurse as liaison between people with SCI living in the community, primary care professionals and the rehabilitation centre. The transmural nurse is member of the clinical rehabilitation team (she also works as a nurse at the spinal cord unit) and is engaged for eight hours a week to perform four main tasks:

- to support people with SCI and their partner/family with their health problems, which come within the scope of the nursing discipline;

- to support primary care professionals with the specific care for people with SCI;

- to promote continuity of care between primary care professionals and the rehabilitation team;

- to give feedback and take initiatives for improvements in care to the rehabilitation team, based on the experiences with patients.

Table 1 shows the job description for the transmural nurses, containing activities to support people with SCI and their family/partners and activities to promote continuity of care. A detailed description of the project is given elsewhere [22]. A process evaluation was performed to monitor the level of implementation of transmural care in both experimental centres [22]. Although the transmural nurses spent most of their time on the individual support of patients after discharge (activity 1-2 in table 1), only $48 \%$ of all patients received the number of contacts indicated in the protocol ( 6 contacts). On average there were 4.3 contacts per patient in the first year after discharge. In one of the 'experimental' rehabilitation centres the number and the variation in types of contacts were less compared with the other 'experimental' rehabilitation centre. The number of interventions per patient were also different in the two 'experimental' rehabilitation centres. Pressure sores were the most common health problem for which interventions were applied, followed by bladder and bowel problems. On average the transmural nurses applied 1.7 intervention per patient, 8 patients didn't receive any intervention. Compared to the individual support of patients, in both rehabilitation centres, little time was paid to activities to promote continuity of care (activities 4-9 in table 1). 
Table 1 Job description of the transmural nurses

\section{Activities to support people with SCI}

1 To introduce the transmural care before discharge from clinical rehabilitation and to explore the needs of follow-up care, and to make agreements about this (Patients with SCI are free to decide whether or not to make use of the transmural care).

2 To give advice and support after discharge from clinical rehabilitation depending on the needs and the complexity of care by means of (at 3 weeks, 3, 6, 9 and 12 months after discharge):

2.1 telephone consultations on the initiative of the transmural nurse;

2.2 consultations in the rehabilitation centre (in addition to the periodical outpatient visit to the rehabilitation doctor);

2.3 home visits in case of health problems;

2.4 telephone consulting hours (consultation of the transmural nurse on the initiative of people with SCI).

3 To organise peer meetings after discharge.

Activities to promote continuity of care

4 To introduce the so-called 'care compass'; a little book which contains individual advice of caregivers to the patient, an overview of health services, and info sheets concerning several consequences and complications of SCI. The patient 'owns' the care compass, but it is also meant to support the caregiving by family/partners and professional caregivers.

5 To organise telephone consulting hours for primary care professionals.

6 To organise a meeting at the patient's home before discharge with the patient, the primary care professionals of all care disciplines involved with the care after discharge, and the transmural nurse to transfer care, in case of complex care.

7 To inform primary care professionals about the transmural care (content and accessibility).

8 To organise presentations to primary care professionals to inform them about SCI, prevention of secondary impairments and the specific care people with SCI need.

9 To organise presentations to the rehabilitation team to inform them about experiences with people with SCI after discharge and to make proposals for improvement in the clinical care, on the basis of the experiences with patients.

Before the start of our intervention and every year afterwards, we monitored the contrast in follow-up care between the experimental and control centres by interviewing their rehabilitation doctors and/or managers about the content and developments regarding their follow-up care. Subgroup-analyses were performed in case the contrast decreases between the intervention and usual follow-up care groups regarding the follow-up care.

\section{Outcome measures}

\section{Primary outcome measures}

Primary outcome measures were:

- the prevalence of pressure sores and urinary tract infections reported during the first year after discharge;

- the number and duration of re-admissions to hospital and rehabilitation centre due to pressure sores, bladder and bowel problems in the first year after discharge. 


\section{Secondary outcome measure}

Secondary outcome measure was the experienced quality of follow-up care. The patients were asked to judge 15 items regarding the quality, continuity and coordination of care. Per item they had to indicate whether this aspect of follow-up care in the first year of discharge was either open for improvement or good. Examples of these items were:

- the degree to which the professional care givers can be reached by phone;

- the knowledge professional care givers have regarding SCI;

- the degree to which professional care givers stimulate me to organise my care as autonomously as possible and desired;

- the degree to which the care meets my needs;

- the degree to which different professional care givers harmonise their care.

The intervention started in January 2002 and ended in June 2004. Participants were interviewed and received self-administered questionnaires at discharge and one year after discharge.

\section{Statistical analysis}

Descriptive analyses were performed to describe the outcomes. Data analysis focused on comparison of the intervention group with the usual follow-up care group. Differences regarding the occurrence of health problems in the intervention and usual follow-up care groups were tested with the Fisher exact test, given the nature of the outcome measures $(\mathrm{p}<0.05)$.

\section{Results}

\section{Participants}

Figure 1 shows the flow of the participants through our intervention study. Overall, 149 people met the inclusion criteria. The transmural care group consisted of 39 people and the usual follow-up care group consisted of 110 people. Six people died during the 12 months of follow-up, five were excluded from follow-up since they were not dependent on a wheelchair anymore, and four were not able to visit the rehabilitation centre for follow-up measurements due to secondary complications. Non-medical reasons for withdrawal were lack of motivation $(n=14)$ and address unknown $(\mathrm{n}=7)$. There were 31 participants who received the intervention and who were followed up at 12 months. There were 84 participants with follow-up measurements in the usual follow-up care group. Matching was applied with regard to the level and motor completeness of the injury, gender and age. Twenty-eight participants of the intervention group (90.3\%) were matched to participants of the control group within five years of age and same sex and same level and motor 
completeness of the injury. For two matched pairs of respondents age differed more than five years. Another matched pair of respondents differed regarding the level of tetraplegia and age.

Figure 1 Flow of participants through this intervention study

\begin{tabular}{|c|c|}
\hline \multicolumn{2}{|c|}{ Met inclusion criteria $(n=149)$} \\
\hline Received intervention $(\mathrm{n}=39)$ & Received usual follow-up care $(n=110)$ \\
\hline Followed up at 12 months $(n=31)$ & Followed up at 12 months $(\mathrm{n}=84)$ \\
\hline 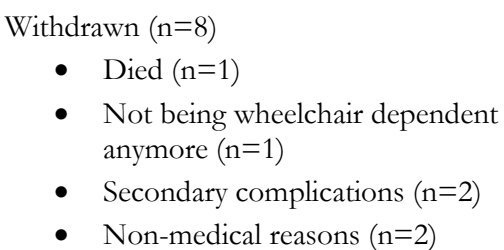 & $\begin{array}{l}\text { Withdrawn }(\mathrm{n}=26) \\
\text { - } \text { Died }(\mathrm{n}=5) \\
\text { - } \text { Not being wheelchair dependent } \\
\text { anymore }(\mathrm{n}=2) \\
\text { - } \\
\text { - } \\
\text { Secondary complications }(\mathrm{n}=2) \\
\text { Nonedical reasons }(\mathrm{n}=17)\end{array}$ \\
\hline $\begin{array}{l}\text { Completed quasi-experiment } \\
(\mathrm{n}=31)\end{array}$ & $\begin{array}{l}\text { Completed quasi-experiment } \\
\text { (1) total control group }(n=84) \\
\text { (2) matched control group }(n=31)\end{array}$ \\
\hline
\end{tabular}

Table 2 shows the general characteristics of the intervention group and the matched usual follow-up care group.

Table 2 Subject characteristics

\begin{tabular}{lrr}
\hline & Transmural care group & Matched control group \\
N= & $\mathbf{N 1}$ \\
\hline Age, mean (yrs) [SD] & $37.8(13.8)$ & $36.1(13.6)$ \\
Men (N) & 24 & 24 \\
Level and type of injury (N) & & \\
Complete tetraplegia (C1-C5) & 2 & 2 \\
Incomplete tetraplegia (C1-C5) & 1 & 2 \\
Complete tetraplegia (C6 - T1) & 5 & 5 \\
Incomplete tetraplegia (C6 - T1) & 5 & 4 \\
Complete paraplegia & 15 & 15 \\
Incomplete paraplegia & 3 & 3 \\
Cause of injury (N) & & 26 \\
Traumatic & 27 & 5 \\
Non-traumatic & 4 & $294.1(168.2)$ \\
Average clinical rehabilitation (days) [SD] & $270.7(123.6)$ & \\
\hline
\end{tabular}




\section{Outcomes}

Table 3 shows the prevalence of urinary tract infections and pressure sores during the first year of discharge. The prevalence of these problems was not significantly different in the two study groups. In addition there were no significant differences between the groups regarding re-admission rate in hospital or rehabilitation centre due to pressure sores, bladder and bowel problems in the first year after discharge (table 4). There were also no significant effects found on the prevalence of spasms, pain, oedema, respiratory tract infections, autonomic dysreflexia, low blood pressure, and increasing weight.

Considerably more participants in the intervention group $(n=29)$ gave their opinion regarding the quality of follow-up care (usual follow-up care group: $n=22$ ). The experienced quality of follow-up care was not significantly different in the two study groups. In the intervention group on average 4.2 quality of care items out of 15 were judged as being open for improvement. In the usual follow-up care group this was 5.4.

There were also no significant differences in the outcome measures between the intervention group and the total usual follow-up care group $(\mathrm{n}=84)$.

Table 3 Prevalence of health problems during the first year after discharge

\begin{tabular}{lrr}
\hline & $\begin{array}{r}\text { Transmural care group } \\
\mathbf{N =} \mathbf{3 1}\end{array}$ & $\begin{array}{r}\text { Matched control group } \\
\mathbf{N}=\mathbf{3 1}\end{array}$ \\
\hline Urinary tract infections (n) & 13 & 15 \\
Pressure sores (n) & 13 & 14 \\
Pressure sores per location (n) & & \\
Heel & 2 & 5 \\
Ankle & 2 & 0 \\
Hip & 0 & 0 \\
Buttock & 5 & 3 \\
Coccyx & 6 & 4 \\
Other location & 3 & 4 \\
Bed rest needed due to pressure sores & 9 & 5 \\
Bed rest due to pressure sores, mean & & $(37.2)$ \\
[days] (SD) & $(49.9)$ & \\
Grade of pressure sores (n) & & 2 \\
Grade I & 6 & 6 \\
Grade II & 7 & 2 \\
Grade III & 5 & 64.8 \\
Grade IV & 0 & \\
\hline
\end{tabular}

During the intervention period, three out of six 'usual follow-up care' rehabilitation centres extended their follow-up care, and although the content of those follow-up programmes differed from our intervention, some components showed similarities. However, subgroup analyses did not show differences in outcomes between the 
intervention group and participants who did not make use of follow-up care innovations in the usual care rehabilitation centres.

Table 4 Re-admissions in the first year after discharge

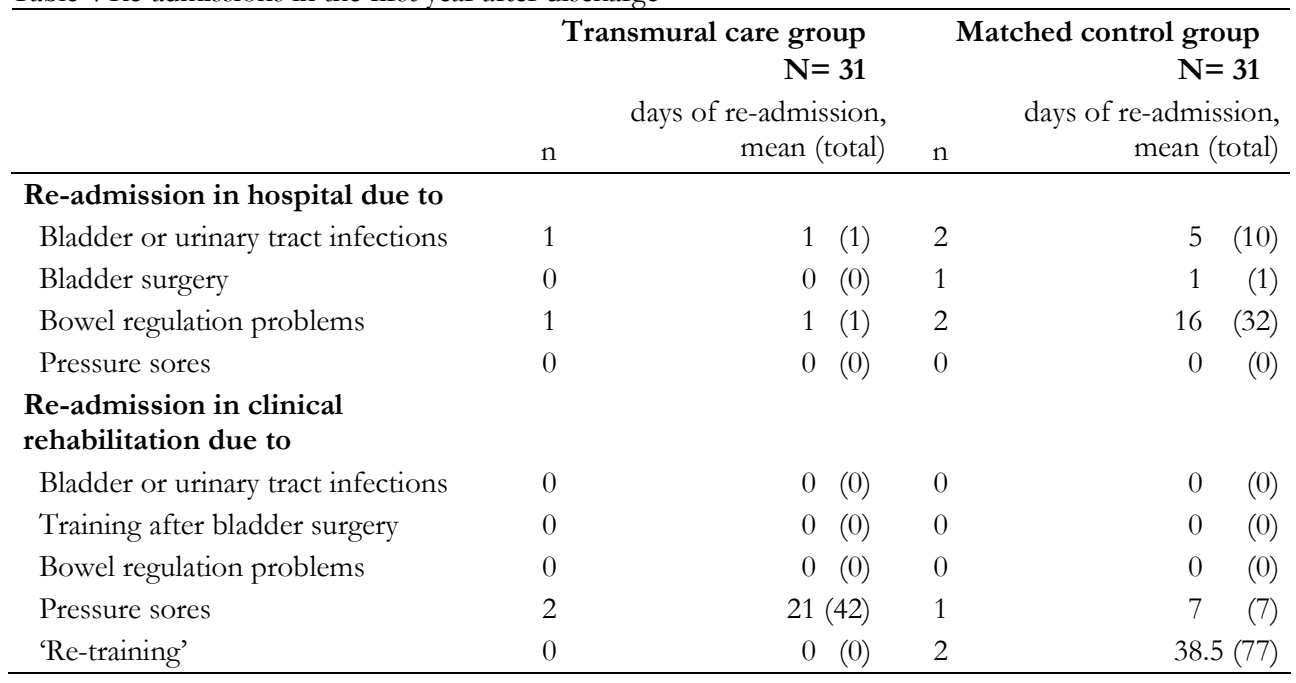

\section{Discussion}

This quasi-experiment showed that transmural care for people with SCI did not reduce the number of health problems and re-admissions to hospital or the rehabilitation centre due to these health problems. Furthermore, the transmural care did not improve the quality of follow-up care as perceived by the patients.

There may be several explanations for not finding our intervention to be effective. Firstly, the process evaluation showed that the transmural care was not fully implemented as planned [22]. Although the transmural nurses spent most of their time on the individual support of patients after discharge (activity 1-2 in table 1), the number of contacts and interventions being applied in the first year after discharge did not meet our expectations (the protocol indicated six contacts). There also was a clear difference in implementation in the two rehabilitation centres. In one centre the number and the variation in types of contacts and the number of interventions were less compared with the other 'experimental' rehabilitation centre. In both rehabilitation centres little attention was paid to activities to promote continuity of care (activities 4-9 in table 1) compared to the individual support of patients. Secondly, the contrast between the intervention and the control group regarding follow-up care decreased during the intervention period, since three out of six 'control' centres extended their follow-up care. Thirdly, the follow-up period of 12 months might have been too short. In the first year after discharge patients possibly 
easily consult the rehabilitation team on their own initiative in case of questions and/or problems. With increasing time after clinical rehabilitation patients might experience more hesitation to consult their rehabilitation team. The presence of a transmural nurse then might be of great importance and possibly might have more effects. Finally, our study population ended up rather small (only 50\% of the targeted inclusion) which clearly reduced the power to observe significant differences. We were not able to extend the inclusion of patients, since our study was linked to the national research programme 'Physical strain, work capacity, and mechanisms of restoration of mobility in the rehabilitation of persons with spinal cord injuries', which involves all SCI rehabilitation centres in the Netherlands. However, since we found hardly any differences, we would not expect to find significant differences by increasing the size of the study population.

The results of our effect evaluation were in sharp contrast with the experiences of the transmural nurses and the rehabilitation teams [22]. According to the nurses, the strength of the transmural care lay in the possibility to give support to patients and primary care professionals after discharge. They felt that their support was appreciated and that it created an opportunity to detect problems and to intervene in an early stage. They had, for instance, the impression that they had been able to prevent readmissions because of pressure sores. The fact that the participants in the intervention group more often held bed rest because of pressure sores, might indicate a more effective and timely treatment. The transmural nurses also strongly believed that their advice regarding bowel problems increased the quality of life of several patients. The rehabilitation teams of the 'experimental' rehabilitation centres were also satisfied with the transmural care and decided to continue the transmural care after the study period. Three out of six 'usual follow-up care' rehabilitation centres, in addition, extended their follow-up care showing a growing consciousness of the importance of follow-up care. In our opinion, therefore, it is important not to be discouraged by the results of one of the first effect studies of follow-up care [23]. The contrast between the results of this evaluation study and the experiences of the rehabilitation teams creates an interesting dilemma; professionals are positive about the intervention and implement it, but the evidence indicates that implementation of the present intervention should probably discouraged. As indicated, our intervention seems not to have been implemented 'strongly enough'. Therefore, we think that professionals have two options to choose from: not implementing it or implementing it more strongly without making 'compromises', otherwise it would probably make little difference, as our study indicates. In our opinion health care professionals and researchers should continue their efforts to improve the effectiveness, the quality and the efficiency of follow-up care. Evaluation and publication of experiences with other interventions is recommended, since information on the evidence of interventions and barriers and facilitators to change are essential for evidence-based improvements of care [24, 25]. 


\section{Clinical messages:}

- Since persons with SCI may encounter many health problems after clinical rehabilitation, it is important not to view rehabilitation as a one-time event.

- Developing and evaluating follow-up care by rehabilitation centres is very relevant.

- Implementing the transmural care model strictly according to protocol may improve its effectiveness.

\section{Acknowledgements}

We would like to thank all patients who participated in our study. Also, we gratefully acknowledge the commitment of the transmural nurses, especially Conny di Bartolomeo and Rudy Sonsma. The study was supported by: ZonMw, the Netherlands Organisation for Health Research and Development, ZonMw, Rehabilitation programme, grant nrs. 01432030 \& 14350003; and the health care insurance companies Agis and CZ. Furthermore, we would like to thank the Dutch Association of SCI Patients and the rehabilitation teams of the 8 participating rehabilitation centres for their commitment and cooperation: De Hoogstraat (Utrecht), Rehabilitation Centre Amsterdam, Het Roessingh (Enschede), Rijndam Revalidatiecentrum (Rotterdam), Rehabilitation Centre Hoensbroeck (Hoensbroek), Sint Maartenskliniek (Nijmegen), Beatrixoord (Haren), and Heliomare (Wijk aan Zee). 


\section{References}

[1] Bloemen-Vrencken JHA, Post MWM, Hendriks J, De Reus ECE, de Witte LP. Health problems of persons with spinal cord injury living in the Netherlands. Disability and Rehabilitation 2005; 27(22): 1381-1389.

[2] van Asbeck FWA, Post MWM, Pangalila RF. An epidemiological description of spinal cord injuries in The Netherlands in 1994. Spinal Cord 2000; 38(7): 420-4.

[3] Anson CA, Shepherd C. Incidence of secondary complications in spinal cord injury. International Journal of Rehabilitation Research 1996; 19(1): 55-66.

[4] Cox RJ, Amsters DI, Pershouse KJ. The need for a multidisciplinary outreach service for people with spinal cord injury living in the community. Clinical Rehabilitation 2001; 15(6): 600-6.

[5] Ernst JL, Thomas LM, Hahnstadt WA, Piskule AA. The self-identified longterm care needs of persons with SCI. SCI Psychosocial Process 1998; 1: 127132.

[6] Glidden MM. Spinal cord injury and case management. Topics in Spinal Cord Injury Rehabilitation 1999; 4 (4): 16-23.

[7] Mattson J. Case management: a historical and future perspective of its influence on outcome for persons who have sustained spinal cord injury. Topics in Spinal Cord Injury Rehabilitation 1999; 4 (4): 30-37.

[8] Rawl SM, Easton KL, Kwiatkowski S, Zemen D, Burczyk B. Effectiveness of a nurse-managed follow-up program for rehabilitation patients after discharge. Rehabilitation Nursing 1998; 23(4): 204-9.

[9] Rosendal H. Comparative cohort studies in transmural care (thesis). Utrecht: Utrecht University; 2002.

[10] Temmink D, Francke AL, Kerkstra A, Abu-Saad HH. Dutch transmural nurse clinics for chronic patients: a descriptive study. Patient Education and Counseling 2000; 39(2-3): 177-84.

[11] Kodner DL. Following the logic of long-term care: toward an independent, but integrated sector. International Journal of Integrated Care (www.ijic.org) 2004; 4(1). 
[12] Kodner DL, Spreeuwenberg C. Integrated care: meaning, logic, applications, and implications - a discussion paper. International Journal of Integrated Care (www.ijic.org) 2002; 2(3).

[13] Gröne O, Garcia-Barbero M. Integrated care. A position paper of the WHO European office for integrated care services. International Journal of Integrated Care (www.ijic.org) 2001; 1(3).

[14] Cardenas DD, Hoffman JM, Kirshblum S, McKinley W, Charlifue S, Lammertse DP, et al. Etiology and incidence of rehospitalization after traumatic spinal cord injury: a multicenter analysis. Archives of Physical Medicine and Rehabilitation 2004; 85(11): 1757-63.

[15] Dryden DM, Saunders LD, Rowe BH, May LA, Yiannakoulias N, Svenson LW, et al. Utilization of health services following spinal cord injury: a 6-year follow-up study. Spinal Cord 2004; 42(9): 513-25.

[16] Middleton JW, Lim K, Taylor L, Soden R, Rutkowski S. Patterns of morbidity and rehospitalisation following spinal cord injury. Spinal Cord 2004; 42(6): $359-67$.

[17] Dunderdale K, Thompson DR, Miles JN, Beer SF, Furze G. Quality-of-life measurement in chronic heart failure: do we take account of the patient perspective? European Journal of Heart Failure 2005; 7(4): 572-82.

[18] Johansson P, Oleni M, Fridlund B. Patient satisfaction with nursing care in the context of health care: a literature study. Scandinavian Journal of Caring Sciences 2002; 16(4): 337-344.

[19] Wessels R. Ask the user. User perspective in the assessment of assistive technology (thesis). Maastricht: Maastricht University; 2004.

[20] Whiteneck GG. The 44th annual John Stanley Coulter Lecture. Measuring what matters: key rehabilitation outcomes. Archives of Physical Medicine and Rehabilitation 1994; 75(10): 1073-6.

[21] De Groot S, Dallmeijer AJ, Post MWM, Van Asbeck FWA, Nene AV, Angenot ELD, Van der Woude LHV. Demographics of the Dutch multicentre prospective cohort study 'Restoration of mobility in spinal cord injury rehabilitation'. Spinal Cord, in press 2006. 
[22] Bloemen-Vrencken JHA, de Witte LP, Engels JPGM, Post MWM, Van den Heuvel WJA. Transmural care in the rehabilitation sector: implementation experiences with a transmural care model for people with spinal cord injury. International Journal of Integrated Care 2005; 5. Available from: www.ijc.org.

[23] Bloemen-Vrencken JHA, de Witte LP, Post MWM. Follow-up care for persons with spinal cord injury living in the community: a systematic review of interventions and their evaluation. Spinal Cord 2005; 43(8): 462-75.

[24] Grol R, Grimshaw J. From best evidence to best practice: effective implementation of change in patients' care. Lancet 2003; 362(9391): 1225-30.

[25] Grol R, Wensing M, Grimshaw J. What drives change? Barriers to and incentives for achieving evidence-based practice. The Medical Journal of Australia 2004; 180(6 Suppl): S57-60. 

8

\section{General discussion}




\section{Introduction}

This thesis describes the results of a research project aimed at the improvement of follow-up care for persons with spinal cord injury (SCI) after discharge from clinical rehabilitation. It focuses on the description of nursing problems and health (behaviour) problems among persons with SCI after discharge from clinical rehabilitation, and on the development, evaluation and implementation of a transmural nursing care model.

The project tried to answer three main research questions:

- What nursing problems and health problems do persons with SCI experience after discharge from clinical rehabilitation and what health behaviours do persons with SCI engage in to prevent or delay these problems?

- What are relevant barriers and enabling factors for successful implementation of a transmural nursing care model in rehabilitation practice?

- What are the effects of a transmural nursing care model (and other follow-up care programmes) on the prevalence of health problems and re-admissions and the perceived quality of follow-up care of persons with SCI?

Before the start of the project, we assumed that many health problems of persons with SCI lie within the scope of rehabilitation nursing and that these health problems are partly preventable, and thus might be mitigated by nursing interventions. We expected that transmural nursing care would be able to decrease the prevalence of health problems, reduce re-admissions after discharge and increase the perceived quality of follow-up care.

This chapter starts with an overview of the main results of the study, then goes on to present some methodological and theoretical considerations, and ends with recommendations for health care practice and future research.

\section{Main results}

\section{Nursing problems, health problems and health behaviour}

The first part of the study identified many health problems that are perceived by persons with SCI within the first few years after discharge from clinical rehabilitation and that lie within the scope of rehabilitation nursing. The following nursing problems were identified as the most important ones after discharge: limitations in activities of daily living, having difficulties asking for help (assertiveness), pain, coping with the disability, being dependent on help from others for personal care and problems with 
changed bladder regulation (chapter 2). According to persons with SCI, nursing care during and after clinical rehabilitation could be improved. In general, persons with SCI would like to be better prepared during rehabilitation for the period after discharge. After discharge, they would like to receive follow-up care in the form of consulting hours and peer meetings. A longer period of day treatment after the inpatient rehabilitation would also be desirable in their opinion.

Based on these results, a larger survey was held among all members of the Dutch Association of SCI Patients. The survey concerned health problems (chapter 3) and health behaviour (chapter 4). Chapter 3 describes the results regarding the prevalence and experienced impact of 13 secondary impairments, eight problems of daily living and five psychosocial problems. On average, the respondents experienced eight different health problems. The most frequently occurring problems regarded bladder $(70.9 \%)$ and bowel regulation $(61.0 \%)$, spasms $(56.6 \%)$, pain $(55.3 \%)$, oedema $(48.5 \%)$ and sexuality $(39.2 \%)$. The respondents experienced many limitations in daily activities and social life due to these problems, but pain was perceived as the most disabling condition. The occurrence of health problems did not diminish with increasing time after injury.

The results regarding health behaviour are described in chapter 4. For this survey, a list of 22 health behaviours was developed. The results showed that the frequency of engaging in health behaviours varied considerably between individuals. There were four health behaviours that were often or always used by more than $85 \%$ of all respondents: 'skin care in the case of incontinence', 'examination of the cause of pressure sores', and 'taking the prescribed medicines in the right amounts'. The least applied health behaviours were: 'monitoring blood pressure' (never or only sometimes applied by $83 \%$ ), 'limiting fat and cholesterol intake' (54\%), and 'pressure relief methods like weight shifts' (52\%). The total health behaviour scores increased significantly with increasing age, and pressure sore prevention was used significantly more by persons with a complete lesion. Health behaviour was significantly more likely to be used by persons who had one or more secondary impairments.

\section{The transmural nursing care model and its implementation}

Chapter 6 describes the development, implementation and process evaluation of the transmural nursing care model. The transmural care model was developed in cooperation with the Dutch Association of SCI Patients, community nurses, general practitioners, rehabilitation nurses, rehabilitation managers, physiatrists and researchers. The core component of the transmural nursing care model consists of the creation of a new position of 'transmural nurse', who 'liaises' between people with SCI living in the community, primary care professionals and the rehabilitation centre. In this care model, the transmural nurse is a member of the clinical rehabilitation team and is engaged for one day a week to perform four main tasks: 
- supporting people with SCI and their partners/families with health problems which come within the scope of the nursing discipline;

- supporting primary care professionals in the specific care for people with SCI;

- promoting continuity of care between primary care professionals and the rehabilitation team;

- giving feedback and taking initiatives to improve the care by the rehabilitation team, based on experiences with patients.

Two rehabilitation centres put the model into practice, but the process evaluation showed that it was not fully implemented as planned. In line with the findings of a study by Grol and Wensing [1], enabling factors and barriers for implementation were found at: (1) the level of the individual professionals (e.g. competencies, attitude and motivation of the transmural nurses), (2) the organisational and financial level (e.g. availability of facilities and funding) and (3) the social context (the opinion of colleagues, managers and other professionals involved in the care). The most important weakness of the implementation of the model was that there was not enough time to put all the activities into practice. The strength of the care model lies in the combination of providing support to patients after discharge, supporting and cooperating with primary care professionals, and providing feedback of experiences to the clinical rehabilitation teams.

\section{Effects of the transmural nursing care model and other follow-up care programmes}

A systematic literature review was performed to identify successful follow-up care models. This systematic review, presented in chapter 5, revealed 24 descriptions of follow-up care programmes implemented by rehabilitation centres. Descriptions of the content of the programmes were sometimes rather scattered, vague or brief. Five methods of follow-up care were identified: telemedicine, outpatient consulting hours, home visits, case management and mixed types of follow-up care. Two thirds of these programmes had been evaluated, but the methodological quality of the studies was. Therefore, it was not possible to draw conclusions about the effects of follow-up care on the prevalence of secondary impairments, well-being and the quality and costs of care.

The effect evaluation of the transmural nursing care model presented in chapter 7 showed that the transmural nursing care as implemented had no favourable effects on the prevalence of health problems, re-admissions to hospitals and rehabilitation centres or the perceived quality of follow-up care. These findings contrasted with our expectations as well as with the experiences of the transmural nurses and the rehabilitation teams involved. They felt that their support was appreciated by persons with SCI and that it created an opportunity to detect problems and to intervene at an early stage. 


\section{Methodological considerations}

A number of methodological issues deserve to be discussed.

\section{Nursing problems, health problems and health behaviour}

The patient's perspective was taken as a starting point to study nursing problems and health problems after discharge from rehabilitation, since the aim was to find a basis for improving follow-up care and to decide which problems a follow-up programme should focus on from their perspective. However, while persons with SCI obviously can give information about their functioning and the presence of health problems, there might be problems in interpreting some of these findings. For example, a health problem relating to breathing may in fact be normal for that individual, but not acceptable as such. As regards spasm, it may be difficult for persons with SCI to distinguish between spasticity, stiffness and pain. Hence, interpretations of the results of these studies should take into account that the information was provided directly by persons with SCI.

The study into the health behaviour of persons with SCI primarily had a descriptive character and raised an important issue regarding the relationship between health behaviour and the prevalence of secondary impairments. Since the health behaviour assessment scale was developed by a multidisciplinary team of rehabilitation professionals and some experienced persons with SCI, the scale can be considered to have face validity. However, more attention could have been paid to the evaluation of other kinds of validity. Furthermore, it was not possible to examine the correspondence between self-reported and actual health behaviour.

\section{Effects of the transmural nursing care model and other follow-up care programmes}

In our opinion, there are two main reasons for the fact that the transmural nursing care did not have the expected favourable effects on the prevalence of health problems and the quality of care. These are related to the design of the study and the implementation of the intervention.

\section{Design}

Firstly, it should be recognised that the quasi-experimental study design was rather weak. Our design lacked a baseline measure and randomisation, and had a nonequivalent control group recruited from other rehabilitation centres. Although the matching procedure applied ensured comparability between the experimental and control groups for some important variables, it is 'second best' from a methodological point of view. Practical circumstances made it impossible to perform baseline measures and to apply randomisation. The effect evaluation of the transmural nursing care was linked to the national research programme entitled 'Physical strain, and 
mechanisms of restoration of mobility in the rehabilitation of persons with spinal cord injuries'. At the time when our intervention could be implemented, the inclusion of participants in this national research project had already been started for several months. Since there were quite a number of patients in both 'experimental' rehabilitation centres who had already been discharged before the start of the transmural nursing care, the group that was available for the effect evaluation remained rather small, which clearly reduced the power to detect significant differences. However, since we found hardly any outcome differences, we cannot expect to find significant differences by increasing the size of the study population.

To control for characteristics of respondents that are likely to affect the experimental outcome, we applied a matching procedure. For each subject in the 'experimental' group, a subject in the control group was selected who was similar in terms of level and motor completeness of the SCI, as well as gender and age. Before the start of our intervention and in each subsequent year, we also monitored the difference in follow-up care between the experimental and control centres by interviewing their rehabilitation doctors and/or managers about the content of and developments in follow-up care. It appeared that the 'usual' (standard) follow-up care was expanded in half of the 'control' centres during the study period, which could act as a confounding factor by reducing the contrast between the 'intervention' and control group. However, since subgroup analyses did not show differences in outcomes between the intervention group and participants who did not make use of follow-up care innovations in the control rehabilitation centres, it is unlikely that this non-equivalent control group has been a major confounder in this study.

\section{Intervention}

Another limitation of the effect evaluation was the fact that the transmural nursing care model was inconsistently and incompletely implemented during the study period in both of the 'experimental' rehabilitation centres. The process evaluation (chapter 6) also showed that there was a considerable difference between the two 'experimental' rehabilitation centres regarding the variation in types of contacts that the transmural nurses had with patients after discharge from rehabilitation and the number of interventions being applied. According to the nurses' records, they applied an average of only two interventions (such as recommendations regarding pressure sores, bladder and bowel problems) to the participants, but it was not checked whether or not the participants complied with the recommendations the transmural nurses gave. Almost $25 \%$ of the patients chose to contact the transmural nurse only if a problem arose.

In both centres, little attention was given to activities promoting continuity of care, like organising presentations to primary care professionals about SCI or transfer of care meetings, and limited professional support and education was provided to community nurses and general practitioners.

In both of the 'experimental' rehabilitation centres, several barriers to implementation were identified, which together caused the incomplete and 
inconsistent implementation. As discussed above, the barriers we identified related to: (1) the level of the individual professionals, (2) the organisational and financial level, and (3) the social context.

- The level of the individual professionals : The knowledge, skills and competencies of the transmural nurses and the support to train them proved to be very important. The nurses, who had only worked within the clinics before, were given new tasks and became a kind of pioneers, who had to learn to liaise between persons with SCI, the rehabilitation team and professional primary caregivers. This meant they had to be able to mediate in certain circumstances, for instance in case of differences of opinion between SCI patients and district nurses. They also had to tailor their recommendations more closely to the patients' situation and the possibilities of home care professionals. In the case of pressure sores, for instance, bed rest is more easily recommended than implemented in the home situation. And how can one disseminate knowledge and expertise among primary care professionals without being pedantic? Sometimes, it was also found difficult to criticise clinical rehabilitation procedures.

- Organisational and financial level: There were also barriers related to the organisational and financial level. Good working conditions were found to be very important, like having a mobile phone and a consultation room at one's disposal, a work schedule in harmony with the schedule of transmural care, and being able to spend eight hours on transmural care on one day. It was especially during the first 10 months of the intervention period that the lack of these facilities hampered the performance of the transmural nurses in one of the 'experimental' rehabilitation centres. Besides, all nurses found the workload of the transmural care model far too high to accomplish in eight hours per week. In one centre, nurses were stimulated to refer patients to the SCI nurse of the day hospital if nursing advice or instruction was needed after discharge. This procedure hampered the transmural nurses, but the structure had already been established for years and allowed the rehabilitation centre to claim expenses for these consultations (rather than for the more 'preventive' consultations by the transmural nurse).

- Social context: With regard to the social context, it appeared to be very important that the intervention protocol matched the views the centres had about rehabilitation. In one of the centres, the managers of the rehabilitation team instructed the transmural nurse to be very reticent regarding some transmural care activities (like home visits, consultations at the rehabilitation centre and organising peer meetings). This was partly because, in their opinion, some activities that were part of the model were too patronising. Compared to the managers at other 'experimental' rehabilitation centre, they felt more strongly that patients should take responsibility for their own care, and should 
take the initiative to contact the transmural nurse if necessary. In their opinion, the transmural nurses should not take the initiative for patient contacts.

\section{Theoretical considerations}

There are a few theoretical dilemmas regarding the main findings of our studies that I would like to discuss in more detail.

\section{Health behaviour}

Our study into health behaviour found a significant correlation between the number of secondary impairments and the frequency of health behaviours being engaged in by persons with SCI. The more secondary impairments the persons with SCI experienced, the more frequently they engaged in health behaviour. This may indicate that persons with secondary impairments modified their health behaviour to prevent these impairments in future or that the health behaviours as measured did not have much impact on the prevalence of secondary impairments. Due to the cross-sectional design of our study, it was not possible to determine which of these two contrasting explanations was valid. In any case, our results suggest it would be useful to test the efficacy of health behaviour and illustrate the importance of a better understanding of people's motivation to engage in health behaviour, and of implementing this understanding in rehabilitation practice. Although persons with SCI are at risk of developing certain secondary impairments, this obviously does not necessarily mean that they will comply with health behaviours promoted during clinical rehabilitation in the short and long-term after clinical rehabilitation. Health promotion activities should take into account the three core determinants of health behaviour as described in health psychology [2-4]:

- the attitude to health behaviour: the outcomes people expect their actions to produce and the advantages and disadvantages they perceive from engaging in health behaviour;

- the social approval or disapproval the health behaviour produces in their interpersonal relationships;

- the perceived self-efficacy in terms of being able to exercise control over their health behaviour.

\section{Follow-up care}

The process evaluation (chapter 6 ) showed that the transmural nurses perceived some tension between stimulating patients to organise their own care on the one hand and protocol prescriptions on the other. Initiating contacts with patients at fixed intervals and using an assessment list to discuss functioning after discharge from clinical rehabilitation sometimes made the nurses feel they were patronising patients too 
much. The results of the process evaluation made us conclude that in order to improve the transmural nursing care, it is important to tailor the care more closely to patients' needs. We argued that there should be more dialogue between the patients and the rehabilitation professionals about aspects of what, how and when. In chapter 7, however, we argued that it is important to implement the transmural nursing care 'more strictly' in order to influence the prevalence of health problems and the quality of follow-up care. The fact that the intervention had been implemented inconsistently and incompletely was in our opinion one of the explanations for the intervention not having the expected favourable effects.

Tailoring the follow-up care more closely to the patients' needs on the one hand and implementing the intervention more strictly on the other hand might seem two conflicting points of view. When persons with SCI, for instance, prefer to organise their own care after discharge and to contact the transmural nurse at their own initiative if necessary, the transmural nurse could easily comply with this request and deviate from protocol prescriptions which indicate she has to contact patients at specific moments after discharge. In our opinion, however, it is most important that patients and transmural nurses thoroughly discuss their points of view about the patients' situation after discharge and their ability to organise their own care. The amount and content of follow-up care should be based on the results of a dialogue that takes into account the patients' wishes and expectations and at the same time meets professional standards. The findings of our study taught us that the transmural nurses found it difficult to provide follow-up care in a patient-centred way. The nurses regularly had too great a feeling of responsibility for the well-being of patients, which resulted in their proposing solutions and having perhaps too much of a 'caring' attitude. Other research [5-7] and practical experience have also shown that it is difficult for professionals to tailor their care to patients' needs.

In other words: implementing the transmural nursing care model in a more clientcentred way and applying it more strictly may both improve its effectiveness.

\section{Recommendations for rehabilitation practice and further research}

Our studies into nursing problems and health problems after discharge from clinical rehabilitation illustrated that persons with SCI may experience a variety of problems immediately after rehabilitation, as well as in the long-term. Although the need for follow-up care has been increasingly recognised [8-13], the systematic review identified only a small number of follow-up care descriptions. Descriptions of the content of follow-up care programmes were often scattered, vague or brief, and their effects had usually not been studied properly. The review, therefore, revealed no clear evidence for the effects of follow-up care programmes on the prevalence of secondary 
impairments, well-being and the quality and costs of care. Since our transmural nursing care model was inconsistently and incompletely implemented in both of the 'experimental' rehabilitation centres in our study, and there were also several methodological and practical limitations that hampered our effect evaluation, we cannot conclude that the transmural care model is not effective regarding the prevalence of health problems, re-admissions or the perceived quality of follow-up care among persons with SCI. After all, we do not know what effects might have been achieved if the transmural nursing care had been implemented more strictly. All this contributes to the most important conclusion of this thesis: there is a need for the development, implementation, well-designed evaluation and publication of follow-up care programmes for persons with SCI, since these persons experience serious health problems after discharge.

\section{Recommendations for rehabilitation practice}

Our thesis leads to several recommendations regarding the care routing of persons with SCI:

- Although this thesis has primarily focused on the care after discharge, our study into nursing problems also identified a need to improve clinical rehabilitation. A number of participants of the first study felt ill-prepared for living in the community as regards practical skills and dealing with the emotional challenges of living with a chronic condition. They suggested organising meetings with SCI patients who are living in the community to discuss the period after discharge from rehabilitation, and to tailor the inpatient care more closely to patients' needs and their situation after discharge. In other words, the results of this thesis give cause to critically review the content and methods of clinical rehabilitation. To improve inpatient rehabilitation, we recommend training rehabilitation professionals to offer care in a more client-centred way. In our opinion, the efficacy of the rehabilitation process would increase if more attention were given to training patients in activities in their future home, work and/or leisure situation. We also recommend considering the possibility of reducing the length of stay in clinical rehabilitation or to create longer periods of practice at home than the currently usual weekend visits. At home, persons with SCI might become more accurately aware of their needs and rehabilitation goals, compared to a situation in which they have to formulate rehabilitation goals for an expected but still unreal future situation. When persons with SCI have functioned at home they might have a better picture of activities, skills and competencies they would like to train during a further period of inpatient rehabilitation. Besides, there might be more opportunities for tailoring health promoting activities to the patients' situation and actual health problems.

- Since persons with SCI may encounter all kinds of health problems in the short and long-term after discharge from clinical rehabilitation, it is also important 
not to view rehabilitation as a one-time event. There should be opportunities for persons with SCI to keep in contact with the rehabilitation centre in the long-term, allowing them to get support if health problems arise, and to remain informed about new interventions and technologies. Rehabilitation professionals should take the lead in optimising the follow-up care to persons with SCI, since rehabilitation teams do have the greatest expertise regarding the specific care needs of persons with SCI. However, cooperation and attuning the follow-up care to the care offered by primary health professionals is also important.

- Implementing the transmural nursing care model according to protocol may improve its effectiveness. The following aspects are important to improve the implementation of the transmural nursing care model or other follow-up care programmes in day-to-day rehabilitation practice. (1) The individual professionals implementing follow-up care should be provided with enough training in the competencies needed in their new tasks (patient-centred care, conversation techniques, networking and the ability to serve as a liaison, mediator and pioneer). (2) Enough time should be available to put the intervention into practice. In addition, the intervention should be embedded in the local organisational structure as well as in a payment system. (3) Attention should be given to creating support for the intervention at both managerial level and the level of professionals indirectly involved with the implementation.

- Since persons with SCI who are living in the community do not frequently engage in certain health behaviours that, according to rehabilitation professionals, are important to delay or prevent secondary impairments, more attention needs to be given to health-promoting activities in the long-term. Currently, education and training is institutionally based and focused on acute rehabilitation [14]. Furthermore, more attention needs to be given to the feasibility of health behaviours and the motivation of persons with SCI to engage in them.

\section{Recommendations for future research}

- Our systematic review has illustrated that it is very important to give more attention to the evaluation of follow-up care programmes. In order to enable researchers and health care professionals to learn from other follow-up care programmes, we strongly advise them to systematically evaluate the process of implementation of follow-up care programmes and their effects on the prevalence of health problems, health care utilisation and the costs and quality of care.

- Communication and publication of process and effect evaluations is also strongly recommended. In our opinion, it is important that researchers and health professionals in the field of SCI rehabilitation exchange knowledge and 
practical experiences regarding follow-up care programmes. A national or international working group of researchers and health professionals could facilitate this exchange.

- Due to the cross-sectional design of our study into the health behaviour of persons with SCI living in the community, it was not possible to distinguish whether persons with secondary impairments modified their health behaviour to prevent secondary impairments in future, or whether the health behaviours assessed do not have much impact on the prevalence of secondary impairments. Since health problems are common and education on health behaviour is a core component of any rehabilitation programme, it is important to test the efficacy of health behaviour and the education methods used to motivate persons with SCI to engage in such health behaviour.

- Longitudinal research is recommended to study what persons with SCI know about health behaviour, as well as when, why and what health behaviours they practice and the impact of health behaviour on the prevalence of secondary impairments. 


\section{References}

[1] Grol R, Wensing M. Implementatie. Effectieve verandering in de patientenzorg. Maarssen: Elsevier; 2001.

[2] Damoiseaux V, Visser AP, al. e. Patientenvoorlichting. Een interdisciplinaire benadering. Assen/Maastricht: Van Gorcum \& Comp. B.V.; 1988.

[3] Brug J, Schaalma H, Kok G, Meertens RM, van der Molen HT. Gezondheidsvoorlichting en gedragsverandering. Assen: Van Gorcum \& Comp. B.V.; 2000.

[4] Taylor SE. Health psychology. Fourth Edition ed: McGraw-Hill; 1999.

[5] Boschen KA, Tonack M, Gargaro J. Long-term adjustment and community reintegration following spinal cord injury. International Journal of Rehabilitation Research. 2003; 26(3): 157-64.

[6] Cott CA. Client-centred rehabilitation: client perspectives. Disability and Rehabilitation 2004; 26(24): 1411-22.

[7] Van de Ven L, Post MW, Krumeich A, de Witte LP. Beter omgaan met verschillende perspectieven op revalidatie. Een brochure voor professionals in de revalidatie. Hoensbroek: iRv, Kenniscentrum voor Revalidatie en Handicap; 2006.

[8] Dunn M, Love L, Ravesloot C. Subjective health in spinal cord injury after outpatient healthcare follow-up. Spinal Cord 2000; 38(2): 84-91.

[9] Levi R, Hultling C, Seiger A. The Stockholm Spinal Cord Injury Study. 3. Health-related issues of the Swedish annual level-of-living survey in SCI subjects and controls. Paraplegia 1995; 33(12): 726-30.

[10] Anson CA, Shepherd C. Incidence of secondary complications in spinal cord injury. International Journal of Rehabilitation Research 1996; 19(1): 55-66.

[11] McKinley WO, Jackson AB, Cardenas DD, DeVivo MJ. Long-term medical complications after traumatic spinal cord injury: a regional model systems analysis. Archives of Physical Medicine and Rehabilitation 1999; 80(11): 140210. 
[12] Noreau L, Proulx P, Gagnon L, Drolet M, Laramee MT. Secondary impairments after spinal cord injury: a population-based study. American Journal of Physical Medicine and Rehabilitation 2000; 79(6): 526-35.

[13] Schönherr MC. Functional outcome after spinal cord injury: Activities and participation (thesis). Groningen: Rijksuniversiteit Groningen; 2003.

[14] Whiteneck GG, Charlifue SW, Gerhart KA, Lammertse DP, Manley S, Menter RR, et al. Aging with spinal cord injury. New York: Demos Publications; 1993. 


\section{Summary}




\section{Introduction}

Improvements in post-injury care and rehabilitation have eliminated or minimised many of the early complications that typically afflict those who have a new spinal cord injury (SCI). Since 1950, the life expectancy of persons with SCI has greatly increased and issues regarding long-term management have become increasingly important.

Previous research has shown that the care of persons with SCI after discharge from clinical rehabilitation is characterised by several shortcomings. The coordination and tailoring of care after discharge from clinical rehabilitation is far from perfect. Furthermore, there is very little agreement between professionals about who is primarily responsible for different aspects of care. Several studies have also illustrated that persons with SCI may experience many problems in daily life.

This thesis reports on the health problems people with SCI encounter in their daily lives once they have been discharged from rehabilitation. Furthermore, this thesis reports on an initiative to improve the follow-up care to persons with SCI after discharge from clinical rehabilitation. The proposed improvements in follow-up care are based on the nursing perspective.

The main research questions were:

- What nursing problems and health problems do persons with SCI experience after discharge from clinical rehabilitation and what health behaviours do persons with SCI engage in to prevent or delay these problems?

- What are relevant barriers and enabling factors for successful implementation of a transmural care model in rehabilitation practice?

- What are the effects of a transmural nursing care model (and other follow-up care programmes) on the prevalence of health problems, re-admissions and the quality of follow-up care as perceived by persons with SCI?

\section{Chapter 1}

This chapter provides background information on SCI and its prevalence, and on the care routing of persons with SCI. It also describes the research questions and presents an outline of the thesis. 


\section{Chapter 2}

This chapter reports on an explorative study into those problems of persons with SCI after discharge from rehabilitation that are within the scope of the nursing discipline (i.e. are nursing problems). The most important nursing problems appeared to be limitations in activities of daily living, having difficulties asking for help (assertiveness), pain, coping with the disability, dependence on personal help and problems with changed bladder regulation. The respondents indicated that nursing care during and after clinical rehabilitation could be improved.

\section{Chapter 3}

This chapter describes the results of a survey assessing the prevalence of health problems among members of the Dutch Association of SCI Patients, the problems perceived as the most important ones, and the perceived impact of these most important problems on daily activities and social life.

The findings illustrate that persons with SCI living in the community experience a variety of health problems after discharge. The most frequently occurring problems regarded bladder and bowel regulation, spasms, pain, oedema and sexuality. The respondents experienced many limitations in daily activities and social life due to these problems, while pain was perceived as the most disabling condition. The occurrence of health problems did not diminish with time after the injury, which strongly underlines the need for follow-up care.

\section{Chapter 4}

This chapter reports on the results of a descriptive study into the health behaviour of persons with SCI living in the community and the relationships between health behaviour, respondent/injury characteristics and health-related variables like the presence and number of secondary impairments.

The frequency of engaging in health behaviours varied considerably between individuals. Variance was observed between different health behaviours intended to delay or prevent secondary impairments, as well as between patients in implementing the same behaviour. The respondents do not frequently engage in pressure relief methods when sitting/driving in their wheelchairs. Hardly any statistically significant differences were observed between the health behaviours of subgroups of respondents based on respondent/injury characteristics. However, the total health behaviour scores increased significantly with increasing age, and pressure sore prevention was significantly more likely to be applied by persons with a complete 
lesion. Health behaviour was significantly more likely to be implemented by respondents who had one or more secondary impairments.

It was concluded that it is of great importance to rigorously test the efficacy of health behaviours promoted during rehabilitation, since education on a healthy lifestyle is a core component of every rehabilitation programme and secondary impairments are common.

\section{Chapter 5}

This chapter describes the results of a systematic review of follow-up care programmes for persons with SCI living in the community, as implemented by rehabilitation centres. The aim of this review was to describe and compare the content of the follow-up care programmes and to assess whether there is convincing evidence for the effects of such programmes on the occurrence of secondary impairments, well-being and the quality and costs of care.

The search yielded 24 papers. The descriptions of the programmes in these papers were sometimes rather scattered, vague or brief. Five methods of follow-up care were identified: telemedicine, outpatient consulting hours, home visits, case management and mixed types of follow-up care. Sixteen programmes had been evaluated to some degree. The quality of the studies was generally poor. Most evaluations used a preexperimental design. Only three were quasi-experimental, and two programmes used an experimental design. Although several studies claimed positive effects, it was not possible to draw conclusions on the effects of follow-up care on the occurrence of secondary impairments, well-being or the quality and costs of care.

\section{Chapter 6}

This chapter describes the development and content of our transmural nursing care model and the results of a process evaluation of its implementation. The transmural care model was developed in cooperation with the Dutch Association of SCI Patients, community nurses, general practitioners, rehabilitation nurses, rehabilitation managers, physiatrists and researchers. The core component of the transmural nursing care model consists of a transmural nurse, who 'liaises' between people with SCI living in the community, primary care professionals and the rehabilitation centre. The transmural nurse is a member of the clinical rehabilitation team and is engaged for one day a week to perform four main tasks:

- supporting people with SCI and their partners/families in coping with those health problems which come within the scope of the nursing discipline;

- supporting primary care professionals in the specific care for people with SCI; 
- promoting continuity of care between primary care professionals and the rehabilitation team;

- giving feedback to the rehabilitation team and taking initiatives to improve care, based on experiences with patients.

Two rehabilitation centres put the model into practice. The process evaluation showed that it was not fully implemented as planned, with a clear difference between the two rehabilitation centres. Enabling factors and barriers for implementation were found at (1) the level of the individual professionals (e.g. competencies, attitude and motivation of the transmural nurses), (2) the organisational and financial level (e.g. availability of facilities and funding) and (3) the social context (opinions of colleagues, managers and other professionals involved in the care). The most important problem experienced was that there was not enough time to put all of the activities into practice. The strength of the care model lies in the combination of supporting patients after discharge, supporting and cooperating with primary care professionals, and giving experience-based feedback to the clinical rehabilitation teams.

\section{Chapter 7}

This chapter describes the results of the effect evaluation of our transmural nursing care model. Thirty-one participants who received transmural nursing care in two experimental rehabilitation centres were compared with a matched sample of participants having received usual follow-up care in six other rehabilitation centres. Matching was applied for level and motor completeness of the SCI, gender and age.

One year after discharge, no differences were found between the intervention and usual care groups in the prevalence of health problems (pressure sores, urinary tract infections, spasms, pain, oedema, respiratory tract infections, low blood pressure and weight increase), nor in re-admissions to hospitals and rehabilitation centres or the perceived quality of follow-up care. Since the 'usual' (standard) follow-up care was extended in $50 \%$ (three out of six) of the 'control' centres during the study period, subgroup analyses were performed between the intervention group and those participants in the control centres who did not make use of innovations in follow-up care. However, these subgroup analyses also did not show differences in outcome variables either.

\section{Chapter 8}

This chapter presents the main results in relation to the research questions, as well as a number of methodological and theoretical considerations with regard to our studies. 
The chapter concludes with recommendations for rehabilitation practice and further research.

The most important conclusion is that persons with SCI may experience a variety of health problems immediately after rehabilitation, as well as in the long-term, which negatively affect their functioning. Although the need for better follow-up care is increasingly recognised, few follow-up care programmes have been described in the literature, and most of these programmes have not been evaluated properly. Therefore, there is no evidence for the effects of follow-up care programmes on the prevalence of secondary impairments, well-being or the quality and costs of care. Since our transmural nursing care model had been inconsistently and incompletely implemented in both of the 'experimental' rehabilitation centres and there were also several methodological and practical limitations, it was not possible to formulate final conclusions regarding its effectiveness. We feel that implementing the transmural nursing care model in a more client-centred way and applying it more strictly may both improve its effectiveness. Because health problems are common among persons with SCI living in the community, further development, implementation, evaluation and publication of follow-up care programmes for persons with SCI remains highly relevant. 
Samenvatting 


\section{Inleiding}

Verbeteringen in de acute zorg en revalidatie van mensen met een dwarslaesie hebben ertoe geleid dat bepaalde specifieke complicaties die samengaan met het optreden van een dwarslaesie niet of minder frequent optreden. Vanaf 1950, is de levensverwachting van mensen met een dwarslaesie aanzienlijk toegenomen en daarmee ook het belang voor zorgaspecten op de lange termijn.

Uit eerdere onderzoeken is bekend dat er verschillende tekortkomingen bestaan in de zorg aan mensen met een dwarslaesie na ontslag uit klinische revalidatie. De coördinatie en afstemming van zorg na ontslag uit het revalidatiecentrum is verre van perfect. Tevens is er weinig overeenstemming tussen professionals voor wat betreft wie primair verantwoordelijk is voor de verschillende zorgaspecten. Verschillende studies toonden tevens aan dat mensen met een dwarslaesie allerlei problemen tegen kunnen komen in hun dagelijkse leven.

Dit proefschrift rapporteert over gezondheidsproblemen die mensen met een dwarslaesie tegenkomen in hun dagelijkse leven na ontslag uit het revalidatiecentrum. Tevens wordt verslag gedaan van een initiatief om de nazorg aan mensen met een dwarslaesie te verbeteren, waarbij het verpleegkundig perspectief als uitgangspunt diende.

De belangrijkste onderzoeksvragen waren:

- Welke verpleegproblemen en gezondheidsproblemen ervaren mensen met een dwarslaesie na ontslag uit het revalidatiecentrum en welk gezondheidsgedrag passen mensen met een dwarslaesie toe om het optreden van deze problemen te voorkomen of te vertragen?

- Wat zijn belemmerende en bevorderende factoren voor het succesvol implementeren van transmuraal verpleegkundige zorg in de revalidatie?

- Wat zijn de effecten van transmuraal verpleegkundige zorg (en andere nazorgprogramma's) op het ontstaan van gezondheidsproblemen, heropnames en de ervaren kwaliteit van nazorg bij mensen met een dwarslaesie?

\section{Hoofdstuk 1}

In dit hoofdstuk wordt uitleg gegeven over dwarslaesie, prevalentie en het zorgtraject dat mensen met een dwarslaesie doorlopen. Tevens worden de onderzoeksvragen en de opzet van het proefschrift beschreven. 


\section{Hoofdstuk 2}

Dit hoofdstuk presenteert de resultaten van een exploratieve studie naar problemen die mensen met een dwarslaesie ervaren na ontslag uit het revalidatiecentrum en binnen het verpleegkundig aandachtsgebied liggen (verpleegproblemen). De volgende problemen bleken het meest belangrijk te zijn: beperkingen in activiteiten van het dagelijkse leven (ADL), moeite hebben om hulp te vragen (assertiviteit), pijn, verwerkingsproblemen, afhankelijk zijn van persoonlijke hulp en problemen met de veranderde blaasregulatie. De respondenten gaven tevens aan dat de verpleegkundige zorg tijdens de klinische revalidatieperiode en na ontslag verbeterd kan worden.

\section{Hoofdstuk 3}

Dit hoofdstuk beschrijft de resultaten van een survey naar de prevalentie van gezondheidsproblemen bij leden van Dwarslaesie Organisatie Nederland, naar de problemen die als meest belangrijk ervaren worden en naar de impact hiervan op dagelijkse en sociale activiteiten.

Deze studie toont aan dat mensen met een dwarslaesie in hun thuissituatie allerlei gezondheidsproblemen ervaren. De meest voorkomende problemen waren: problemen ten gevolge van een veranderende blaas- en darmregulatie, spasme, pijn, oedeem en problemen op sexueel gebied. De respondenten gaven aan veel belemmeringen te ervaren voor wat betreft dagelijkse en sociale activiteiten ten gevolge van deze problemen. Pijn werd als het meest belemmerende probleem ervaren. Het optreden van deze problemen nam niet af naarmate mensen langer de dwarslaesie hadden. Hetgeen de noodzaak voor nazorg sterk onderstreept.

\section{Hoofdstuk 4}

Dit hoofdstuk beschrijft de resultaten van een beschrijvende studie naar het gezondheidsgedrag van mensen met een dwarslaesie in hun thuissituatie, naar de relatie tussen gezondheidsgedrag en respondent/laesiekenmerken, en gezondheidsgerelateerde variabelen als de aanwezigheid van en het aantal secundaire stoornissen.

De frequentie waarmee bepaalde gezondheidsbevorderende gedragingen werden toegepast varieerde aanzienlijk. Zowel per patiënt als per gezondheidsbevorderend item. De respondenten passen drukverlagende methoden niet frequent toe wanneer ze in hun rolstoel zitten of rijden. Er werden bijna geen statistisch significante verschillen geobserveerd tussen subgroepen van respondenten gevormd op basis van respondent of laesie kenmerken. De totaalscores voor gezondheidsgedrag namen echter significant toe naarmate de respondenten ouder waren. Preventieve maatregelen tegen 
decubitus werden significant frequenter toegepast door mensen met een complete dwarslaesie. Tevens werden gezondheidsgedragingen meer toegepast door mensen met één of meerdere secundaire stoornissen.

Er werd geconcludeerd dat het heel belangrijk is de efficacy van gezondheidsgedragingen, die tijdens de klinische revalidatie gepromoot worden, goed te testen, aangezien gezondheidsvoorlichting en educatie een centraal onderdeel vormen van elk revalidatieprogramma en secundaire stoornissen veelvuldig voorkomen.

\section{Hoofdstuk 5}

Dit hoofdstuk rapporteert over de resultaten van een literatuurstudie (systematic review) naar nazorgprogramma's voor mensen met een dwarslaesie in hun thuissituatie uitgevoerd door revalidatiecentra. Het doel van deze review is doel en inhoud van de nazorgprogramma's te beschrijven en te vergelijken en na te gaan of er bewijzen zijn voor de effectiviteit van deze programma's op het optreden van secundaire stoornissen, welzijn, de kwaliteit en de kosten van zorg.

In totaal werden 24 artikelen in de review opgenomen. De beschrijvingen van nazorgprogramma's waren soms erg kort, vaag en versplinterd. Vijf methoden van nazorg werden geïdentificeerd: telemedicine, poliklinische spreekuren, huisbezoeken, case management en gemende methoden van nazorg. Zestien van de 24 programma's werden tot op bepaalde hoogte geëvalueerd. Over het algemeen was de kwaliteit van de evaluaties laag. De meeste evaluaties waren pre-experimenteel van aard. Slechts drie evaluaties waren quasi-experimenteel en twee waren experimenteel in opzet. Ondanks het feit dat verschillende studies positieve effecten claimden, was het niet mogelijk conclusies te trekken over de effectiviteit van nazorg op het optreden van secundaire stoornissen, welzijn, de kwaliteit en de kosten van de zorg.

\section{Hoofdstuk 6}

Dit hoofdstuk beschrijft de ontwikkeling en inhoud van het transmuraal verpleegkundig zorgmodel en de resultaten van de procesevaluatie. Dit zorgmodel werd ontwikkeld in samenwerking met Dwarslaesie Organisatie Nederland, wijkverpleegkundigen, huisartsen, revalidatie -verpleegkundigen, -managers, en -artsen en onderzoekers. Het centrale element van het zorgmodel bestaat uit een transmuraal werkende dwarslaesie verpleegkundige met een 'brugfunctie' tussen thuiswonende mensen met een dwarslaesie, hulpverleners uit de eerste lijn en het revalidatiecentrum. De transmuraal verpleegkundige is lid van het klinische revalidatieteam en geeft één dag in de week nazorg. De vier hoofdtaken zijn: 
- het ondersteunen van mensen met een dwarslaesie en hun partner/familie bij gezondheidsproblemen op verpleegkundig gebied

- het ondersteunen van hulpverleners in de eerste bij de specifieke zorg aan mensen met een dwarslaesie

- het bevorderen van een goede afstemming van zorg tussen hulpverleners van de eerste lijn en het revalidatieteam

- het geven van feedback aan het revalidatieteam naar aanleiding van ervaringen met ex-revalidanten en het doen van verbetervoorstellen voor de klinische zorg

In twee revalidatiecentra werd het zorgmodel ingevoerd. De procesevaluatie liet zien dat de interventie niet in alle details geïmplementeerd was en dat er een duidelijk verschil was tussen de twee centra. Belemmerende en bevorderende factoren werden op drie niveaus gevonden: (1) het niveau van de individuele beroepsbeoefenaar (kennis, kunde en vaardigheden van de transmuraal verpleegkundige), (2) het niveau van de organisatie en de financiële structuur (de beschikbaarheid van faciliteiten en financiën), (3) de sociale context (mening van collega's, managers en andere betrokkenen). Het feit dat er niet voldoende tijd was om alle activiteiten van het zorgmodel in praktijk te brengen, werd als belangrijkste belemmerende factor ervaren. De kracht van het model ligt in de combinatie van ondersteuning aan patiënten na ontslag, samenwerking met eerstelijns hulpverleners en feedback aan het revalidatieteam op basis van ervaringen met ex-revalidanten.

\section{Hoofdstuk 7}

In dit hoofdstuk worden de resultaten van de effectevaluatie van het transmuraal verpleegkundig zorgmodel beschreven. In totaal werden 31 mensen die transmuraal verpleegkundige zorg ontvingen in de twee experimentele revalidatiecentra vergeleken met een 'gematchte' steekproef van mensen met een dwarslaesie uit zes andere revalidatiecentra, die de gebruikelijke nazorg ontvingen. Matching werd toegepast voor het niveau en motorische compleetheid van de dwarslaesie, geslacht en leeftijd.

Eén jaar na ontslag bleken er geen significante verschillen te zijn tussen de interventie- en controlegroep voor wat betreft het voorkomen van gezondheidsproblemen (decubitus, urineweginfecties, spasme, pijn, luchtweginfecties, lage bloeddruk en gewichtstoename), heropnames in ziekenhuis of revalidatiecentrum en de ervaren kwaliteit van nazorg. Aangezien de 'gebruikelijke' nazorg in de helft (drie van de zes) van de controlecentra werd uitgebreidt gedurende de interventieperiode zijn er subgroep analyses uitgevoerd tussen de interventiegroep en deelnemers in de controlegroep waar de nazorg niet werd uitgebreidt gedurende onze studie. Deze subgroep analyses lieten echter ook geen verschillen zien voor wat betreft de uitkomstvariabelen. 


\section{Hoofdstuk 8}

In dit hoofdstuk worden de belangrijkste resultaten aan de hand van de centrale vraagstellingen van het onderzoek beschreven. Tevens worden er een aantal methodologische en theoretische kanttekeningen bij de verschillende deelstudies geplaatst. Het hoofdstuk wordt afgesloten met een aantal aanbevelingen voor de praktijk en toekomstig onderzoek.

De belangrijkste conclusie van het onderzoek is dat mensen met een dwarslaesie allerlei gezondheidsproblemen kunnen ervaren zowel op de korte als de lange termijn na klinische revalidatie, die hun functioneren negatief beïnvloeden. Alhoewel het belang van betere nazorg steeds meer onderkend wordt, zijn er pas enkele nazorgprogramma's beschreven in de literatuur. De meeste van deze nazorgprogramma's zijn niet goed geëvalueerd. Daarom is er geen bewijs voor de effectiviteit van nazorgprogramma's op het optreden van gezondheidsproblemen, welzijn, de kwaliteit en kosten van de zorg. Aangezien ons transmuraal verpleegkundig zorg model niet consistent en volledig werd ingevoerd in beide experimentele revalidatiecentra en er tevens enkele methodologische en praktische problemen waren, bleek het niet mogelijk definitieve conclusies te trekken over de effectiviteit. De effectiviteit zou mijn inziens verbeteren indien het zorgmodel meer vraaggericht en strikter volgens plan ingevoerd zou worden. Aangezien bij thuiswonende mensen met een dwarslaesie veel gezondheidsproblemen voorkomen, blijft verdere ontwikkeling, implementatie, evaluatie en publicatie van nazorgprogramma's uitermate relevant. 
Dankwoord 
Gedurende de 15 jaar die ik binnen Stichting Revalidatie Limburg werkzaam ben, zocht en kreeg ik veel kansen mezelf te ontwikkelen, voor mijn eigen ik en vooral ook voor mensen met zorgbehoeften. Op de afdeling dwarslaesie deed ik ervaring op als verpleegkundige en leidinggevende. Hierna begaf ik me op onderzoeksgebied en studeerde Verplegingswetenschap aan de Universiteit Maastricht. Voor mijn afstudeeronderzoek zocht ik naar een onderwerp relevant voor de klinische praktijk. Later vormde dit onderzoek de aanleiding voor dit proefschrift. In de vijf jaar dat ik aan dit promotieonderzoek werkte, kreeg ik hulp en steun van velen. Een aantal mensen wil ik hiervoor graag bedanken.

Allereerst wil ik mijn promotieteam bedanken: Wim van den Heuvel (promotor), Luc de Witte (copromotor) en Marcel Post (copromotor). Jullie waren een prima begeleidingsteam, helder en doelgericht. Wim, jou wil ik bedanken voor de ondersteuning vanuit het $\mathrm{iRv}$ en de zinvolle commentaren bij werkbesprekingen. Luc, zonder jouw motivatie en steun was dit proefschrift er niet geweest! Al sinds mijn afstudeerfase aan de Universiteit Maastricht heb ik veel van je geleerd, en niet alleen op wetenschappelijk gebied. Je keek altijd kritisch naar mijn werk en ideeën, en zorgde voor veel inspiratie. Marcel, jouw kritische commentaren en inhoudelijke discussies vormden waardevolle leermomenten, vooral onderzoekstechnisch.

Ook wil ik graag alle mensen met een dwarslaesie, die meededen aan het onderzoek, bedanken. Zonder jullie medewerking zou het onderzoek niet uitgevoerd kunnen worden. Vooral de diepte-interviews waren voor mij heel waardevol om meer te begrijpen van het perspectief van de cliënt.

Conny di Bartolomeo en Rudy Sonsma wil ik bedanken voor hun gedrevenheid om het transmurale zorgmodel in te voeren in de praktijk. Het was prettig met jullie samen te werken. Het feit dat we niet de gewenste effecten hebben waargenomen heeft niet aan jullie geweldige inzet gelegen. Conny, heel veel succes gewenst met de opleiding tot nurse practitioner!

Jeanny Engels wil ik bedanken voor haar vele bijdragen aan dit proefschrift. Jouw ondersteuning bij de implementatie van de interventie, het verzamelen van gegevens voor de procesevaluatie en de discussies over de inhoud van artikelen waren erg waardevol. Ook op het gebied van vraaggerichte zorg heb ik veel van je geleerd. Ik hoop dan ook dat we in de toekomst blijven samenwerken, want er is nog veel werk te verzetten op het gebied van Zorg in Dialoog.

De projectgroep bestaande uit Jos Hendriks, Angèle Rademacher, Jo Genten, Kees Pons, Conny di Bartolomeo, Hans Liefhebber, Floris van Asbeck en Rudy Sonsma wil ik bedanken voor hun continue ondersteuning bij het onderzoek, de ontwikkeling en implementatie van de interventie.

Erwin Hout, Marco Lempens, Dhr. Kusters, Fried Steeghs, Elly de Reus, Lou Cleophas, José de Swart en Annelien Kappeyne vd Capello, jullie wil ik hartelijk bedanken voor jullie inbreng bij de ontwikkeling van de interventie. Annelien, Mirjam en Lou, ook bedankt voor het geven van de aftrap aan de interventie. 
Mijn project was onderdeel van het landelijke onderzoeksprogramma 'Functionele belasting, belastbaarheid en mechanismen van herstel van mobiliteit in de revalidatie van personen met een dwarslaesie' (koepelproject). Luc van der Woude, Annet Dallmeijer en Sonja de Groot, bedankt voor jullie interesse en de geboden implementatiemogelijkheden van mijn onderzoeksresultaten. Luc, mijn complimenten voor hetgeen je op het gebied van dwarslaesie onderzoek gerealiseerd hebt.

Ook de onderzoeksassistenten van het koepelproject, Sacha van Langeveld, Annelieke Niezen, Karin Postma, Hennie Rijken, Marijke Schuitemaker, Linda Valent en Ferry Woldring, wil ik bedanken voor het afnemen van de extra metingen. Ik vind het leuk dat ik jullie in het vervolgtraject weer zal tegenkomen.

De deelnemende revalidatiecentra aan het koepelproject wil ik bedanken voor het feit dat ik gebruik mocht maken van de verzamelde data.

Collega's van het iRv en de dwarslaesieafdeling van de SRL, allemaal bedankt voor jullie steun en interesse. Op een heel verschillende wijze werken jullie aan hetzelfde doel. Ik hoop dat beide organisaties de kansen weten te benutten elkaars kennis en ervaring te delen, opdat revalidatieprocessen verder geoptimaliseerd kunnen worden. Mij is de combinatie van praktijk en onderzoek in ieder geval goed bevallen!

Een speciaal dankjewel aan Chantal, Leontine, Béatrice, Ieke, Anita, Petra, Sascha, Nathalie en Jacques, voor de gezellige pauzes. Door die geregelde frisse neus of frisse duik kreeg ik bovendien vaak een frisse blik op het werk.

Dhr. Spreeuwenberg, mevr. Kiekens, mevr. Lindeman, dhr. Philipsen en mevr. De Wit wil ik bedanken voor de beoordeling van dit proefschrift.

Beide paranimfen Ingrid \& Ingrid, heel erg bedankt voor al jullie meeleven en steun door de jaren heen, ik hoop dat onze vriendschap nog lang mag bestaan. Ik vind het fijn dat jullie naast me willen staan als ik het proefschrift verdedig!

Mijn familie en vrienden, bedankt dat jullie er zijn, en gewoon voor alles! Beste pap en mam, mede dankzij jullie ben ik geworden wie ik ben, bedankt voor wat jullie me hebben meegegeven en voor jullie onvoorwaardelijke steun.

En dan tot slot een dankjewel aan Maurice. Jij hebt als geen ander met me meegeleefd gedurende het hele onderzoekstraject. Bedankt voor het delen van lief en leed. En het klopt: waar een wil is, is een weg.... Ben benieuwd waar onze wegen nog allemaal naar toe gaan!

Jos 

About the author 


\section{Curriculum Vitae}

$\begin{array}{ll}\text { Name } & \text { Jos Bloemen-Vrencken } \\ \text { Date of birth } & \text { June 23, 1969 }\end{array}$

\section{Professional objective}

My profession is nursing researcher. For 15 years I have been working in the field of rehabilitation of persons with a spinal cord injury, having practical, managerial and research functions. Having my $\mathrm{PhD}$, I will continue to combine research and rehabilitation practice. Herewith, I would like to improve rehabilitation processes for persons with chronic disabilities

\section{Employment}

1991 - Today Rehabilitation Foundation Limburg (SRL), Hoensbroek, the Netherlands. I always have been employed by this foundation, however, I also performed several research activities at the Institute for Rehabilitation Research (iRv)

2001 - 2006 iRv, Hoensbroek, the Netherlands. PhD study: 'Transmural nursing care of spinal cord injured patients after discharge from clinical rehabilitation; development, evaluation and implementation of a care model'.

http://www.fbw.vu.nl/onderzoek/A4zon/ZONenglish/inhoudp10.htm

2000 - $2003 \quad i R v$, Hoensbroek, the Netherlands. PhD assistant: 'Physical strain, work capacity, and mechanisms of restoration of mobility in the rehabilitation of persons with a spinal cord injury'.

http://www.fbw.vu.nl/onderzoek/A4zon/ZONenglish/inhoudp2.htm

$1995-2000 \quad$ Team leader at the rehabilitation department for persons with SCI

$1991-1994 \quad$ Nurse at the rehabilitation department for persons with SCI

\section{Education}

$1993-1997$

Maastricht University, Faculty of Health Sciences

Specialisation: Nursing Science

1987 - $1991 \quad$ Higher education for health service and nursing

1981 - 1987 High school 


\section{Articles in international journals}

Bloemen-Vrencken JHA, de Witte LP. Post-discharge nursing problems of spinal cord inured patients: on which fields can nurses contribute to rehabilitation? Clinical Rehabilitation 2003; 17(8): 890-898.

Post MWM, Bloemen-Vrencken JHA, de Witte LP. Burden of support for partners of persons with spinal cord injuries. Spinal Cord. 2005 May; 43(5): 311-9.

Bloemen-Vrencken JHA, Post MWM, Hendriks JMS, de Reus ECE, de Witte LP. Health problems of persons with spinal cord injury living in the Netherlands. Disability and Rehabilitation 2005; 27(22): 1381-1389.

Bloemen-Vrencken JHA, de Witte LP, Post MWM. Follow-up care for persons with spinal cord injury living in the community: a systematic review of interventions and their evaluation. Spinal Cord 2005; 43: 462-475.

Bloemen-Vrencken JHA, de Witte LP, Engels JPGM, van den Heuvel WJA, Post MWM. Transmural care in the rehabiliation sector: implementation experiences with a transmural care model for people with spinal cord injury. International Journal of Integrated Care 2005; 5, www.ijic.org.

Bloemen-Vrencken JHA, de Witte LP, Post MWM, van den Heuvel WJA. Health behaviour of persons with spinal cord injury. Accepted for publication in Spinal Cord, July 2006.

Bloemen-Vrencken JHA, de Witte LP, Post MWM, Pons C, van Asbeck FWA, van der Woude LHV, van den Heuvel WJA. Effects of a Dutch follow-up care model for spinal cord injured patients on health problems, re-admissions, and quality of care. Submitted for publication.

Post MWM, Bloemen-Vrencken JHA, de Witte LP. Abstract: Health problems of Dutch spinal cord injured patients living in the community. Journal of Spinal Cord Medicine 2002; 25: S46.

Bloemen-Vrencken JHA, de Witte LP, Post MWM. Abstract: Follow-up care for persons with SCI: (1) a systematic review of interventions and their evaluation (2) a comparison of care in the Netherlands and the US. Journal of Rehabilitation Research and Development 2004; 41(2, supplement 2): 37. 
Post MWM, Bloemen-Vrencken JHA, de Witte LP. Abstract: Burden of support for partners of persons with spinal cord injuries. Journal of Rehabilitation Research and Development 2004; 41(2, supplement 2): 41.

\section{Conferences \& presentations}

Vrencken JHA, de Witte LP. Nursing problems of spinal cord injured patients after discharge from clinical rehabilitation. $6^{\text {th }}$ European congress on Research in Rehabilitation. Berlin, 1998-06-03.

Post MWM, Bloemen-Vrencken JHA, de Witte LP. Health problems of Dutch spinal cord injured patients living in the community. Poster presented at the 1 th joint meeting of ASIA and IMSOP. Vancouver, 2002-05-04 2002-05-06.

Bloemen-Vrencken JHA, Kilkens OJE. SCI Rehabilitation in the Netherlands, Research and Practice. Presentations in all Spinal Cord Injury Model Systems visited during studytrip. New York, Mount Sinai Medical Center, 2003-05-29, Philadelphia, Magee Rehabilitation Hospital, 2003-06-05. Atlanta, Shepherd Center, 2003-06-12. Houston, The Institute for Rehabilitation \& Research, 2003-06-17. San Jose, Santa Clara Valley Medical Center, 2003-06-27.

Post MWM, Bloemen-Vrencken JHA, de Witte LP. Burden of support for partners of persons with spinal cord injuries. 3rd International Congress, 'Restoration of (wheeled) mobility in spinal cord injury rehabilitation: State of the art III'. Amsterdam, 2004-04-21.

Bloemen-Vrencken JHA, de Witte LP, Post MWM. Follow-up care for persons with SCI: (1) a systematic review of interventions and their evaluation (2) a comparison of care in the Netherlands and the US. 3rd International Congress, 'Restoration of (wheeled) mobility in spinal cord injury rehabilitation: State of the art III'. Amsterdam, 2004-04-21.

Bloemen-Vrencken JHA, de Witte LP, Post MWM, Sonsma R, Liefhebber H, van Asbeck FWA, di Bartolomeo C, Rademacher A, Pons C. Posterpresentatie: Transmurale verpleegkundige zorg voor mensen met een dwarslaesie. Revalidatie onderzoekscongres: Resultaten en toekomst. Utrecht, 2004-11-04.

Bloemen-Vrencken JHA, De Witte LP, Post MWM. Nazorg kan beter, nazorg moet beter. Jaarlijks symposium van het Nederlands Vlaams Dwarslaesie Genootschap. Wijk aan Zee, Heliomare, 2005-05-28. 
Bloemen-Vrencken JHA, Sonsma R, di Bartolomeo C. Workshop: Een betere voorbereiding op de thuissituatie door vraaggerichte zorg. Jaarlijks symposium van het Nederlands Vlaams Dwarslaesie Genootschap. Wijk aan Zee, Heliomare, 2005-05-28.

Bloemen-Vrencken JHA. A Dutch follow-up care model for persons with spinal cord injury. Conference of the American Association of Spinal Cord Injury Nurses (AASCIN). Las Vegas, 2005-09-08.

Minisymposia van het onderzoeksprogramma: 'Functionele belasting, belastbaarheid en mechanismen van herstel van mobiliteit in de revalidatie van personen met een dwarslaesie':

- Bloemen-Vrencken JHA. Transmurale verpleegkundige zorg voor mensen met een dwarslaesie na ontslag uit het revalidatiecentrum; ontwikkeling, evaluatie en implementatie van een zorgmodel. Utrecht, Revalidatiecentrum De Hoogstraat, 2001-06-22.

- Bloemen-Vrencken JHA. Gezondheidsproblemen bij mensen met een dwarslaesie. Haren, Revalidatiecentrum Beatrixoord, 2002-06-07.

- Bloemen-Vrencken JHA. Dwarslaesie Revalidatie Verenigde Staten Nederland vergeleken. Nijmegen, Revalidatiecentrum St. Maartenskliniek, 200312-19.

- Bloemen-Vrencken JHA, De Witte LP, Post MWM. Gezondheidsgedrag bij mensen met een dwarslaesie. Enschede, Revalidatiecentrum Het Roessingh, 2005-12-16.

\section{Publications}

Post MWM, Bloemen-Vrencken JHA, Hendriks J, de Reus ECE, de Witte LP. Gezondheid en behoefte aan zorg van mensen met een dwarslaesie na ontslag uit het revalidatiecentrum: onderzoeksverslag. iRv rapport 2002.

Bloemen-Vrencken JHA, di Bartolomeo C. Mensen met een dwarslaesie gebaat bij transmurale zorg. Mercurieus (Communicatieblad Stichting Revalidatie Limburg) 2003; 6 (19): 18-19.

Bloemen-Vrencken JHA, Kilkens OJE. Reisverslag van een bezoek aan vijf SCI Model Systems in de Verendigde Staten. iRv rapport 2003. 
Bloemen-Vrencken JHA, Kilkens OJE. Dwarslaesierevalidatie in de Verenigde Staten, ervaringen van een studiereis. Mercurieus (Communicatieblad Stichting Revalidatie Limburg) 2003; 6 (20): 26-27.

Bloemen-Vrencken JHA. Nazorg voor mensen met een dwarslaesie. Revalidatie Magazine 2003 december; 9 (4): 14-15.

Bloemen-Vrencken JHA, Kilkens OJE. Dwarslaesierevalidatie in de Verenigde Staten, ervaringen van een studiereis. De Ketting (Tijdschrift van Dwarslaesie Organisatie Nederland) 2004; 27 (1): 7-8. 